\title{
Role of miRNAs in Oligodendrocyte Development
}

\author{
Dissertation \\ zur Erlangung des mathematisch-naturwissenschaftlichen Doktorgrades \\ „Doktor rerum naturalium“ \\ der Georg-August-Universität Göttingen
}

vorgelegt von

Holger Budde

aus Bad Pyrmont

Göttingen, 2010 
Referent: $\quad$ Prof. Dr. Ivo Feußner

Albrecht-von-Haller-Institut für Pflanzenwissenschaften

Georg-August-Univerität Göttingen

Korreferent: Prof. Dr. Mikael Simons

Max-Planck-Institut für Experimentelle Medizin

Abteilung für Neurologie, Georg-August-Univerität Göttingen

Tag der mündlichen Prüfung: 05.07.2010 


\section{Eidesstattliche Erklärung}

Hiermit versichere ich, dass ich die vorliegende Dissertation „Role of miRNAs in Oligodendrocyte Development“ selbständig angefertigt habe und keine anderen als die angegebenen Hilfsmittel und Hilfen benutzt habe,

Holger Budde

Göttingen, 07. Juni 2010 
Im Zusammenhang mit der vorliegenden Dissertation wurde folgende wissenschaftliche Publikation veröffentlicht:

Holger Budde, Sebastian Schmitt, Dirk Fitzner, Lennart Opitz, Gabriela Salinas-Riester and Mikael Simons. (2010) Control of oligodendroglial cell number by the miR-17-92 cluster. Development 137, 2127-2133. 


\section{Contents}

List of figures.....................................................................................................................................1

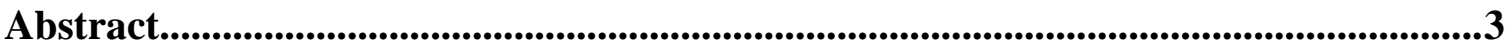

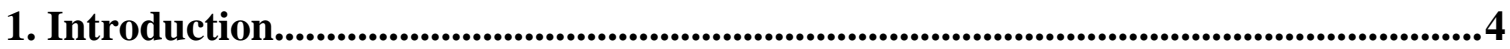

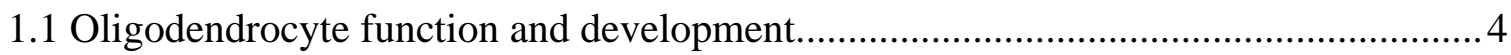

1.1.1 Morphology and function of oligodendrocytes......................................

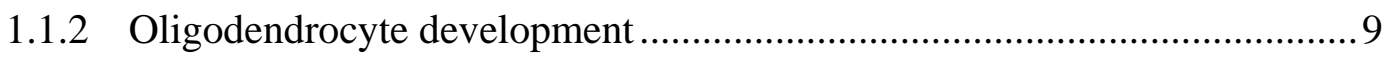

1.1.2.1 Oligodendrocyte precursor cells ................................................ 9

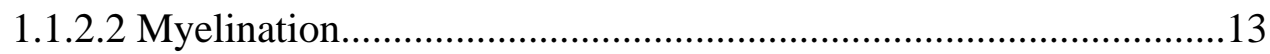

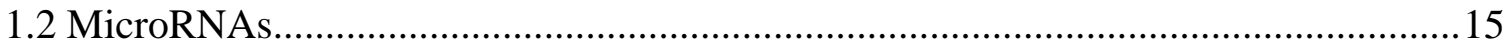

1.2.1 MicroRNA discovery and genomic organisation.....................................15

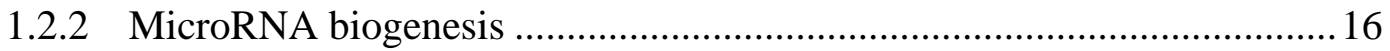

1.2.3 Transcriptional control of MicroRNA biogenesis .................................. 19

1.2.4 Comparison of MicroRNAs with other small RNAs ............................... 20

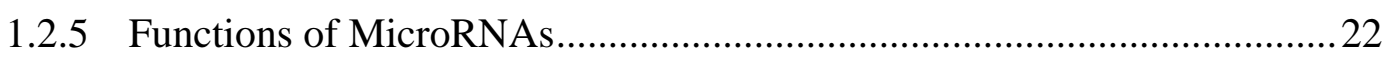

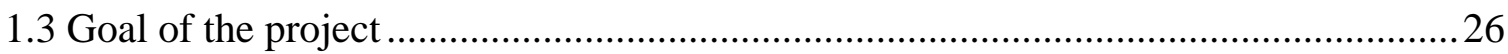

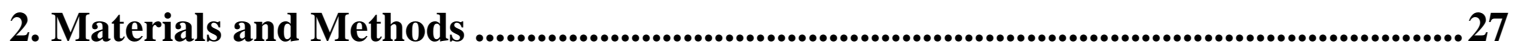

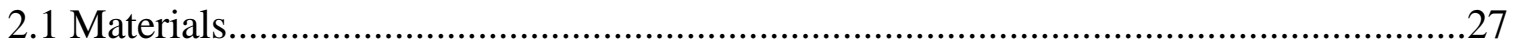

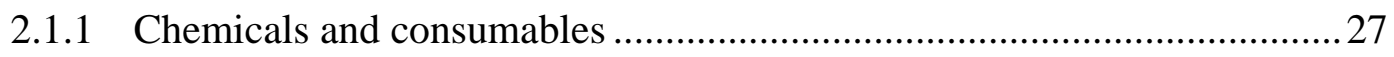

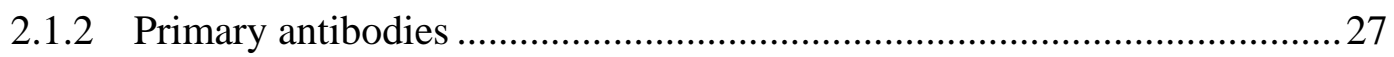

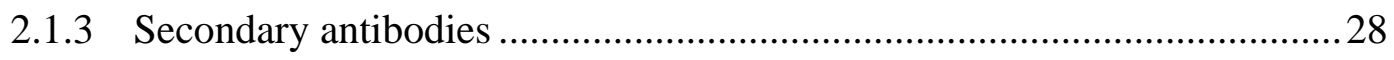

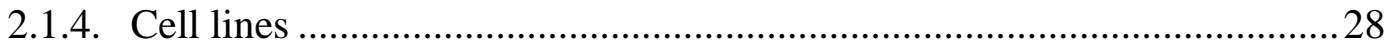

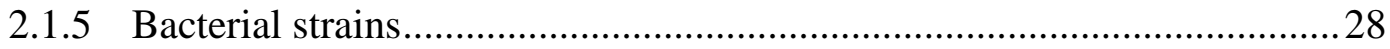

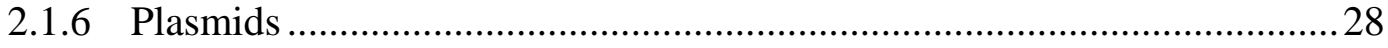

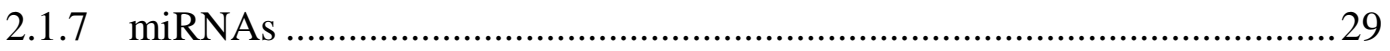

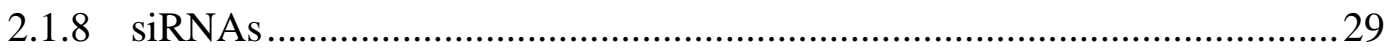




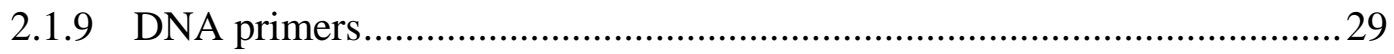

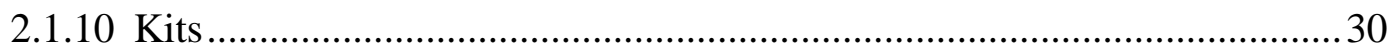

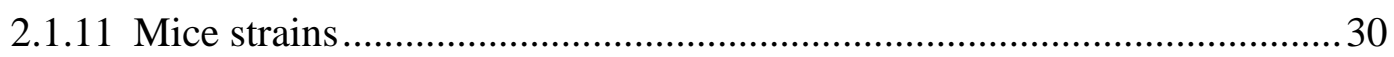

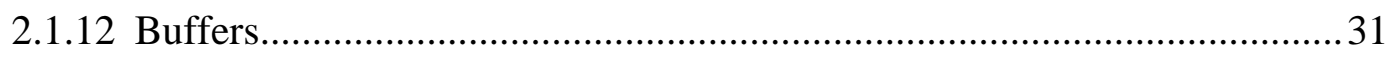

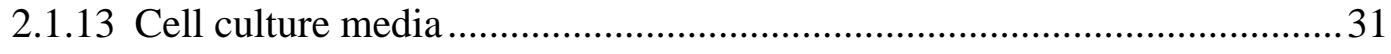

2.1.13.1 Commercial media and supplements ......................................... 31

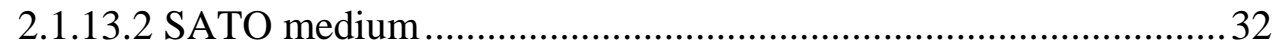

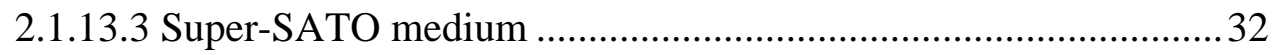

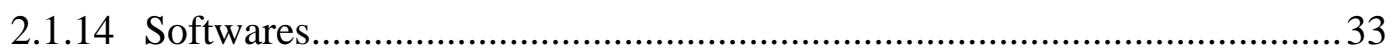

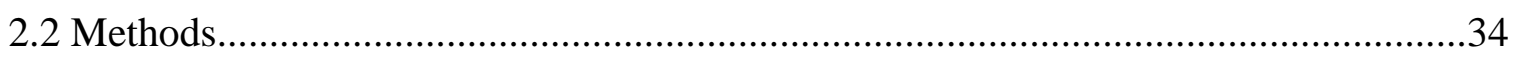

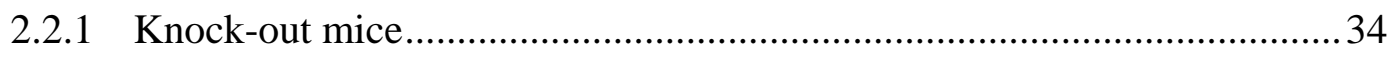

2.2.1.1 Dicer knock-out mice................................................................... 34

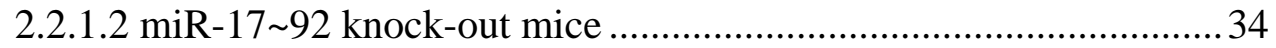

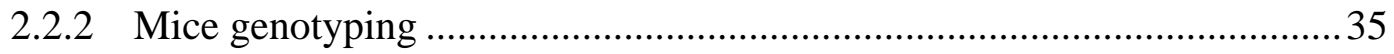

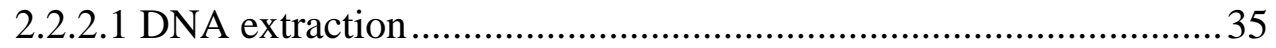

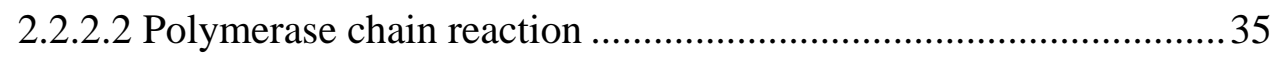

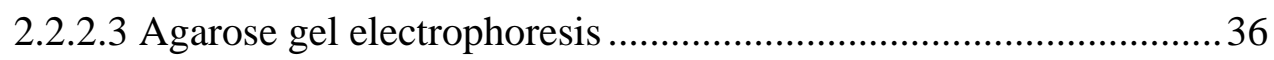

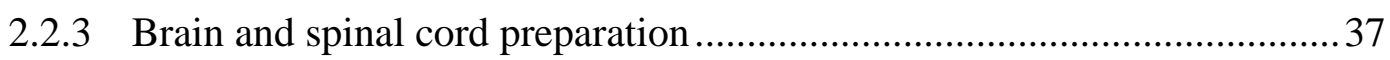

2.2.4 White- and grey-matter preparation........................................................... 37

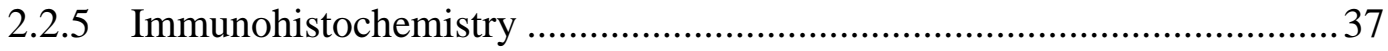

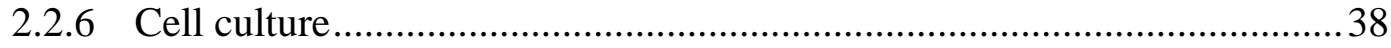

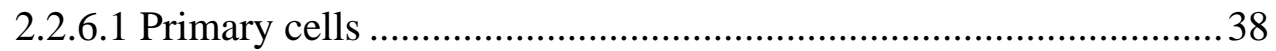

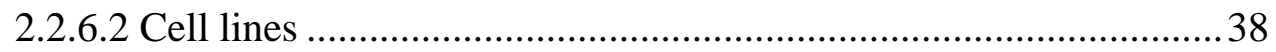

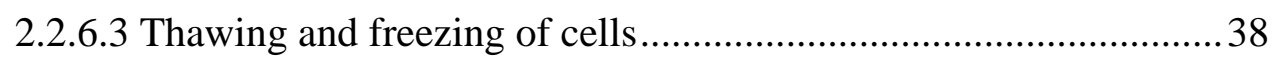

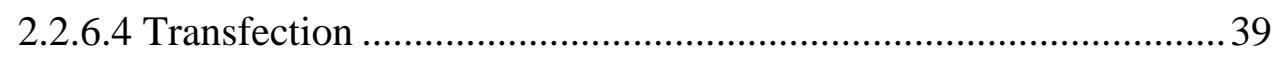

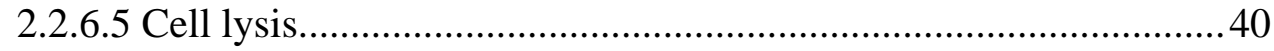

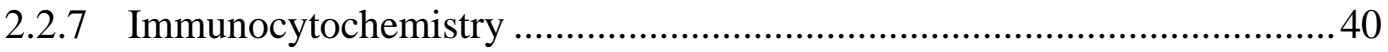

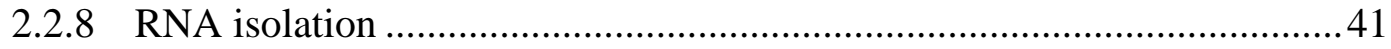

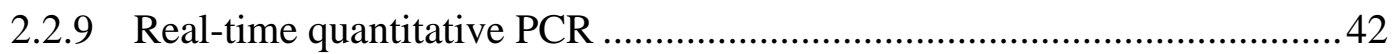

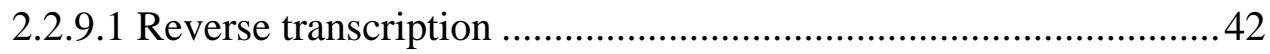

2.2.9.2 Real-time quantitative PCR .................................................... 42

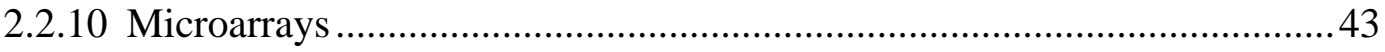

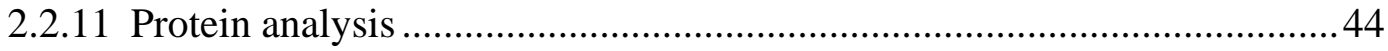




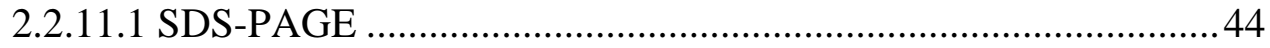

2.2.11.2 Western blot .........................................................................46

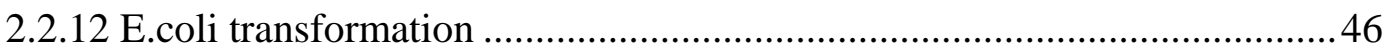

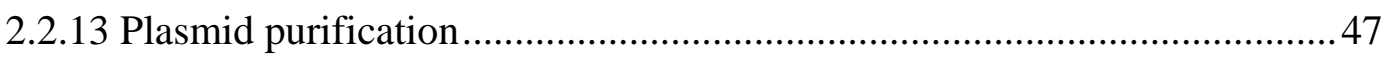

2.2.14 Luciferase assay ..................................................................................4

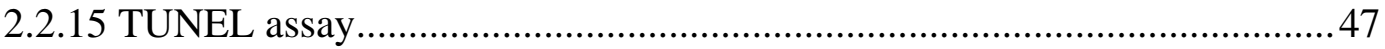

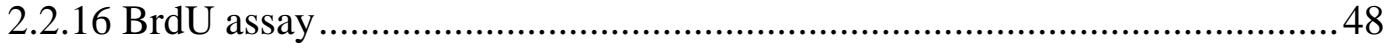

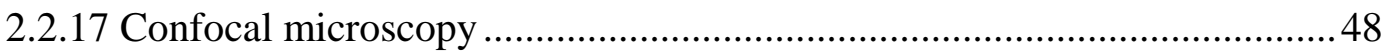

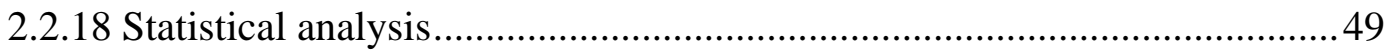

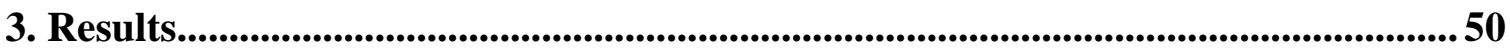

3.1 Reduction of oligodendrocyte cell number by CNP-Cre mediated deletion of Dicer 50

3.2 Role of the miR-17 92 cluster in oligodendrocyte development..............................55

3.2.1 Identification of the miR-17 92 cluster as highly enriched miRNAs in oligodendrocytes by microarray profiling …...........................................5

3.2.2 The miR-17 92 cluster regulates oligodendrocyte cell number

- in vivo evidence

3.2.3 The miR-17 92 cluster regulates oligodendrocyte cell number

- in vitro evidence .65

3.2.3.1 The miR-17 92 cluster regulates Oli-neu cell number.

3.2.3.2 The miR-17 92 cluster regulates the cell number of primary oligodendrocytes

3.2.3.3 Apoptosis of oligodendrocytes is not affected by the miR-17 92 cluster .70

3.2.3.4 The miR-17 92 cluster promotes oligodendrocyte cell proliferation 72

3.2.3.5 Activation of the Pten-Akt signalling pathway in oligodendrocytes by miR-19b .73

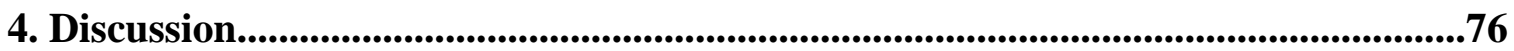

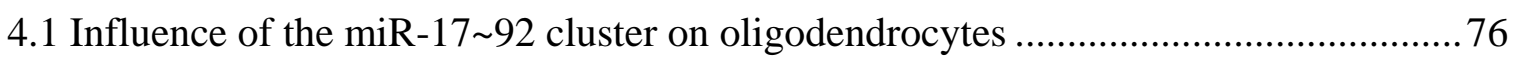

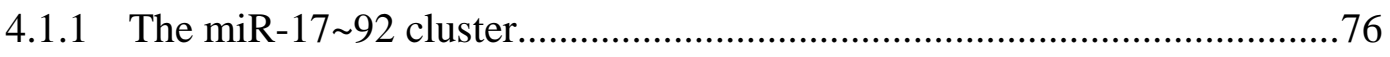

4.1.2 Functions of the miR-17 92 cluster in oligodendrocyte proliferation ...... 79 
4.1.2.1 miRNA microarray profiling shows that the miR-17 92 cluster is enriched in oligodendrocytes.................................................... 79

4.1.2.2 Factors and pathways in OPC proliferation ..................................81

4.1.2.3 The miR-17 92 cluster regulates OPC proliferation .....................83

4.1.2.4 miR-19b promotes OPC proliferation by regulating the Pten-Akt signalling pathway ....................................................... 85

4.2 Dicer is essential for the regulation of oligodendrocyte cell number in vivo ...............86

4.3 miRNA profiling uncover a subset of miRNAs important for oligodendrocytes .......90

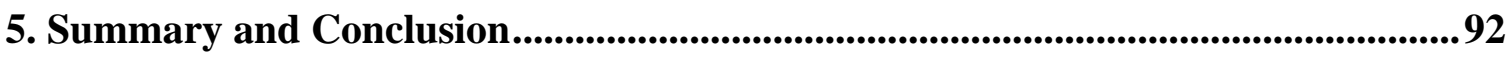

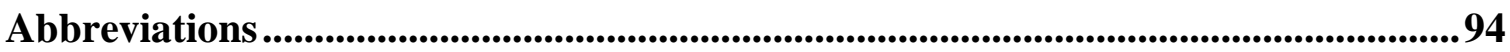

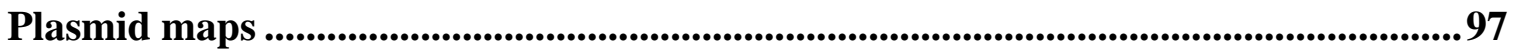

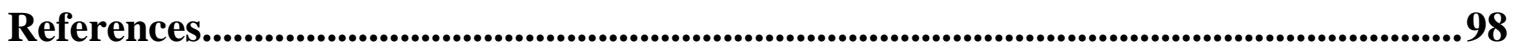

Acknowledgements .................................................................................................................... 117

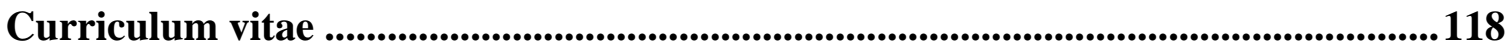




\section{List of figures}

1.1: Ensheatment of axons by myelin-forming cells

1.2: $\quad$ Electron micrograph of myelinated axons from the optic nerve

1.3: $\quad$ Biogenesis of miRNAs

1.4: $\quad$ Potential pathways of mRNA repression by miRNAs

3.1: $\quad$ Targeting strategy for Dicer conditional deletion

3.2: $\quad$ Breeding strategy for Dicer conditional deletion in oligodendrocytes

3.3: Conditional deletion of Dicer using CNP-Cre does not significantly impair oligodendrocyte differentiation

3.4: Conditional deletion of Dicer using CNP-Cre reduces the cell number of oligodendrocytes

3.5: Dicer knock-down results in a reduction of O1-positive oligodendrocytes

3.6: Conditional deletion of Dicer using CNP-Cre does not reduce the cell number of oligodendrocytes in the spinal cord

3.7: Dicer knock-out does not change the apoptosis rate in the brain

3.8: Schematic representation of the miR-17 92 cluster and its two paralogs miR106a 363 and miR-106b 25 cluster

3.9: Validation of differentially expressed miRNAs by qRT-PCR

3.10: Deletion of the miR-17 92 cluster reduces the number of oligodendrocytes

3.11: Transfection of FITC-labelled oligonucleotides in primary oligodendrocytes

3.12: Analysis of miR-19b inhibition by a luciferase-based assay

3.13: Real-time PCR analysis of miR-17 and miR-19b levels after transfection of pre-17 and pre-19b into oligodendrocytes

3.14: The miR-17 92 cluster regulates Oli-neu cell number

3.15: The miR-17 92 cluster regulates primary oligodendrocyte cell number

3.16: Down-regulation of oligodendrocyte cell number by growth factor deprivation and cell rescue by neuronal conditioned medium or insulin 
3.17: The miR-17 92 cluster has no influence on oligodendrocyte survival

3.18: The miR-17 92 cluster regulates oligodendrocyte cell proliferation

3.19: miR-19b down-regulates Pten in oligodendrocytes

3.20: miR-19b leads to enhanced phosphorylation of Akt

3.21: miR-19b is sufficient to increase oligodendrocyte cell proliferation and is involved in the Akt signalling pathway in oligodendrocytes

\section{Tables}

3.1: $\quad$ Enriched mRNAs in primary oligodendrocyte cultures

3.2: Identification of the miR-17 92 cluster as highly enriched miRNAs in oligodendrocytes by microarray profiling

3.3: miRNA microarray profiling showing the expression levels of miRNAs in oligodendrocyte differentiation

3.4: Differential miRNA expression in developing oligodendrocytes

3.5: Microarray miRNA profiling of white- and grey-matter

3.6: $\quad$ Seed sequences of the miR-17 92 cluster 


\section{Abstract}

MicroRNAs (miRNAs) are important for the regulation of various processes in cell biology. However, the function of miRNAs in the central nervous system and especially in glial cells is still poorly understood. Oligodendroglial cells in the CNS are required for the myelination of the axonal tracts. At initial stages of CNS development and maturation, cells of the oligodendroglial lineage are produced in great excess to ensure sufficient myelination of the CNS. Specific gene regulation programs are required for proliferation, differentiation and apoptosis of oligodendrocytes. We determined whether miRNAs are participating in these processes by regulating important developmental genes. We generated oligodendrocyte-specific Dicer knock-out mutant mice to show the general impact of miRNAs on oligodendrocytes in vivo. The depletion of mature miRNAs resulted in a decreased oligodendrocyte cell number. Microarray profiling of primary oligodendrocytes revealed that the miR-17 92 family of miRNA cluster is highly enriched in the cells of the oligodendroglial lineage. Mutant mice with oligodendrocyte-specific deletion of the miR-17 92 cluster also revealed a reduction of oligodendrocyte cell number. In gain of function experiments we found that the expression of the miR-17 92 cluster promotes oligodendrocyte cell proliferation. Furthermore, we could show that the proliferation is regulated by miR-19b and its influence on the Akt signalling pathway. Together these findings illustrate that miRNAs play essential roles in the regulation of oligodendrocyte cell number and that the miR-17 92 cluster is crucial in this process by influencing the cell proliferation of the oligodendroglial lineage. 


\section{Introduction}

\subsection{Oligodendrocyte function and development}

\subsubsection{Morphology and function of oligodendrocytes}

The nervous system is the central control network in vertebrates. All information of the internal and external environment has to be processed by the nervous system in a fast and precisely coordinated way. The brain and the spinal cord are referred to as the central nervous system (CNS), whereas all other parts of the nervous system belong to the peripheral nervous system (PNS). Neuronal signal propagation is achieved by conduction of the action potential along the axon. The complex information processing in the nervous system depends on fast conduction of the action potential. To speed up this process, the axon is ensheated by myelin for its insulation. The myelinated part of the axon, which is located between the nodes of Ranvier, is called internode. At the node of Ranvier, the voltage-gated ion channels are responsible for the generation of the action potential. This cellular architecture allows the action potential to "jump" from one node of Ranvier to the other, called rapid saltatory conduction. The process results in very fast and efficient information conduction. Oligodendrocytes in the CNS and Schwann cells in the PNS are responsible for the myelin formation.

The name oligodendrocyte comes from the Greek language and literally describes a cell with several processes. Compared to other glial cells such as astrocytes, oligodendrocytes have a smaller size of the cell body with a greater density of the cytoplasm and the nucleus (Peters et al., 1991). In contrast to Schwann cells, a single oligodendrocyte is able to enwrap several different axons (Figure 1.1). Depending on the localization within the brain, a single oligodendocyte can form up to 40 of these processes (Peters et al., 1991). Every process covers the axon by a multi-spiral myelin layer (Figure 1.2) (Bunge et al., 1962). 

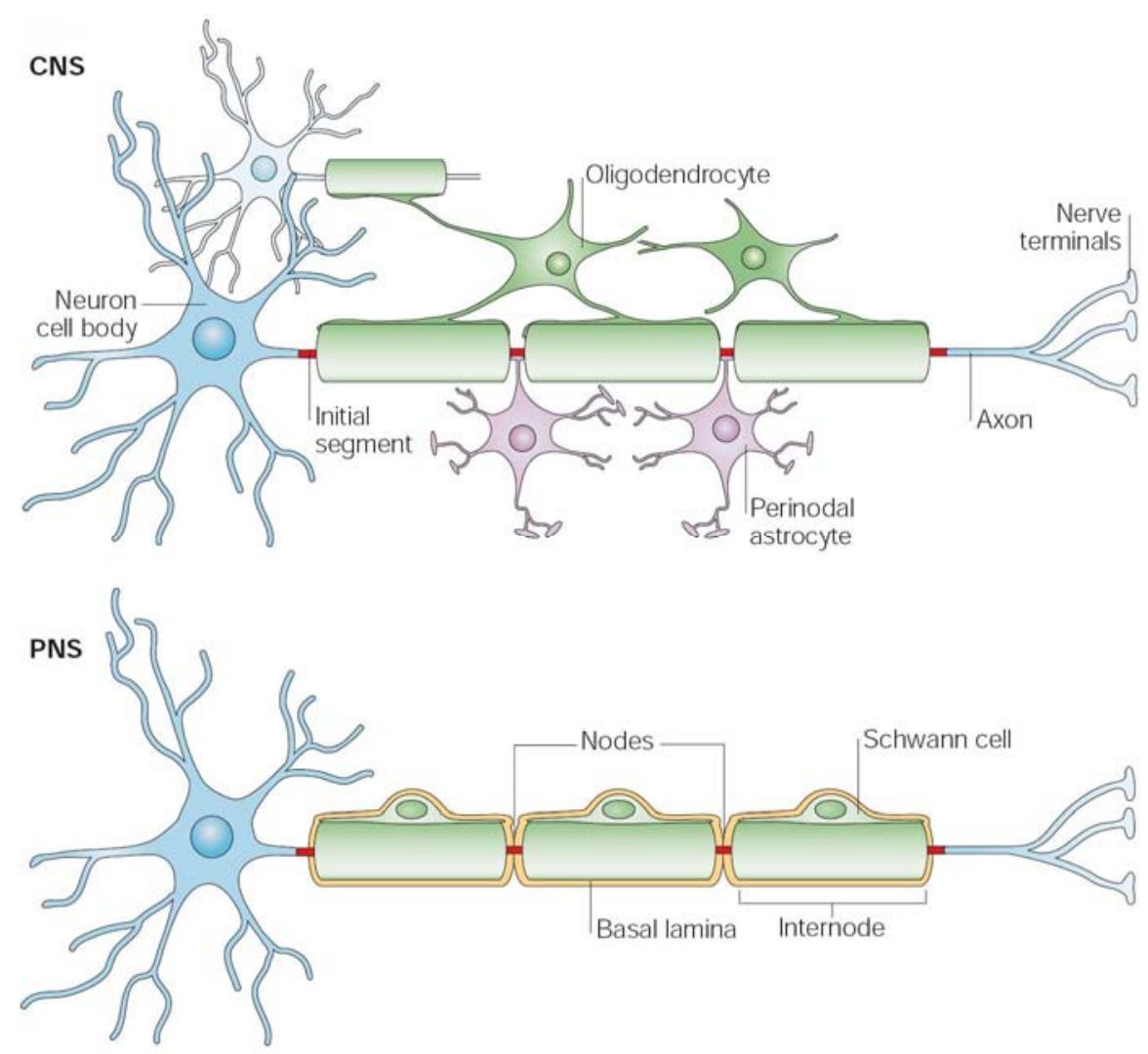

Figure 1.1: Ensheatment of axons by myelin-forming cells. In the central nervous system (CNS) axons are ensheated by oligodendrocytes. A single oligodendrocyte is forming several internode myelin sheaths at different axons. In the peripheral nervous system (PNS) every Schwann cells is forming just a single internode and the soma of the cell is tightly associated to its myelin membrane (adapted from Poliak and Peles, 2003). Reprinted with permission from Nature Publishing Group, 2010

Myelination of the numerous axons requires a high amount of membrane synthesis. The dense structure with a very high content of lipids on the one hand, and a very low amount of $\sim 40 \%$ water on the other hand, leads to the electrical insulation of the axon. Only myelinated axons can fulfil their assignment of nerve conduction in an efficient way. Prevention or disturbance of myelination results in serious axonal damage and subsequent neuronal cell death (Griffiths et al., 1998). The specialized lipid and protein composition of the myelin membrane is crucial for the maintenance of the axonal integrity (Dupree et al., 1999). Even small changes in the myelin structure have a severe effect on the axon, shown 
by PLP-deficient mice, which form almost normal myelin sheaths but axonal degeneration (Griffiths et al., 1998). Demyelination in the human CNS is a feature of severe neurological diseases such as multiple sclerosis (MS).

The importance of myelin is also underlined by the fact, that all vertebrates form myelin structures. The myelin structure itself is an extension of the oligodendrocyte plasma membrane. The myelin sheaths have a length of about $200 \mu \mathrm{m}$ (Butt and Ransom, 1989). Very high compaction is a key feature of the myelin membrane. Therefore the majority of the membrane structure consists of compact myelin which is devoid of cytoplasm. In contrast to compact myelin, the non-compacted myelin includes cytoplasm and organelles. Next to the node of Ranvier is the paranodal region of the myelin membrane, which consists of loops that are tightly connected to the axons. The size of the nodes of Ranvier depends on the axon diameter. Thick axons show bigger nodes of Ranvier (Bjartmar et al., 1994). At the node of Ranvier, processes of astrocytes get close to the axonal membrane (Figure 1.1) (Black and Waxman, 1988).

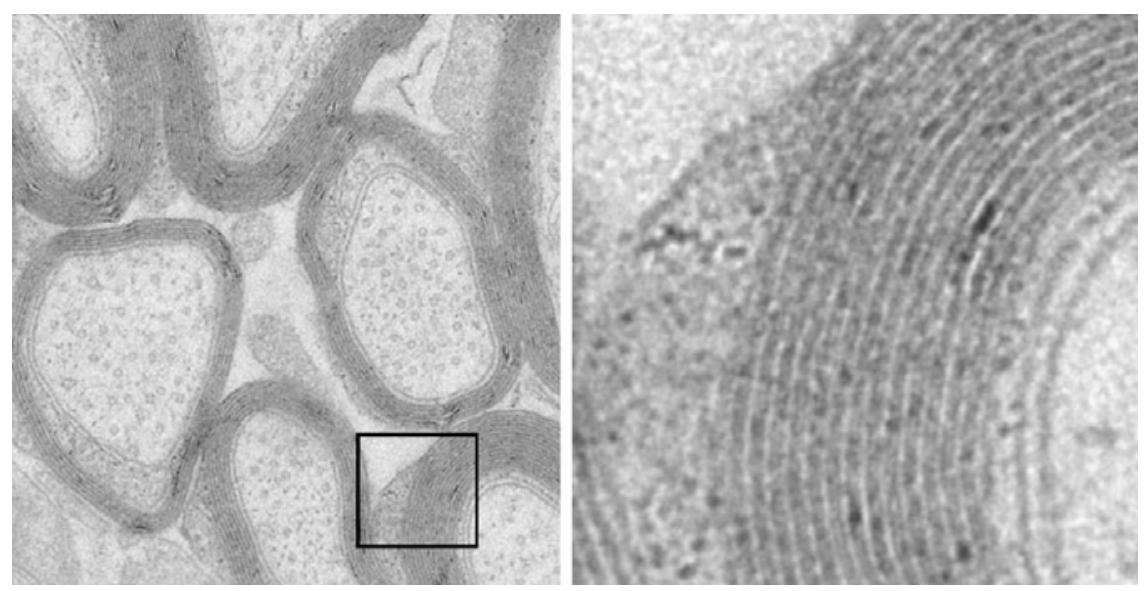

Figure 1.2: Electron micrograph of myelinated axons from the optic nerve. The axons are ensheated by oligodendrocytes with multiple spiral-wrapped myelin membranes (adapted from Simons and Trajkovic, 2006). Reprinted with permission from The Company of Biologists, 2010 
The dry weight of the CNS contains about 40-50\% myelin (Baumann and Pham-Dinh, 2001). Myelin constitutes of a specialised membrane composition with $70 \%$ of lipids and only $30 \%$ of proteins. In contrast to myelin, other cellular membranes contain only $30 \%$ of lipids. The lipid composition of the myelin membrane is also different from other membranes. Myelin consists of cholesterol, phospholipids and glycolipids. A very characteristic feature is the high amount of glycosphingolipids, especially galactosylceramide (GalC), a lipid belonging to the group of galactocerebrosides. $20 \%$ of the myelin dry weight consists of GalC. It is therefore an important antigen in immunostaining of oligodendrocytes and myelin. The specificity of myelin galactocerebrosides is also underlined by the fact, that the concentration of galactocerebrosides in brain development is proportional to the myelination level.

Even though the protein amount of $\sim 30 \%$ is relatively low in the myelin membrane, its proteins are unique compared to other cellular membranes (Campagnoni and Macklin, 1988).

Myelin basic protein (MBP) and proteolipid protein (PLP) are the most abundant myelin proteins. These two proteins reach up to $80 \%$ of all myelin proteins.

PLP is the major myelin protein making up $50 \%$ of the proteins in the myelin membrane. The name proteolipid protein corresponds to the first PLP extraction, where lipid-protein complexes of PLP were isolated with organic solvent mixtures (Folch and Lees, 1951). PLP consists of four hydrophobic $\alpha$-helices spanning through the lipid bilayer of the myelin membrane. It interacts with cholesterol, the major myelin lipid (Simons et al., 2000). PLP might be required for the transport of cholesterol to myelin (Saher et al., 2005; Werner et al., 2007). Furthermore, a PLP dependent transport of some proteins, such as sirtuin, was observed (Werner et al., 2007). Two isoforms of the protein are formed by alternative splicing of the seven PLP gene exons. PLP is the most important isoform with a molecular mass of $25 \mathrm{kDa}$. The second isoform is called DM-20 and represents $10-20 \%$ of both PLP isoforms (Baumann and Pham-Dinh, 2001). PLP isoforms are posttranslational acetylated (Tetzloff and Bizzozero, 1998). The location of PLP is restricted to compact myelin structures. PLP knock-out mice show that axonal myelination occurs, at least in part, even in the absence of PLP/DM-20 proteins (Klugmann et al., 1997). On the other hand, the structural stability of the compact myelin layers seems to be disturbed as a result of missing membrane junctions, probably formed by PLP (Boison et al., 1995). The PLP knock-out phenotype reveals severe axonal swellings associated with axonal degeneration 
(Griffiths et al., 1998). A genetic defect in the PLP gene is the cause for the PelizaeusMerzbacher disease (Pelizaeus, 1885; Merzbacher, 1909), which is leading to early onset demyelination (Inoue, 2005). Not only the loss of PLP, but also duplications of the human PLP gene can induce severe dysmyelination (Jung et al., 1996). However, the exact role of PLP in the myelination process still remains elusive.

The second most abundant myelin protein is MBP, which represents about $30 \%$ of the total myelin proteins (Kies et al., 1965). The MBP isoforms are generated by alternative transcripts of the seven exons of the MBP gene (Roach et al., 1985). Two major isoforms exist with 18.5 and $17.2 \mathrm{kDa}$ in humans or 18.5 and $14 \mathrm{kDa}$ in mice (Staugaitis et al., 1990). MBP undergoes different posttranslational modifications, for example acetylation, phosphorylation and methylation. MBP seems to be important for the compaction of the myelin structure and may interact with PLP (Edwards et al., 1989). The myelin membrane arrangement and the lipid packing are influenced by MBP (Fitzner et al., 2006). Shiverer mutant mice, lacking a large part of the MBP gene, show abnormalities in the compact myelin structure (Privat et al., 1979). Posttranslational methylation of the MBP protein probably plays a major role in myelin membrane compaction (Calver et al., 1998).

2',3'-cyclic nucleotide 3' phosphodiesterase (CNP) is less abundant than PLP or MBP, but is important for the interaction of the myelin membrane with the axon. Two isoforms of the protein, CNP1 with $46 \mathrm{kDa}$ and CNP2 with $48 \mathrm{kDa}$, are translated after alternative splicing of the four CNP exons. CNP mRNA can be detected in mouse embryogenesis at embryonic day 12.5 (Peyron et al., 1997; Yu et al., 1994). CNP is found in the noncompacted cytoplasm and the paranodal loops of the oligodendrocytes (Trapp et al., 1988). The protein undergoes posttranslational modifications, for example acetylation and phosphorylation (Vogel and Thompson, 1988) and is associated to the plasma membrane of the oligodendrocytes (Braun et al., 1991). When CNP is overexpressed in mice, abnormally oligodendrocyte membrane expansion occur (Gravel et al., 1996). CNP knockout mice do not show structural alterations in myelin, but axonal swellings and neurodegeneration throughout the brain combined with premature death of the animals (Lappe-Siefke et al., 2003). CNP is suggested to play a role in the oligodendrocyte-axon interaction and the integrity of the paranode (Rasband et al., 2005).

Another minor myelin protein is myelin-associated glycoprotein (MAG). It is representing only $1 \%$ of the myelin proteins. MAG is a highly glycosylated protein with $30 \%$ of carbohydrates. The molecular weights of the two isoforms large MAG (L-MAG) and small 
MAG (S-MAG) are 72 and $67 \mathrm{kDa}$. Together with its carbohydrates the weight is $\sim 100$ $\mathrm{kDa}$. A membrane-spanning domain and an extracellular region with homology to immunoglobulin domains are characteristic for the MAG protein (Salzer et al., 1987). Besides glycosylation, the protein is also phosphorylated and acetylated posttranslationally. L-MAG is the predominant isoform in the CNS (Fujita et al., 1996), whereas S-MAG is the most abundant MAG isoform in the PNS (Frail et al., 1985). MAG knock-out mice are able to form CNS myelin but show a delayed or blocked myelin compaction (Montag et al., 1994). It was suggested that MAG could be important for the outgrowth of oligodendrocyte processes ( $\mathrm{Li}$ et al., 1994). MAG is only expressed in myelinating cells and is located in the innermost periaxonal non-compacted myelin wrap with direct contact to the axonal membrane (Bartsch et al., 1989; Trapp and Quarles, 1982). Due to its localization MAG was suggested to play a role in neuron-oligodendrocyte interaction and cell surface recognition (Poltorak et al., 1987).

Myelin oligodendrocyte glycoprotein (MOG) is another minor glycoprotein of the myelinating oligodendrocyte and it is specifically expressed in CNS myelin (Lebar et al., 1986). Next to one transmembrane domain, MOG has an extracellular domain with homology to the variable domain of immunoglubulins. MOG onset is used as a marker for late stages of oligodendrocytes maturation (Solly et al., 1996).

Myelin-associated oligodendrocyte basic protein (MOBP) is a small myelin-specific protein. MOBP is alternatively spliced to three isoforms with $8.2,9.7$ and $11.7 \mathrm{kDa}$. It is localized in the compact myelin and therefore might be important for myelin compaction (Holz and Schwab, 1997). However, MOBP knock-out mice develop normally, are able to form intact myelin and do not show any obvious clinical phenotype (Yool et al., 2002).

\subsubsection{Oligodendrocyte development}

\subsubsection{Oligodendrocyte precursor cells}

Oligodendrocyte precursor cells (OPCs) arise from multiple regions of the ventricular zones of the spinal cord, diencephalon and telencephalon. The neural precursors which develop to cells of the oligodendrocyte lineage can be detected at embryonic day 12 (E12) in the mouse (Pringle and Richardson, 1993). These cells express mRNA for plateletderived growth factor alpha receptor (PDGFaR) and the DM-20 isoform of PLP. The 
transcription factors Olig1 and Olig2 are also already expressed at this time (Zhou and Anderson, 2002). Furthermore, the NG2 chondroitin sulphate proteoglycan (NG2) is also an important marker of these cells of the oligodendroglial lineage. NG2 and PDGFaR are not expressed by neural stem cells but by proliferative cells of the oligodendroglial lineage. OPCs are often referred to as NG2-positive cells. The majority of NG2-positive cells give rise to cells of the oligodendrocyte lineage in grey and white matter. However some NG2positive cells also differentiate later into astrocytes of the grey matter (Diers-Fenger et al., 2001). The exact mechanism for the commitment of NG2-positive cells into cells of the oligodendrocyte lineage or into astrocytes still remains elusive. There is a broad discussion in the current literature about the potency and lineage plasticity of NG2-positive cells (Nishiyama et al., 2009).

Three heterogeneous waves of OPCs, showing different spatiotemporal occurrence and transcription factor expression, populate the brain (Kessaris et al., 2006). First the forebrain is populated by OPCs arised from the medial ganglionic eminence. This population is followed by OPCs from the caudal and lateral ganglionic evidence. The third wave arises from the postnatal cortex. The early prenatal migration leads to a widespread distribution of PDGFaR positive OPCs throughout the spinal cord, hindbrain and basal forebrain at E17 (Nishiyama et al., 1996). During the first postnatal week most OPCs start to express the O4 antigen, a marker for immature oligodendrocytes (Reynolds and Hardy, 1997). When OPCs turn to differentiate into mature oliogdendrocytes they gradually lose the expression of their early markers NG2 and PDGF $\alpha$ R. Down-regulation of PDGF $\alpha \mathrm{R}$ is accompanied by reduced OPC proliferation. Before differentiation, OPCs start to express galactocerebroside, the antigen of the $\mathrm{O} 1$ marker. Finally differentiated oligodendrocytes show immunoreactivity for MBP and PLP, markers exclusively for mature myelin-forming oligodendrocytes, but also for $\mathrm{O} 1$ and $\mathrm{O} 4$.

During migration OPCs extend and retract processes to search for axons (Kirby et al., 2006). Most OPCs differentiate into myelin forming cells, but some remain as undifferentiated adult OPCs which are distributed all over the brain. However, the majority of differentiated oligodendrocytes is located in the white matter.

The overall process of oligodendrocyte development and myelination is a complex process orchestrated by dynamic cell-cell interaction. Isolated OPCs show a time-dependent program for their proliferation and differentiation (Raff, 2006). PDGF is secreted by neurons and astrocytes and plays an important role in the regulation of OPC proliferation 
and apoptosis (Noble et al., 1988). OPCs precisely react to all extrinsic factors in their environment to ensure the proper maturation in time and place. Neuronal PDGF $\alpha$ overexpression in transgenic mice leads to enhanced OPC proliferation, but the final number of mature oligodendrocytes and the differentiation itself is not altered, pointing to the important role of apoptosis in the cell regulation of developing oligodendrocytes (Calver et al., 1998).

Apoptosis of immature oligodendrocytes is a crucial event in the correct distribution of the oligodendrocytes. At initial stages of the oligodendroglial lineage, OPCs are produced in great excess to ensure sufficient distribution of oligodendrocytes to cover all axons. The cells that are produced in excess are not provided with enough trophic factors and undergo apoptosis. The factors, which the oligodendrocytes need for the survival, seemed to be secreted by both neurons and astrocytes (Barres and Raff, 1994; Fernandez et al., 2000; Raff et al., 1988). These factors include PDGF, fibroblast growth factor 2 (FGF-2), insuline-like growth factor 1 (IGF-1), neurotrophin 3 (NT-3) and ciliary neurotrophic factor (CNTF) (Baron et al., 2005; Barres and Raff, 1994; Miller, 2002). For example, FGF-2 up-regulates the PDGF $\alpha \mathrm{R}$ expression and blocks the differentiation of OPCs resulting in high proliferation of the precursors (McKinnon et al., 1990). IGF-1 is another important factor for OPC proliferation and also prevents OPC apoptosis (Zeger et al., 2007).

The addition of thyroid hormone to OPC cultures results in the induction of OPC differentiation after some steps of division. The differentiation promoting effect of thyroid hormone has been used in some studies to induce differentiation of immature adult OPCs after demyelination (Fernandez et al., 2004; Harsan et al., 2008). Triggering of myelinprotein expression is observed when thyroid hormone interacts with both thyroid hormone receptor $\alpha(\mathrm{THR} \alpha)$ and THR $\beta$ (Jones et al., 2003). Furthermore, thyroid hormone is able to speed-up OPC proliferation, when it is only binding to THR $\alpha$.

Neuregulins are a family of neuronal secreted factors that activate the membraneassociated receptor tyrosine kinases ErbB2, ErbB3 and ErbB4 in the oligodendrocyte membrane. Oligodendrocytes lacking ErbB2 are not able to differentiate into myelinforming cells (Park et al., 2001). Neuregulin-1 plays a role in the differentiation of oligodendrocytes (Brinkmann et al., 2008) and also inhibits apoptosis of these cells (Fernandez et al., 2000). Oligodendrocyte survival in this process is controlled by the 
interaction of axonal Laminin with $\alpha 6 \beta 1$-Integrin located at the oligodendrocytic plasma membrane (Colognato et al., 2002).

Moreover, Notch signalling is involved in the maturation of oligodendrocytes. Activation of the Notch signalling pathway leads to decreased oligodendrocyte differentiation (Wang et al., 1998). Jagged 1 at the axonal membrane is responsible for the Notch signalling. The Jagged 1 expression is decreased at the same time as myelination occurs.

In contrast, CNTF has a function in OPC differentiation (Talbott et al., 2007).

Not only axon-oligodendrocyte interactions, but also oliogodendrocyte-oligodendrocyte interactions participate in the differentiation process. Neuron-OPC co-cultures show that the cell density of OPCs affects the control of OPC maturation (Rosenberg et al., 2008). Differentiation is triggered by an increased number of OPCs in these cultures.

Several transcription factors are necessary for oligodendrocyte commitment and differentiation. Olig1 and Olig2 are prominent members of oligodendrocyte specific transcription factors which are expressed both in OPCs and in differentiated oligodendrocytes (Zhou et al., 2000). The expression of Olig1/2 depends on the morphogene Sonic hedgehog (Lu et al., 2000). Olig1 and Olig2 differ in their sub-cellular localisation. Olig2 is located in the nucleus, both in OPCs and in mature oligodendrocytes, whereas Olig1 is located in the nucleus of OPCs and later in the cytoplasm of mature oligodendrocytes (Arnett et al., 2004). Olig1/2 are essential in the oligodendrocyte lineage, underlined by the fact, that development of cells of the oligodendroglial lineage is suppressed in Olig 1/2 knock-out mice (Zhou and Anderson, 2002). Only Olig2 is necessary for the initial commitment of the oligodendroglial lineage whereas Olig1 is crucial for the OPC differentiation, shown by specific Olig1 knock-out mice which are able to develop a normal pool of OPCs (Xin et al., 2005). Olig1 is responsible for the upregulation of the myelin genes MBP, PLP and MAG (Li et al., 2007; Xin et al., 2005). Furthermore, Olig1 seems to be involved in remyelination, shown by Olig1 knock-out mice in which the repair of myelin lesions is disturbed (Balabanov and Popko, 2005). The receptor GPR17, which is a negative regulator for oligodendrocyte maturation, is controlled by Olig1 (Chen et al., 2009). In mature myelin-forming oligodendrocytes GPR17 is down-regulated and in animals with myelin lesions the receptor is up-regulated. GPR17 knock-out mice exhibit an early onset of myelination. 


\subsubsection{Myelination}

Myelination of the axons occurs in the early postnatal life. When OPCs arrive at their final resting stage and receive all necessary factors for terminal differentiation, they undergo a massive change of their morphology. They send out numerous processes that have to establish contact with the axon. The synthesis and transport of myelin lipids and proteins, combined with the formation of many myelin sheaths around the axons, is a complex logistical effort.

One example for the axon-oligodendrocyte interaction is the neural cell adhesion molecule (NCAM). Axons express poly-sialyated (PSA)-NCAM before myelination occurs (Jakovcevski et al., 2007). PSA-NCAM interacts with other glycans, for example with heparin sulphate proteoglycans which are expressed by immature OPCs (Winkler et al., 2002). Directly before myelination, expression of the PSA-NCAM is down-regulated in the axon (Charles et al., 2002). The change in the axonal PSA-NCAM expression is controlled by the electrical activity of the neuron (Coman et al., 2005).

The contact of an oligodendroglial process with an axon probably induces the recruitment of polarity complexes. These complexes act to point out the location were new myelin membrane components are attached to the membrane. Sec 8 is a member of the exocyst complex, which is important for the targeting of transport vesicles to the membrane. Sec8 was shown to support myelin-like membrane assembly in cell culture experiments (Anitei et al., 2006).

The inactivation of the RhoA GTPase is an essential step in the formation of the processes (Kippert et al., 2007; Liang et al., 2004). Neurons seem to secrete soluble factors responsible for the down-regulation of RhoA activity in oligodendrocytes. This change in RhoA activity accelerates the transport of PLP to the plasma membrane (Kippert et al., 2007). Myelin lipids are synthesized in the endoplasmatic reticulum. Some lipid microdomains are probably assembled during early steps of the secretory pathway. PLP already interacts with cholesterol and galactosylceramide before leaving the Golgi network (Simons et al., 2000).

MBP, in contrast to PLP, is transported as mRNA to the myelin membrane (Barbarese et al., 1999). Local translation of MBP mRNA could be important due to membrane interactions with the highly positive charged MBP. The plasma membrane is negatively charged and therefore MBP binding accounts for packaging and compaction of the dense 
myelin membrane (Fitzner et al., 2006; Harauz et al., 2009). Shiverer MBP knock-out mice show severe hypomyelination supporting the hypothesis that MBP is a crucial factor for the assembly of the myelin membrane. The MBP interaction with the lipid-rafts gives a hint to the specific local assembly of the myelin-dedicated lipid rafts exclusively at the place of the assembling myelin membrane. 


\subsection{MicroRNAs}

\subsubsection{MicroRNA discovery and genomic organisation}

MicroRNAs (miRNAs) belong to the group of small non-coding RNAs. They are endogenous single-stranded RNAs (ssRNAs) and consist of only 19-25 nucleotides (nt) (Ambros et al., 2003; Bartel, 2004). miRNAs are essential for post-transcriptional gene silencing, performed by base pairing with their complementary target messenger RNAs (mRNAs).

The miRNA function was described in 1993 for the first time (Lee et al., 1993). Working on the development of the nematode C. elegans, Lee et al. revealed that a 22-nucleotide RNA molecule inhibits the translation of the lin-14 mRNA. However, it was not clear at that time, that this kind of post-transcriptional regulation is a general control mechanism in biology. Several years later, in 2000, another miRNA named let-7 was discovered (Pasquinelli et al., 2000; Reinhart et al., 2000). Now it became obvious that there is a general mechanism of transcriptional regulation by a new class of small RNA molecules.

By now, $\sim 700$ miRNAs have been identified in human. Bioinformatic approaches predict even more than 800 different miRNAs in the human genome (Bentwich et al., 2005; Kim et al., 2009). Actually miRNAs constitute one of the largest gene families and represent $\sim 1 \%$ of the whole genome (Bartel, 2004). In the human genome more than 45,000 miRNA binding sites are detected and it is supposed that at least $60 \%$ of the protein-coding genes are influenced by miRNAs (Friedman et al., 2009).

Many miRNAs are phylogenetically conserved pointing to an important role in evolution. In C. elegans more than $50 \%$ of the miRNAs have homologues in humans (IbanezVentoso et al., 2008). Many mammalian miRNAs have paralogs in the genome, characterised by highly similar sequences. These paralogs were probably generated by gene duplications during the evolutionary process. In most cases, these miRNAs show identical sequences at the nucleotide positions 2-7 related to the $5^{\prime}$ end of the miRNA. This sequence is called 'seed sequence' and it is exactly complementary to the binding sequence of the target mRNA. Therefore paralogs are supposed to have the same target mRNAs. Many miRNA genes in the genome are located close to other miRNA genes. These miRNAs are forming clusters which are transcribed together as a polycistronic 
transcription unit (Lee et al., 2002). The clusters often act together to regulate a specific cellular process.

\subsubsection{MicroRNA biogenesis}

The final mature miRNA is a $\sim 22 \mathrm{nt}$ long ssRNA, generated from hairpin-structured transcripts (Kim, 2005). The maturation process of the miRNA includes several steps both inside the nucleus and in the cytoplasm (Figure 1.3). Most miRNA genes are located in intergenic regions, but can also be found in sense- or antisense orientation of intronic regions of the genes (Lagos-Quintana et al., 2001; Lau et al., 2001). Therefore miRNA genes have their own promoters and are transcribed as autonomous transcription regions (Lau et al., 2001; Lee et al., 2004a).

The primary transcript (pri-miRNA) is synthesized by RNA polymerase II (Pol II) (Lee et al., 2004a). This immature product is usually thousands of nucleotides in length and includes several stem-loop structures. The pri-miRNA is capped at the 5'end with a 7methylguanylate-triphosphate group (Cai et al., 2004). The 3'end of the pri-miRNA contains a Poly(A)-tail. The 5'end capping and the 3'end Poly(A)-tail are the same modifications occurring in almost all eukaryotic mRNAs.

The maturation of the pri-miRNA starts already in the nucleus. The nuclear RNase III-type enzyme Drosha is responsible for the first maturation step. Drosha forms a complex with its cofactor, the DiGeorge syndrome critical region gene 8 (DGCR8) protein (called Pasha in invertebrates) (Denli et al., 2004; Han et al., 2004). This complex is also referred to as the Microprocessor complex. Drosha is responsible for the cleavage of the pri-miRNA, 11 base pairs (bp) away from the hairpin base (Han et al., 2006). DGCR8 orients the Microprocessor complex at ssRNA segments at the terminal loop of the pri-miRNA. The $\sim 70 \mathrm{nt}$ stem loop product of the cleaved pri-miRNA is called pre-miRNA. Drosha is also able to cleave mRNAs which contain long hairpins (Han et al., 2009). Interestingly, Drosha is involved in the degradation of its own cofactor DGCR8, by cleavage of the DGCR8 hairpin structured mRNA. Therefore the Microprocessor complex is regulated by a self-controlling mechanism. 


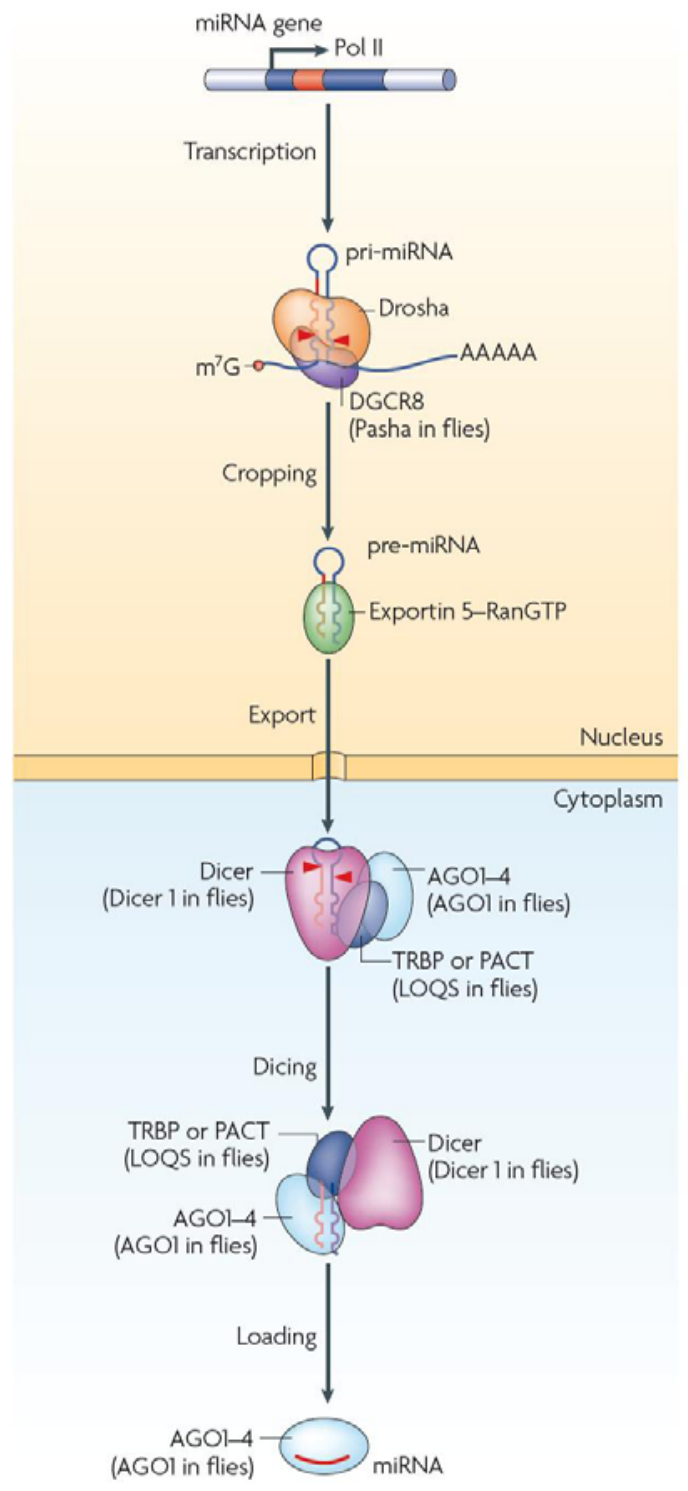

Figure 1.3: Biogenesis of miRNAs. In the nucleus, the miRNA gene is transcribed by RNA Polymerase II (Pol II) and processed by Drosha to a $\sim 70$ nucleotide (nt) long miRNA precursor (pre-miRNA). The pre-miRNA is transported to the cytoplasm with the help of the nuclear transport receptor exportin 5. This process is energy dependent and is mediated by the cofactor Ran in the GTP-bound form. In the cytoplasm, the pre-miRNA is further cleaved by the endoribonuclease Dicer to the mature $\sim 22$ nt long miRNA. In this process Dicer interacts with the TRBP, PACT and Argonaute (AGO1-4) proteins. TRBP and PACT probably contribute to the forming of the RNA-induced silencing complex (RISC). Within this complex one strand of the double-stranded miRNA duplex is removed and the single stranded miRNA, complementary to the target mRNA, remains in the complex (adapted from Kim et al., 2009). Reprinted with permission from Nature Publishing Group, 2010 
Although Drosha is the major enzyme for the processing of the pri-miRNA, other pathways of pri-miRNA cleavage supposed to exist. In fact, groups of miRNA-like RNAs have been discovered which are processed in a Drosha-independent way (Ruby et al., 2007).

The pre-miRNA is exported from the nucleus to the cytoplasm by the nuclear transport receptor exportin-5 (Kim, 2004). A short 3'overhang of the pre-miRNA serves as the recognition site for exportin-5 (Lund et al., 2004). In the nucleus, exportin-5 binds to the pre-miRNA together with the GTP-bound cofactor Ran. Subsequently the shuttle complex moves to the cytoplasm. After hydrolysis of GTP in the cytoplasm the pre-miRNA is released from the complex.

The next step in miRNA maturation is the processing of the pre-miRNA by the cytoplasmic RNase III Dicer (Bernstein et al., 2001). The pre-miRNA is cleaved next to the terminal loop by the endoribonuclease Dicer, resulting in a miRNA-miRNA duplex $\sim 22 \mathrm{nt}$ in length. The loop of the hairpin structured pre-miRNA is therefore removed in this maturation process. In Dicer knock-out animals, the immature pre-miRNAs accumulate and the mature miRNAs are depleted (Hutvagner et al., 2001; Knight and Bass, 2001). As miRNAs itself, Dicer is also highly conserved during evolution (Lee et al., 2004b). The nuclease is present in almost all eukaryotic organisms. In some organisms different Dicer homologues exist. In the fruit fly D. melanogaster, Dicer-1 is responsible for the premiRNA maturation whereas Dicer-2 is important for the siRNA biogenesis (Lee et al., 2004b). In humans and mice, only the Dicer-1 homologue exists. Dicer is a $200 \mathrm{kDa}$ multi-domain protein consisting of two RNase III domains, one double-stranded RNAbinding domain, a Dead-Box RNA Helicase (DEAD) domain, a DUF283 domain and a PAZ domain. The DEAD domain belongs to the family of enzymes which unwind RNA duplexes and the PAZ domain binds to the 3'end of small RNA molecules (Ma et al., 2004; Yan et al., 2003).

The miRNA duplex is assembled to the final effector complex, the RNA-induced silencing complex (RISC). This complex consists of the mature miRNA, Dicer, and several associated proteins and is responsible for the translational inhibition or degradation of the target mRNA (Chendrimada et al., 2005; Lee et al., 2006). The miRNA duplex is attached to an Argonaute protein, a family of proteins which are playing crucial roles in the RISC (Carmell et al., 2002). Like the Dicer enzyme, Argonaute proteins also have a PAZ domain for binding the 3 'end of small RNAs (Ma et al., 2004). Other proteins associated to the 
RISC are TAR RNA-binding protein (TRBP) and PACT. The functions of these proteins are mainly unknown, but TRBP is supposed to function by binding to the miRNA duplex (Preall and Sontheimer, 2005; Tomari et al., 2004). Only one strand of the miRNA duplex remains in the RISC, whereas the other strand, called passenger strand, is degraded. The degradation depends on the thermodynamic stability of the ends of the miRNA duplex (Khvorova et al., 2003). Usually the strand being more unstable at the 5 'end remains. The removal of the passenger strand is mediated by an endoribonuclase of the Argonaute family (Miyoshi et al., 2005). There are also some exceptions in which both strands serve as binding partners for different target mRNAs (Okamura et al., 2008b).

Within the RISC, the target mRNA binds to the complementary miRNA. In humans the Argonaute 2 member of the Argonaute family cleaves the target mRNA (Liu et al., 2004). Therefore the Argonaute2 is named 'slicer' enzyme. However, in animals most target mRNAs are not degraded but the translation is repressed due to the miRNA binding.

Mature miRNAs are supposed to have a long half-life, because knock-down of Drosha, exportin-5 or Dicer results into strongly decreased levels of mature miRNAs without a full loss (Bohnsack et al., 2004; Hutvagner et al., 2001; Ketting et al., 2001; Lee et al., 2003).

\subsubsection{Transcriptional control of MicroRNA biogenesis}

The regulation of miRNA biogenesis is essential for the different tissue-specific functions of miRNAs. In many diseases a dysregulation of miRNAs can be observed (Jiang et al., 2009). Changes in the miRNA expression are often involved in the onset of human tumours (Croce, 2009)

Many examples of transcriptional control of miRNAs have been discovered up to now. For the miRNA let-7 in C. elegans, a temporal regulatory element (TRE) acts as a transcriptional enhancing element (Johnson et al., 2003). During myogenesis transcription factors bind upstream of the miR-1 and miR-133 gene to regulate the transcription of these miRNAs (Rao et al., 2006). Translation of the miR-34 family genes is induced by the p53 tumor suppressor protein (He et al., 2007). Many miRNAs involved in cell proliferation and apoptosis are regulated by the oncogenic protein MYC (Chang et al., 2008).

Different kinds of post-transcriptional regulation of miRNAs have been observed. The overall expression of let-7 pri-miRNA occurs both in undifferentiated and in differentiated embryonic stem cells (ES cells) (Wulczyn et al., 2007). However the mature let-7 miRNA 
is present only in differentiated cells, pointing at a post-transcriptional control of miRNA maturation. Furthermore, it is presumed that Drosha and Dicer processing of particular miRNAs could be specifically regulated (Rybak et al., 2008; Viswanathan et al., 2008). The over-expression of Argonaute proteins revealed up-regulation of mature miRNAs, probably supporting the cleavage of pre-miRNAs by Dicer (Diederichs and Haber, 2007). For some miRNAs, RNA editing has been observed (Kawahara et al., 2008; Yang et al., 2006). The exchange of adenines to inosines by andenine deaminases leads to decreased processing of pri-miRNAs and pre-miRNAs during maturation. Mature miRNAs which undergo RNA editing change their specificity for their target mRNAs.

Another important part in the control of miRNA homeostasis is the turnover of mature miRNAs. The general half-life of miRNAs is often more than 14 hours, but precisely coordinated changes in the level of distinct miRNAs are crucial to mediate the cellular functions (Hwang et al., 2007). When a miRNA is bound by Argonaute proteins it is thought to be stabilized and protected from early degradation. Degradation of miRNAs can be inhibited or prevented by protective modifications. Uridylation at the $3^{\prime}$ end, which is a tag leading to increased degradation of the miRNA, can be avoided by $3^{\prime}$ methylation in plants ( $\mathrm{Yu}$ et al., 2005). Degradation of mature miRNAs is carried out by the 5 '-to-3' exoribonuclease XRN-2 in animals (Chatterjee and Grosshans, 2009). XRN-2 exclusively degrades single-stranded miRNAs and catalyses therefore the degradation of passenger strands which are not bound by Argonaute or miRNA strands which are released from the RISC. This degradation depends on the amount of target mRNAs, suggesting that the miRNA is preferentially retained by Argonaute in the RISC when many target mRNAs exist. This control mechanism points to a miRNA homeostasis which is linked to target substrates. XRN-2 is also responsible for the degradation of other miRNA products resulting from the precursor cleavage and different non-functional products of the processing events (Gy et al., 2007; Morlando et al., 2008).

\subsubsection{Comparison of MicroRNAs with other small RNAs}

miRNAs constitute the major and best explored class of endogenous small RNAs. However, there are other classes of small RNAs. Although the boundaries between the different small RNA subtypes getting more diffuse with the discovery of new small RNA classes, a definition of miRNAs is based on four criteria (Kim, 2005). First, the 
endogenous expression of the miRNA must be confirmed. This is done preferentially by northern-blot hybridization which shows bands both for the mature miRNA ( $\sim 22 \mathrm{nt}$ in length) and for the pre-miRNA ( $\sim 70 \mathrm{nt}$ in length). The second criterion postulates that the mature miRNA sequence is located in one arm of the hairpin structured pre-miRNA without noticeable internal loops. Third, the miRNA sequence should by phylogenetically conserved, to exclude sequences originated by spontaneous mutations. The fourth criterion is based on Dicer knock-out or knock-down experiments. When Dicer function is abolished, an accumulation of the immature pre-miRNAs must be observed. Many small RNAs fulfil these criteria and therefore belong to the class of miRNAs. However, there are other classes of small RNAs, for example endogenous small interfering siRNAs (endosiRNAs) and Piwi-interacting RNAs (piRNAs).

Endo-siRNAs have been recently discovered in plants, flies and mammals (Babiarz et al., 2008; Okamura et al., 2008a). In mice endo-siRNAs are present in oocytes and less abundantly in ES cells (Watanabe et al., 2008). Endo-siRNAs are mainly derived from sense-antisense pairs of transposon transcripts. Other minor types of endo-siRNAs are transcribed from different loci resulting in dsRNA precursors with several mismatches (Ghildiyal et al., 2008; Kawamura et al., 2008). In some cases endo-siRNA precursors constitute single stranded transcripts which are self hybridised with long stem-loop structures. Endo-siRNAs associate with the Argonaute2 protein and are processed by Dicer (Watanabe et al., 2008). In flies the endo-siRNA processing is mediated by the Dicer2 homologue, whereas miRNAs are processed by Dicer1 (Czech et al., 2008; Kawamura et al., 2008). With a size of $\sim 21 \mathrm{nt}$, mature endo-siRNAs are smaller than miRNAs.

Another heterogeneous group of small RNAs are the Piwi-interacting RNAs (piRNAs). The name derived from the interaction with P-element induced wimpy testis (Piwi) proteins which belong to the family of the argonaute proteins. piRNAs are endogenous germ-cell-specific RNAs which are 24-29 nt in length and therefore larger than miRNAs (Aravin et al., 2003). In contrast to miRNAs and to the most endo-siRNAs, piRNAs derive from ssRNA precursors. 


\subsubsection{Functions of MicroRNAs}

miRNAs are crucial for several cellular processes such as development, haematopoiesis, proliferation and apoptosis. The miRNA function is mainly mediated by posttranscriptional repression of the target mRNA. In this process the miRNA serves as an adaptor within the RISC to recognise distinct mRNAs. In general the target binding site is located in the 3' untranslated region (3' UTR) of the mRNA (Bartel, 2004). In contrast to siRNAs, most miRNAs bind their target with several mismatches. However, for the specific target recognition a perfect Watson-Crick base pairing of the miRNA nucleotides 2-7 (seed region) to the mRNA is essential (Maziere and Enright, 2007). The degree of the complementary binding is an indication for the kind of target regulation. In plants miRNAs mostly bind to targets with very high or full complementary resulting in the cleavage of the mRNA. In animals, where several mismatches are frequently observed in miRNA-mRNA binding, the translation of the target mRNA is often repressed. Central mismatches are the reason that cleavage of the mRNA does not occur. However, the translational repression evolved as a powerful tool in controlling numerous cellular functions.

The mechanism of translational inhibition of the target mRNA by RISC is still elusive. It is unknown whether the initiation of the translation, the subsequent elongation or both processes are disturbed by the RISC. Three competing theories have been proposed to answer this question (Figure 1.4) (Carthew and Sontheimer, 2009). The first model proposes that RISC and elF4E, a subunit of the elF4F complex for the initiation of the translation, are competing for binding to the $5^{\prime}$ cap structure of the mRNA. A domain of Argonaute 2 protein was found to have a similar structure compared to elF4E and therefore competing directly with elF4E (Kiriakidou et al., 2007).

Another model is based on the assumption that the RISC is mediating deadenylation of the Poly(A) mRNA tail (Behm-Ansmant et al., 2006; Giraldez et al., 2006). This explanation is based on the interaction of the elF4F complex with the Poly(A)-binding protein PABP1 which results in circularization of the mRNA. The circularization strongly enhances the translation efficiency. The model therefore suggests prevented circularization of the mRNA caused by missing PABP1 binding to the Poly(A)-free mRNA tail. 


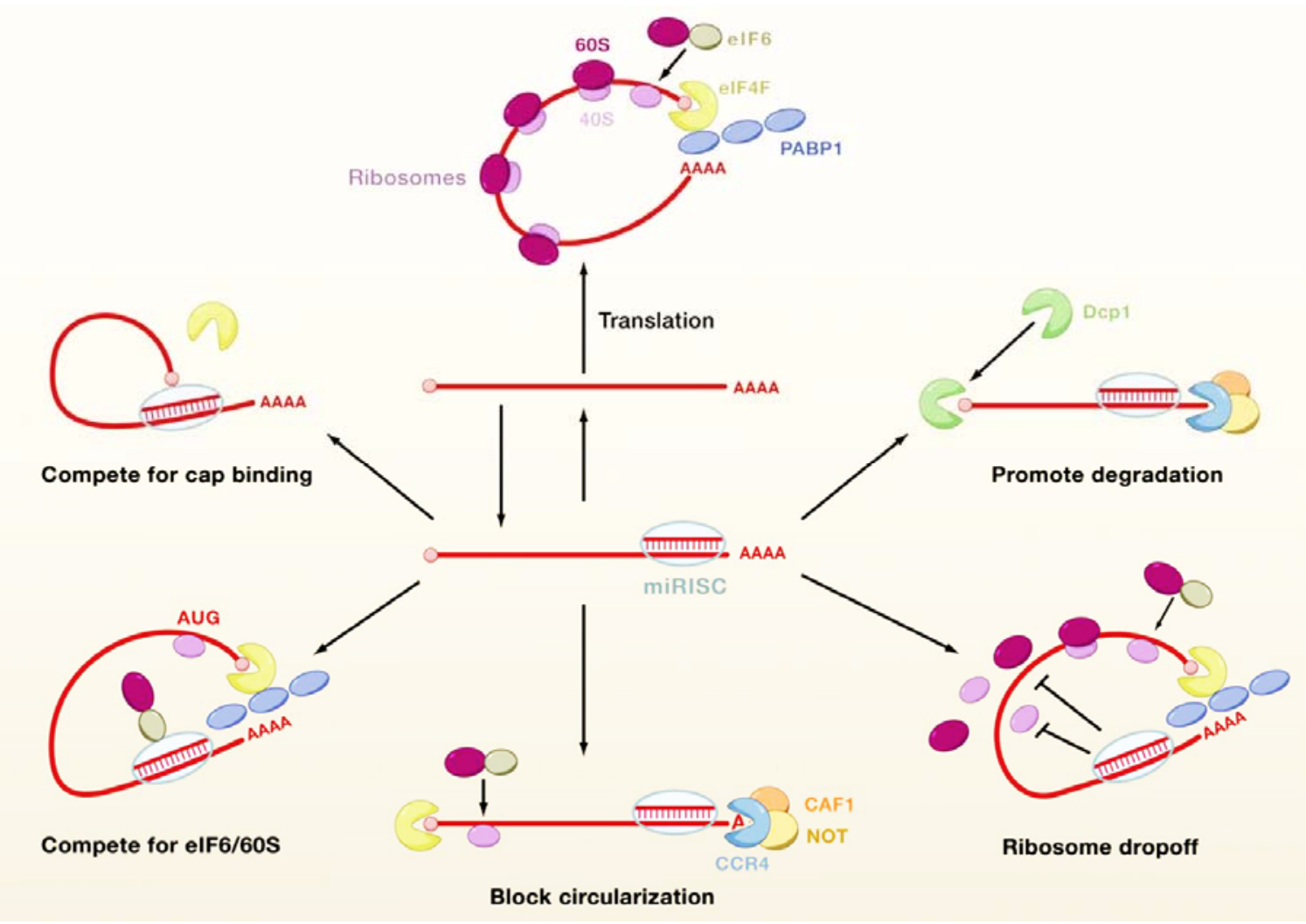

Figure 1.4: Potential pathways of mRNA repression by miRNAs. In mammals, mRNA targets are generally not degraded but the translation is repressed by the RISC. Different models of translational repression by miRNA/RISC are currently discussed. It is possible, that the RISC is competing with initiation factors of the translation process for binding the 5 terminal cap of the mRNA (upper left). Another explanation is based on the assumption that the RISC could block the association of the $60 \mathrm{~S}$ ribosomal subunit with the $40 \mathrm{~S}$ subunit of the initiation complex (lower left). Furthermore, the RISC is thought to stimulate the deadenylation of the $3^{\prime}$ Poly $(A)$-tail of the mRNA and thereby inhibiting the circularisation of the mRNA, which is necessary for the efficient translation (bottom). Due to steric effects, binding of the RISC to the mRNA could also lead to ribosome removal from the mRNA (lower right) (adapted from Carthew and Sontheimer, 2009). Reprinted with permission from Elsevier, 2010

In the third model the association of the $40 \mathrm{~S}$ pre-initiation complex with the $60 \mathrm{~S}$ ribosomal subunit is blocked by the RISC. This model is supported by an in vitro study showing that Argonaute 2 is able to associate with 60S ribosomal subunits (Chendrimada et al., 2007). In addition to these models, RISC binding to the mRNA could lead to steric competition and displacement of the ribosomes. 
However, in contrast to the mainly occurring translational repression, some target mRNAs are also degraded. It is supposed that this degradation is not mediated directly by RISC/Argonaute cleavage of the mRNA but indirectly by deadenylation and decapping of the mRNA through the RISC (Behm-Ansmant et al., 2006; Giraldez et al., 2006; Wu et al., 2006). The question why some mRNAs are degraded and others not is still unanswered. The number and type of mismatches in the miRNA-mRNA complex could be responsible for this process (Aleman et al., 2007).

miRNAs act on many cellular pathways in all tissues. The impact of a general in vivo loss of miRNA function in mammals was shown by disrupting the Dicer gene in mice (Bernstein et al., 2003). The first RNase III domain, encoded by exon 21, was replaced in these mice. Mice deficient for functional Dicer are unable to produce mature miRNAs. At E7.5 only $\sim 50 \%$ of Dicer knock-out embryos were found compared to the expected mendelian ratio. Oct4, which is a key regulator of ES cell proliferation, was reduced in the Dicer knock-out embryos. All knock-out animals died during early embryogenesis. This study indicates a crucial role of miRNAs for the organism. Later on, the involvement of miRNA pathways in ES cells was studied in more detail. Dicer knock-out mice show strong differentiation defects and prolonged G0- and G1-phases in the cell cycle (Kanellopoulou et al., 2005). The differentiation markers hepatocyte nuclear factor 4A (HNF4A), bone morphogenetic protein 4 (BMP4) and erythroid transcription factor (GATA1) were not expressed in Dicer knock-out cells in vitro. Therefore ES cell differentiation was disrupted in both endodermal (HNF4A) and mesodermal (BMP4 and GATA1) tissue. These results are based on the effect of the lack of mature miRNAs (Calabrese et al., 2007). The levels of other small RNAs in ES cells were not changed in the absence of Dicer. DGCR8, the cofactor of Drosha in the Microprocessor complex, was also used in knock-out approaches to study the effect of miRNA depletion. The knock-out of DGCR8 also results in reduced differentiation and proliferation of ES cells (Wang et al., 2007). Cell cycle arrest in the G1-phase was observed, pointing to miRNA functions in the transition of the G1-phase into the S-phase.

miRNAs do not only influence stem cells, but almost all cell types within an organism. An important field of miRNA mediated translation control is the interference with numerous signalling pathways (Inui et al., 2010). Often gene expression is regulated by the active repression of factors which are expressed by distinct signalling events. Hedgehog and Notch are prominent examples for these default repression pathways. The Hedgehog 
pathway controls the proliferation of neuronal progenitors in the mammalian brain (Jiang and Hui, 2008). In human meduloblastomas miR-324-5p was shown to down-regulate the transcription factor GLI1 which mediates Hedgehog signalling (Ferretti et al., 2008). The diminished Hedgehog signalling results in tumour formation. Related miRNAs (miR-2, miR-4, miR-7, miR-11 and miR-79) are discovered to regulate a family of downstream effectors of Notch signalling and therefore controlling aberrant signalling in a whole developmental process (Hornstein and Shomron, 2006; Lai et al., 2005). On the other hand miRNAs can also contribute to the activation of signalling pathways. The Hippo tumour suppressor pathway is controlling tissue growth in mammals. In the activated pathway two downstream transcription factors are inactivated by phosphorylation. miR-372 and miR373 are targeting the responsible kinases and therefore activate the transcription factors (Voorhoeve et al., 2006). This activation leads to excessive cell proliferation explaining the oncogenic potential of miR-372 and miR-373.

Today basic research on miRNAs is object of investigation in numerous fields of cell biology. miRNAs play important roles in the immune system (Xiao and Rajewsky, 2009), in cardiovascular diseases (Latronico and Condorelli, 2009) and especially in many different types of cancer (Croce, 2009). Research of the miRNA world has grown up in the last decade in a very fast way. miRNAs are suggested to be important targets in drug therapy or even used as therapeutic agents themselves (Esau and Monia, 2007; Mack, 2007). Looking at the whole process from the first discovery until today, miRNAs are an outstanding example of how many secrets still exists in nature and how fast they can be explored as soon as the first discovery is made. 


\subsection{Goal of the project}

The goal of the project was to elucidate the function of miRNAs in oligodendroglial cells. We generated knock-out mice in which Dicer, the enzyme for miRNA maturation, was deleted by using 2'3'-cyclic nucleotide 3'phosphodiesterase (CNP)-Cre mice. Using this strategy, the depletion of miRNAs results in reduced oligodendrocyte cell number. In the second part of the project we wanted to find out, which particular miRNAs are enriched in oligodendrocytes and to elucidate their specific function. Microarray profiling of primary oligodendroglial cells was used to investigate the miRNA levels in oligodendrocytes. The miR-17 92 cluster of miRNAs was found to be strongly enriched in oligodendrocytes. In cell culture experiments we could show that these miRNAs promote oligodendrocyte cell proliferation by regulating the Akt signalling pathway. We got additional data for the importance of this cluster by generating miR-17 92 knock-out mice, in which the oligodendrocyte cell number was decreased. 


\section{Materials and Methods}

\subsection{Materials}

\subsubsection{Chemicals and consumables}

Chemicals were purchased from AppliChem, Merck, Sigma-Aldrich and Invitrogen. Consumables were purchased from Eppendorf, Falcon, Starlab and Sartorius Stedim Biotech. Other companies are indicated when the products are mentioned.

\subsubsection{Primary antibodies}

\begin{tabular}{llll} 
Target & & Dilution & Origin \\
\hline A2B5 & mouse monoclonal IgM & $1: 200$ & Millipore \\
Actin & mouse monoclonal IgG2a & $1: 500$ & Sigma \\
Akt & rabbit monoclonal IgG & $1: 1000$ & Cell Signalling \\
Phospho-Akt & rabbit polyclonal & $1: 1000$ & Cell Signalling \\
Dicer & mouse monoclonal IgG1 & $1: 100$ & Santa Cruz \\
GalC & mouse monoclonal IgM & $1: 50$ & \\
MBP & mouse monoclonal IgG1 & $1: 200$ & Sternberger Monoclonals Inc. \\
Olig2 & rabbit polyclonal IgG & $1: 300$ & IBL \\
Pten & rabbit monoclonal IgG & $1: 1000$ & Cell Signaling
\end{tabular}




\subsubsection{Secondary antibodies}

\begin{tabular}{llll} 
Target & & Dilution & Origin \\
\hline mouse IgG1 & Alexa Fluor 488-conjugated & $1: 200$ & Molecular Probes / Invitrogen \\
rabbit IgG & Alexa Fluor 488-conjugated & $1: 200$ & Molecular Probes / Invitrogen \\
mouse IgM & Cy 3-conjugated & $1: 200$ & Jackson Immuno Research \\
mouse IgG & Horseradish-peroxidase- & $1: 1000$ & Jackson Immuno Research \\
& conjugated & & \\
rabbit IgG & Horseradish-peroxidase- & $1: 1000$ & Jackson Immuno Research \\
& conjugated & &
\end{tabular}

\subsubsection{Cell lines}

Cell line Origin

Oli-neu J. Trotter, University of Mainz, Mainz, Germany

\subsubsection{Bacterial strains}

\begin{tabular}{ll} 
Strain & Origin \\
\hline DH5 $\alpha$ & Invitrogen
\end{tabular}

\subsubsection{Plasmids}

Plasmid

pMiR19b-Luc Reporter Vector (LR-0053)

phRL-SV40
Origin

Signosis Inc.

Promega 


\subsection{7 miRNAs}

Precursor molecules Origin

Pre-miR-17 Ambion

Pre-miR-19b Ambion

Inhibitors

\begin{tabular}{ll}
\hline Anti-miR-17 & Ambion \\
Anti-miR-19b & Ambion \\
miR-17 miRCURY LNA & Exiqon
\end{tabular}

Knockdown probes

miR-19b miRCURY LNA Exiqon

Knockdown probes

\subsection{8 siRNAs}

siRNA Origin

Mm_Dicer1_6 QIAGEN

\subsubsection{DNA primers}

Primer Sequence

CNP forward 5'-CATAGCCTGAAGAACGAGA-3

CNP-Cre forward 5'-GCCTTCAAACTGTCCATCTC-3'

CNP reverse 5'-CCCAGCCCTTTTATTACCAC-3'

Dicer forward 5'-CCTGACAGTGACGGTCCAAAG-3'

Dicer reverse 5'-CATGACTCTTCAACTCAAACT-3'

miR-17 92 forward 5'-TCGAGTATCTGACAATGTGG-3'

miR-17 92 reverse 5'-TAGCCAGAAGTTCCAAATTGG-3' 


\subsubsection{Kits}

Kit

Company

BrdU Assay

Millipore

DeadEnd Fluorometric TUNEL System

Promega

GoTaq Flexi DNA Polymerase

Promega

Invisorb Spin Tissue Mini Kit

Invitek

Low RNA Input Linear Amplification Kit PLUS

Agilent Technologies

Luciferase Assay System with Reporter Lysis Buffer

Promega

miRCURY LNA microRNA Array Labelling Kit

Exiqon

miRNA Complete Labelling and Hyb Kit

Agilent Technologies

Plasmid DNA Purification

Macherey-Nagel

(NucleoBond Xtra Midi)

RNA 6000 Nano LabChip Kit

Agilent Technologies

RNA 6000 Pico LabChip Kit

Agilent Technologies

RNA Spike-In Kit

Agilent Technologies

Spike-In miRNA controls miRCURY LNA microRNA-

Exiqon

Array kit

TaqMan MicroRNA Assays for:

Applied Biosystems

miR-17, miR-19b, miR-34b, miR-125b and snoRNA 234

TaqMan MicroRNA Reverse Transcription Kit

Applied Biosystems

\subsubsection{Mice strains}

\begin{tabular}{lll} 
Strain & Genetic alteration & Origin \\
\hline CNCE & Cre expression under CNP promoter & K.-A. Nave, MPI for \\
& & Experimental Medicine, \\
& & Göttingen, Germany \\
Dicer1 $^{\mathrm{tml} \mathrm{Bdh} / \mathrm{J}}$ & Exon 23 of Dicer1 gene flanked by loxP & The Jackson Laboratory \\
& sites & \\
Mir17-92 $^{\mathrm{tm} 1.1 \mathrm{Tyj} / \mathrm{J}}$ & miR-17 92 cluster flanked by loxP sites & The Jackson Laboratory
\end{tabular}




\subsubsection{Buffers}

Phosphate buffered saline (PBS)

in $11 \mathrm{H}_{2} \mathrm{O}$, $\mathrm{pH} 7.2-7.4$

$80 \mathrm{~g} \quad \mathrm{NaCl}$

$2 \mathrm{~g} \quad \mathrm{KCl}$

$14,4 \mathrm{~g} \quad \mathrm{Na}_{2} \mathrm{HPO}_{4}$

$2,4 \mathrm{~g} \quad \mathrm{KH}_{2} \mathrm{PO}_{4}$

\subsubsection{Cell culture media}

\subsubsection{Commercial media and supplements}

Component Company

B27 supplement

Gibco/Invitrogen

DMEM for primary cells

Gibco/Invitrogen

DMEM for cell lines

PAA

GlutaMAX

Gibco/Invitrogen

Fetal calf serum (FCS)

PAA

Horse serum (HS)

PAA

Insulin-Transferrin-Selenium-A supplement 100x

Gibco/Invitrogen

LB Medium

AppliChem

LB-Agar plate

AppliChem

Penicillin/Streptomycin (Pen/Strep) 100x

Gibco/Invitrogen

PBS

PAA 


\subsubsection{SATO medium}

$\begin{array}{ll}5 \% & \text { Horse serum } \\ 110 \mu \mathrm{g} / \mathrm{ml} & \text { Pyruvate } \\ 5 \mu \mathrm{g} / \mathrm{ml} & \text { Transferrin } \\ 10 \mu \mathrm{g} / \mathrm{ml} & \text { Insulin } \\ 100 \mu \mathrm{M} & \text { Putrescine } \\ 200 \mathrm{nM} & \text { Progesterone } \\ 500 \mathrm{pM} & \text { Tri-iodo-thyronine } \\ 220 \mathrm{nM} & \text { Na-selenite } \\ 520 \mathrm{nM} & \text { L-thyroxine } \\ 1 \mathrm{x} & \text { Pen/Strep } \\ 1 \mathrm{x} & \text { GlutaMAX }\end{array}$

In DMEM with $4.5 \mathrm{~g} / 1$ glucose. Insulin-Transferrin-Selenium-A was used as a supplement for insulin, transferrin, Na-selenite and pyruvate.

\subsubsection{Super-SATO medium}

$\begin{array}{ll}2 \% & \text { B27-supplement } \\ 1 \% & \text { Horse serum } \\ 110 \mu \mathrm{g} / \mathrm{ml} & \text { Pyruvate } \\ 1 \mu \mathrm{g} / \mathrm{ml} & \text { Transferrin } \\ 10 \mu \mathrm{g} / \mathrm{ml} & \text { Insulin } \\ 500 \mathrm{pM} & \text { Tri-iodo-thyronine } \\ 520 \mathrm{nM} & \text { L-thyroxine } \\ 1 \mathrm{x} & \text { Pen/Strep } \\ 1 \mathrm{x} & \text { GlutaMAX }\end{array}$

In DMEM with $4.5 \mathrm{~g} / 1$ glucose. 


\subsubsection{Softwares}

Adobe Illustrator CS 3

Adobe Photoshop CS 3

Agilent Feature Extraction (Microaray analysis software)

Image $J$

Leica SP2 Confocal Software

Microsoft Office 2003 


\subsection{Methods}

\subsubsection{Knock-out mice}

\subsubsection{Dicer knock-out mice}

Mice carrying loxP-sites flanking the exon 23 of the Dicer allels (Dicer ${ }^{\text {flox/flox }}$ ) (Harfe et al., 2005) were bred with mice heterozygously expressing Cre recombinase under the control of the 2',3'-cyclic nucleotide 3'phosphodiesterase (CNP) promoter $\left(\mathrm{CNP}^{+/ \mathrm{Cre}}\right)$ (LappeSiefke et al., 2003). Mice were genotyped directly after birth at postnatal day 0 (P0) or after weaning (3 weeks after birth). Offspring were genotyped by PCR analysis of tail DNA using CNP- and CNP-Cre-specific primers (see 2.1.8) that produce 550 bp products for CNP-Cre allele and 750 bp products for the wild-type CNP allele. The primers specific for the Dicer gene (see 2.1.8) produced 420 bp products for the Dicer ${ }^{\text {flox }}$ allele and $351 \mathrm{bp}$ products for the Dicer wild-type allele. Offspring with the genotype $\mathrm{Dicer}^{+/ f l o x} \mathrm{CNP}^{+/ C r e}$ were mated with Dicer ${ }^{\text {flox/flox }} \mathrm{CNP}^{+/+}$mice to generate $\mathrm{Dicer}^{\text {flox/flox }} \mathrm{CNP}^{+/ \mathrm{Cre}}$ mutant mice. Littermates were used as control animals.

\subsubsection{2 miR-17 92 cluster knock-out mice}

Mice with loxP-sites flanking the miR-17 92 cluster (miR-17 92 ${ }^{\text {flox/flox }}$ ) (Ventura et al., 2008) were bred with $\mathrm{CNP}^{+/ C r e}$ mice. Offspring were sacrificed after birth (P0) and genotyped. miR-17 92 cluster specific primers (see 2.1.8) produced 289 bp products for the miR-17 92 floxed allele and 255 bp products for the wild-type allele. CNP-Cre primers and PCR products are described in 2.2.1.1. Offspring with the genotype miR$17 \sim 92^{+/ f l o x} \mathrm{CNP}^{+/ \mathrm{Cre}}$ were bred with miR-17 92 $2^{\text {flox/flox }} \mathrm{CNP}^{+/+}$mice to get miR-17 92 cluster knockout mice (miR-17 92 flox/flox $\mathrm{CNP}^{+/ \mathrm{Cre}}$ ). Littermates were used as control animals. 


\subsubsection{Mice genotyping}

\subsubsection{DNA-extraction}

Mice tail tips (approx. $3 \mathrm{~mm}$ in length) were used for animal genotyping. DNA extraction was performed using the Invisorb ${ }^{\circledR}$ Spin Tissue Midi Kit (Invitek) according to manufacture's instructions. DNA was eluted in $50 \mu 1$ elution buffer and stored at $-20^{\circ} \mathrm{C}$.

\subsubsection{Polymerase chain reaction}

DNA was amplified for analysis by polymerase chain reaction (PCR) (Mullis et al., 1986) using the GoTaq ${ }^{\circledR}$ Flexi DNA Polymerase kit (Promega). The PCR reaction mix is described below. For negative control, $\mathrm{ddH}_{2} \mathrm{O}$ was used instead of DNA.

\section{PCR reaction mix}

$\begin{array}{ll}0.5 \mu \mathrm{M} & \text { Forward primer } \\ 0.5 \mu \mathrm{M} & \text { Reverse primer } \\ 0.2 \mathrm{mM} & \text { dNTPs } \\ 1 \mathrm{x} & 5 \mathrm{x} \mathrm{GoTaq}^{\circledR} \text { Flexi Buffer } \\ 1.25 \mathrm{mM} & \mathrm{MgCl}_{2} \\ 1.25 \mathrm{u} & \mathrm{GoTaq}^{\circledR} \text { DNA Polymerase } \\ 1 \mu 1 & \mathrm{DNA}^{\circ} \\ \text { filled up to } 20 \mu \mathrm{l} & \mathrm{ddH}_{2} \mathrm{O}\end{array}$

PCR reactions were pipetted on ice in thin wall $200 \mu \mathrm{l}$ PCR tubes and transferred to a thermocycler (Biometra T 3000). The cycling conditions are described below. 


\section{PCR cycling conditions for Dicer and CNP-Cre}

\begin{tabular}{llll} 
Cycling step \# & Temp. ${ }^{\circ} \mathrm{C}$ & Time & \\
\hline 1 & 95 & $3 \mathrm{~min}$ & \\
2 & 50 & $30 \mathrm{sec}$ & \\
3 & 72 & $90 \mathrm{sec}$ & \\
4 & 95 & $30 \mathrm{sec}$ & repeat steps $2-4$ for 35 cycles \\
5 & 50 & $1 \mathrm{~min}$ & \\
6 & 72 & $10 \mathrm{~min}$ & \\
7 & 4 & - & hold
\end{tabular}

\section{PCR cycling conditions for the miR-17 92 cluster}

\begin{tabular}{llll} 
Cycling step \# & Temp. ${ }^{\circ} \mathrm{C}$ & Time & \\
\hline 1 & 94 & 3 min & \\
2 & 53 & 1 min & \\
3 & 72 & 1 min & \\
4 & 94 & $30 \mathrm{sec}$ & repeat steps 2-4 for 35 cycles \\
5 & 72 & 2 min & \\
6 & 4 & - & hold
\end{tabular}

\subsubsection{Agarose gel electrophoresis}

Following PCR, DNA was separated according to its size by agarose gel electrophoresis (Wagner, 1964). Loading buffer for the DNA was already included in the $5 \mathrm{x} \mathrm{GoTaq}^{\circledR}$ Flexi Buffer. Gels contained $2 \%$ agarose and $0.5 \mu \mathrm{g} / \mathrm{ml}$ ethidium bromide in Tris acetate EDTA

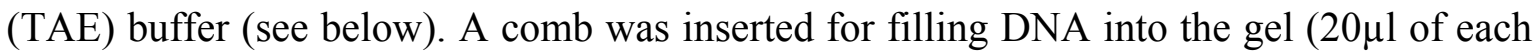
PCR mix per gel pocket).

\section{TAE buffer (pH 8.5)}

$\begin{array}{ll}4.84 \% & \text { Tris base } \\ 1.14 \% & \text { Acetic acid } \\ 0.01 \mathrm{M} & \text { EDTA }\end{array}$


After loading the gel, DNA separation was performed at $130 \mathrm{~V}$ for 1.5 hours. The gel was scanned by using the INTAS UV-System and INTAS GDR software.

\subsubsection{Brain and spinal cord slice preparation}

Brains of newborn mice were fixed with $4 \%$ paraformaldehyde over night at $4{ }^{\circ} \mathrm{C}$, incubated in $30 \%$ sucrose in phosphate-buffered saline (PBS) for $\sim 12$ hours at $4^{\circ} \mathrm{C}$ and embedded in O.C.T. $^{\text {TM }}$ Tissue-Tek $^{\circledR}$. Cryosections $(20 \mu \mathrm{m})$ were cut with a Leica CM1900 cryostat and stored free-floating in PBS containing $25 \%$ glycerol and $25 \%$ ethylene glycol at $-20^{\circ} \mathrm{C}$. For spinal cord slice preparation mice torsos of the thoragic region were treated as described for the brain, but with prolonged fixation and sucrose incubation times of 24 hours each. $30 \mu \mathrm{M}$ sections were cut for spinal cord analysis.

\subsubsection{White- and grey-matter preparation}

White- and grey-matter were prepared from CNS tissue of adult wild-type C57 black 6 (C57BL/6) mice. White-matter mainly consisting of myelinating oligodendrocytes was extracted from the corpus callosum. Grey-matter with a high amount of neurons and astrocytes and only a low number of oligodendrocytes was extracted from the frontal cortex. Cell lysates were stored in Trizol reagent at $-80^{\circ} \mathrm{C}$ before RNA isolation for miRNA microarray profiling.

\subsubsection{Immunohistochemistry}

Brain or spinal cord slices were washed twice for 10 minutes with PBS. For blocking and permeabilisation slices were treated with $5 \%$ HS and $0.3 \%$ Triton X-100 in PBS for one hour at RT. The primary antibody was diluted in the blocking and permeabilisation solution and the slices were incubated o/n at $4^{\circ} \mathrm{C}$. After two washing steps with PBS for 10 minutes, incubation with Alexa Flour 488-labelled secondary antibodies (in PBS with $2 \%$ HS) was carried out for two hours at RT. Finally slices were washed twice with PBS and 
once rinsed with $\mathrm{H}_{2} \mathrm{O}$ and mounted with VECTASHIELD mounting medium and DAPI on microscope slides.

\subsubsection{Cell culture}

\subsubsection{Primary cells}

Preparation of mouse oligodendrocyte primary cultures was performed as described previously (Trajkovic et al., 2006). Cells were extracted from newborn (P0) mice brains. After 10 to 14 days, oligodendrocytes were shaken off the mixed glial cultures, resulting in cultures with an oligodendrocyte purity of $\sim 75$ to $95 \%$. After shaking, cells were plated in Super-SATO medium (see 2.1.13.3) on poly-L-lysine coated $(100 \mu \mathrm{g} / \mathrm{ml})$ dishes or glass coverslips. Cells were seed at a density of $3 \times 10^{4}$ cells per $\mathrm{cm}^{2}$. Primary astrocyte cultures were prepared by trypsination of mixed glial cultures after oligodendrocytes and microglia were shaken off and maintained in DMEM with $10 \%$ FCS.

\subsubsection{Cell lines}

Oli-neu cells, an oligodendrocyte precursor cell line (Jung et al., 1995), were plated on glass coverslips. The coverslips were coated with $33 \mu \mathrm{g} / \mathrm{ml}$ PLL for 1 hour and washed twice with $\mathrm{H}_{2} \mathrm{O}$. Cells were grown in SATO medium (see 2.1.13.2) and passaged 1:5 after reaching confluency of $\sim 80 \%$. Passage numbers higher 30 were discarded and not used for experiments.

\subsubsection{Thawing and freezing of cells}

For thawing, Oli-neu cells were transferred from liquid nitrogen immediately to $37^{\circ} \mathrm{C}$ water bath. Afterwards the cell suspension $(1 \mathrm{ml})$ was filled up with $10 \mathrm{ml}$ SATO medium and centrifuged at $900 \mathrm{~g}$ for $10 \mathrm{~min}$ at RT. The cell pellet was resuspended in $10 \mathrm{ml}$ SATO medium and cells were plated on dishes for expansion. 
For freezing, Oli-neu cells were centrifuged in $5 \mathrm{ml} \mathrm{SATO} \mathrm{medium} \mathrm{at} 900 \mathrm{~g}$ for $5 \mathrm{~min}$ at RT. The pellet was resuspended in $0.5 \mathrm{ml}$ DMEM and mixed with $0.5 \mathrm{ml}$ freezing medium (40\% DMEM, $40 \%$ FCS and $20 \%$ DMSO). Cooling down to $-80^{\circ} \mathrm{C}$ was performed in a freezing container with a cooling rate of $-1^{\circ} \mathrm{C} / \mathrm{min}$. Finally cells were stored in liquid nitrogen.

\subsubsection{Transfection}

Cells were transfected either 4 or 24 hours after shaking using Lipofectamine 2000 (Invitrogen). Lipofectamine 2000 was diluted in OPTI-MEM medium and incubated for 5 min. The oligonucleotides (miRNA precursors, antisense nucleotides or siRNA) were also diluted in OPTI-MEM medium. Nucleotides were mixed with Lipofectamine 2000 and incubated for 20 minutes at RT for liposome-DNA complex-formation before adding to growth medium.

\section{Transfection mix in one 12-well chamber}

$1 \mathrm{ml} \quad$ Super-Sato medium (without antibiotics)

$2 \times 100 \mu 1 \quad$ OPTI-MEM

40 pmol Oligonucleotides

$2 \mu 1 \quad$ Lipofectamine 2000

Transfection efficiency was confirmed using FITC-labelled oligonucleotides. For the down-regulation of specific miRNAs, miRCURY ${ }^{\mathrm{TM}}$ LNA Knockdown probes (Exiqon) or Anti-miR miRNA inhibitors (Ambion) against miR-17 and miR-19b were used in combination. Pre-miR ${ }^{\mathrm{TM}}$ miRNA precursors (Ambion) for miR-17 and miR-19b were used in combination to raise intracellular levels of miR-17 and miR-19b. The miRCURY ${ }^{\mathrm{TM}}$ LNA Scramble-miR (Exiqon) and the $\mathrm{miR}^{\mathrm{TM}}$ Negative Control (Ambion) were used as negative controls. For Dicer knock-down in primary oligodendrocytes, siRNA against Dicer mRNA (see 2.1.7) was transfected. siRNA control oligonucleotides (Qiagen) were used as negative controls. 


\subsubsection{Cell lysis}

Cells were washed twice with PBS and the cell layer was detached from the culture dish with a sterile cell scraper and $2 \mathrm{x}$ lysis buffer (see below). For $10^{5}$ cells, $40 \mu 1$ of $2 \mathrm{x}$ lysis buffer was used.

\section{2x lysis buffer (in 2x PBS)}

$\begin{array}{ll}4 \% & \text { NP-40 } \\ 0.4 \% & \text { SDS } \\ 1 \mathrm{mM} & \text { EGTA }\end{array}$

Protease inhibitors (Complete, Roche) were used according to the instructions of the manufacturer. Additionally phosphatase inhibitors (PhosStop, Roche) were used in experiments investigating the expression of phospho-Akt.

\subsubsection{Immunocytochemistry}

Cells on cover slips were washed three times with PBS and fixed in $4 \%$ paraformaldehyde at RT for 15 minutes. After 3 washing steps with PBS, the cells were permeabilised with $0.1 \%$ Triton X100 for 1 min and washed again 3 times with PBS. Unspecific binding sites were blocked for $30 \mathrm{~min}$ at RT with blocking solution (see below). The primary antibody was diluted in $10 \%$ blocking solution in PBS and cells were incubated with the antibody solution for $1 \mathrm{~h}$ at RT in a humidified chamber. Afterwards cells were washed 3 times with PBS and incubated again for 1 hour at RT with Cy3- or Alexa Flour 488-labelled secondary antibodies (diluted in 10 \% blocking solution in PBS). Finally cells were washed 3 times with PBS, nuclei were stained with DAPI and the cells were mounted with VECTASHIELD mounting medium (Vector Laboratories Inc.) on microscope slides. 


\section{Blocking solution (in PBS)}

$2 \% \quad$ BSA

$0.1 \% \quad$ Gelatine

$2 \% \quad$ Horse serum

$0.02 \%$ Biotin

$0.1 \%$ Saponin

\subsubsection{RNA isolation}

Total RNA from primary oligodendrocytes was extracted three days after shaking. Cells were washed 3 times with PBS and lysed using $1 \mathrm{ml}$ Trizol Reagent (Invitrogen) for $5 \mathrm{x}$ $10^{5}$ cells. The cell lysates were washed with $200 \mu \mathrm{l}$ chloroform and nucleic acids were precipitated with $500 \mu \mathrm{l}$ isopropanol. Following precipitation nucleic acids were centrifuged at $13000 \mathrm{~g}$ for 10 minutes at $4^{\circ} \mathrm{C}$ and the cell pellet was resuspended in the DNase treatment reaction mix (see below). DNA was incubated for 20 minutes at $37^{\circ} \mathrm{C}$ for digestion.

\section{DNase treatment reaction mix}

$5 \mu 1 \quad$ 10x Incubation buffer

$1 \mu \mathrm{l} \quad$ DNase I

$0.5 \mu 1 \quad$ RNase OUT

$43.5 \mu \mathrm{l} \quad \mathrm{H}_{2} \mathrm{O}$

Following DNA digestion, RNA was purified by adding $200 \mu \mathrm{l}$ Phenol/Chloroform/Isoamylalcohol. After centrifugation at $13000 \mathrm{~g}$ for 10 minutes at $4{ }^{\circ} \mathrm{C}$, RNA was precipitated by adding $20 \mu \mathrm{l}$ of $3 \mathrm{M} \mathrm{Na-acetate} \mathrm{pH} 4.8$ and $200 \mu \mathrm{l}$ isopropanol. After incubation at $4^{\circ} \mathrm{C}$ o/n cells were washed twice with ethanol and centrifuged each time at $13000 \mathrm{~g}$ for 10 minutes at $4^{\circ} \mathrm{C}$. After final centrifugation, the cell pellet was dried at $37^{\circ} \mathrm{C}$ and resuspended in $15 \mu 1$ RNase-free $\mathrm{H}_{2} \mathrm{O}$. RNA quantity and quality was checked by using a NanoDrop ND-1000 spectrophotometer and an Agilent 2100 Bioanalyzer according to manufacture's instructions. 


\subsubsection{Real-time quantitative PCR}

\subsubsection{Reverse transcription}

Reverse Transcription of RNA into cDNA was performed with the TaqMan ${ }^{\circledR}$ MicroRNA Reverse Transcription Kit (Applied Biosystems) according to the manufacture's instructions. The master mix for the cDNA synthesis and the conditions for the thermal reaction are described below.

\section{Reverse transcription master mix}

$5 \mu 1 \quad$ Total RNA $(2 \mathrm{ng} / \mu \mathrm{l})$

$3 \mu \mathrm{l} \quad$ Specific miRNA primers

$0.15 \mu \mathrm{d} \quad \mathrm{dNTP} \operatorname{mix}(100 \mathrm{mM}$ total $)$

$1 \mu \mathrm{l} \quad$ Multiscribe ${ }^{\mathrm{TM}} \mathrm{RT}$ enzyme $(50 \mathrm{U} / \mu \mathrm{l})$

$1.5 \mu 1 \quad 10 \times$ RT buffer

$0.19 \mu \mathrm{l} \quad$ RNase inhibitor $(20 \mathrm{U} / \mu \mathrm{l})$

$4.16 \mu 1 \quad$ Nuclease-free $\mathrm{H}_{2} \mathrm{O}$

\section{Reverse transcription reaction}

\begin{tabular}{ll} 
Temperature $\left({ }^{\circ} \mathrm{C}\right)$ & Time (minutes) \\
\hline 16 & 30 \\
42 & 30 \\
85 & 5 \\
4 & hold
\end{tabular}

\subsubsection{Real-time quantitative PCR}

Expression levels of miR-17, miR-19b, miR-125b and miR-34b in primary oligodendrocytes and astrocytes were measured by quantitative real-time reverse transcriptase PCR (qRT-PCR) (Higuchi et al., 1993). For each condition triplicates were used. Internal snoRNA-234 levels were used for normalization. The quantitative PCR was performed using the $\mathrm{iQ}^{\mathrm{TM}} 5$ Real-Time PCR Detection System (Bio-Rad) and the TaqMan ${ }^{\circledR}$ 
Universal Master Mix (Applied Biosystems) according to manufacture's protocols. The master mix and the thermal cycling parameters are described below.

\section{Real-time PCR master mix}

$1.33 \mu 1 \quad$ Product from the reverse transcription

$1 \mu 1 \quad$ TaqMan MicroRNA Assay (primers)

$10 \mu \mathrm{l} \quad$ TaqMan Universal PCR Master Mix

$7.67 \mu \mathrm{l} \quad$ Nuclease-free $\mathrm{H}_{2} \mathrm{O}$

\section{Real-time PCR cycling conditions}

\begin{tabular}{llll} 
Cycling step \# & Temp. ${ }^{\circ} \mathrm{C}$ & Time & \\
\hline 1 & 95 & $10 \mathrm{~min}$ & \\
2 & 95 & $15 \mathrm{sec}$ & \\
3 & 60 & $1 \mathrm{~min}$ & repeat steps $2-3$ for 40 cycles \\
4 & 4 & - & hold
\end{tabular}

\subsubsection{Microarrays}

Total RNA from primary oligodendrocyte cultures was isolated three days after shaking for hybridisation onto the microarrays. Three replicates were used for every microarray analysis.

For the comparison of miRNA expression levels of primary oligodendrocytes and primary astrocytes the miRNAs were hybridized onto microRNA Arrays (miRCURY LNA microRNA Array, v. 9.2, Exiqon). The miRCURY LNA microRNA Array labelling kit (Exiqon) and the Spike-In miRNA control miRCURY LNA microRNA Array kit (Exiqon) were used for labelling and hybridisation according to manufacture's recommendations.

The miRNA expression during different oligodendrocyte developmental stages was assessed by hybridization onto miRNA microarrays (Agilent-021828 Mouse miRNA Microarray Release 12.0, Agilent Technologies). For this time-line experiment miRNAs of primary oligodendrocytes were examined directly after shaking (d0, unmature oligodendrocytes), 24 hours after shaking (d1) and 6 days after shaking (d6, mature oligodendrocytes). Labelling and hybridization of miRNAs were performed with the 
miRNA Complete Labelling and Hyb Kit (Agilent Technologies) according to manufacture's recommendations.

Transcriptome analysis of oligodendrocyte was performed with mRNA microarrays (Agilent-014868 Whole Mouse Genome Microarray 4x44k, Agilent Technologies). The Low RNA Input Linear Amplification Kit PLUS (Agilent Technologies) and the RNA Spike-In Kit (Agilent Technologies) were used for labelling and hybridisation according to manufacture's recommendations.

The arrays were scanned using an Agilent Technologies (G2505B) microarray scanner. Intensity data were extracted and summarized using Agilent's Feature Extraction software, version 9.5.3. Quantile-normalization was applied to the log2-transformed intensity values as a method for between-array normalization. For the detection of differential expression, limma was used to fit the data to a linear model. Obtained p-values were corrected for multiple testing with the Benjamini-Hochberg method. The microarray data are generated conforming the MIAME guidelines and have been deposited in NCBI's Gene Expression Omnibus (http://www.ncbi.nlm.nih.gov/geo/) (accession number GSE 21801).

\subsubsection{Protein analysis}

\subsubsection{SDS-PAGE}

Protein separation according to the molecular weight was performed with sodium dodecyl sulfate polyacrylamide gel electrophoresis (SDS-PAGE) (Raymond and Weintraub, 1959). For separation, two-layer gels in a Bio-Rad Mini-PROTEAN 3 casting system were used. The composition of the upper stacking gel and lower resolving gel are described in the following tables:

\section{Stacking gel}

$4 \%$

$125 \mathrm{mM}$

$0.1 \%$

$0.05 \%$

$0.005 \%$
Acrylamide / bis-acrylamide $(37,5: 1)$ solution

Tris- $\mathrm{HCl} \mathrm{pH} 6.8$

SDS

Ammonium persulfate (APS)

$\mathrm{N}, \mathrm{N}, \mathrm{N}, \mathrm{N}^{\prime}$-Tetramethyl-ethylene diamine (TEMED) 


\section{Resolving gel}

$10-12 \%$

Acrylamide / bis-acrylamide (37,5:1) solution

$325 \mathrm{mM}$

Tris-HCl pH 6.8

$0.1 \%$

SDS

$0.05 \%$

Ammonium persulfate (APS)

$0.005 \%$

$\mathrm{N}, \mathrm{N}, \mathrm{N}, \mathrm{N}^{\prime}$-Tetramethyl-ethylene diamine (TEMED)

First the resolving gel was cast up to approximately $70 \%$ of the height of the glass chamber in the casting system. Filling the system with $\mathrm{H}_{2} \mathrm{O}$ ensured an equal horizontal edge of the gel. After 30 min of polymerisation, $\mathrm{H}_{2} \mathrm{O}$ was removed and the stacking gel was cast onto the resolving gel. The wells for loading the protein samples were formed by inserting a comb into the stacking gel before polymerisation.

Protein lysates were diluted $1 / 1$ in 2x protein sample buffer (see below) and denatured by heating for five minutes at $95^{\circ} \mathrm{C}$. After heating, protein samples were loaded on the gel. The gelelectrophoresis was performed with a Bio-Rad mini gel electrophoresis system filled with PAGE buffer (see below) at $100 \mathrm{~V}$ for approximately 1.5 hours until the samples reached the bottom of the gel.

\section{$2 x$ protein sample buffer}

$\begin{array}{ll}10 \% & \text { Glycerol } \\ 50 \mathrm{mM} & \text { Tris-HCl pH } 6.8 \\ 2 \mathrm{mM} & \text { EDTA } \\ 2 \% & \text { SDS } \\ 144 \mathrm{mM} & \beta \text {-mercaptoethanol } \\ 0.05 \% & \text { Bromophenol blue }\end{array}$

\section{PAGE buffer}

$\begin{array}{ll}0.25 \mathrm{M} & \text { Tris base } \\ 1.92 \mathrm{M} & \text { Glycine } \\ 1 \% & \text { SDS }\end{array}$




\subsubsection{Western blot}

Following SDS-PAGE, proteins were transferred from the gel to a nitrocellulose membrane. For transferring, the gel was assembled with the membrane in a sandwich blotting cassette. Transfer was performed at $100 \mathrm{~V}$ for one hour in a Bio-Rad Mini-Protein System filled with transfer buffer (see below). After transfer, unspecific binding sites of the proteins were blocked by washing the membrane in $4 \%$ blocking solution (PBS with $0.1 \%$ Tween 20 (PBST) and $4 \%$ non-fat dried milk powder) for 30 minutes at RT. Following blocking procedure the membrane was incubated with the primary antibody in PBST for 16-20 hours at $4^{\circ} \mathrm{C}$. After incubation the membrane was washed three times for 5 minutes with PBST and incubated with horseradish peroxidase- (HRP-) conjugated secondary antibody for 30 minutes at RT. The membrane was washed again 3 times for 5 minutes. The specific target protein was detected by enhanced chemiluminescence. Therfore, the membrane was rinsed with the chemiluminescence substrate (Pierce/Thermo Scientific) and the light emission was detected using X-ray films. Signal intensities were analyzed with the ImageJ software and normalized to the Actin signal.

\section{Transfer buffer}

$\begin{array}{ll}0.25 \mathrm{M} & \text { Tris base } \\ 1.92 \mathrm{M} & \text { Glycine } \\ 20 \% & \text { Methanol }\end{array}$

\subsubsection{E. coli transformation}

$50 \mu \mathrm{l}$ of competent E. coli bacteria (DH5 $\alpha$ strain, Invitrogen) were thawed on ice and $\sim 0.5$ $\mu \mathrm{g}$ of Plasmid DNA were added to the bacteria. The mixed cell suspension was incubated for 20 minutes on ice before exposing to a heat shock for 42 seconds at $42^{\circ} \mathrm{C}$. After two minutes on ice, $400 \mu \mathrm{l}$ of prewarmed $\left(37^{\circ} \mathrm{C}\right) \mathrm{LB}$ medium were added and the cell suspension was placed for 30 minutes at $37^{\circ} \mathrm{C}$. $200 \mu 1$ of the cell suspension were seed on agar plates containing $100 \mu \mathrm{g} / \mathrm{ml}$ ampicillin and incubated $\mathrm{o} / \mathrm{n}$ in a $37^{\circ} \mathrm{C}$ shaker. 
On the next day, a single colony was selected and placed with a sterile pipette tip in $200 \mathrm{ml}$ LB media containing $100 \mu \mathrm{g} / \mathrm{ml}$ ampicillin. Cells were incubated for $12-16$ hours at $37^{\circ} \mathrm{C}$ and subsequently centrifuged for ten minutes at $3000 \mathrm{~g}$ and $4^{\circ} \mathrm{C}$.

\subsubsection{Plasmid purification}

Bacterial lysis and Plasmid purification were performed with the NucleoBond ${ }^{\circledR}$ Xtra Midi kit (Macherey-Nagel) according to manufacture's recommendations.

\subsubsection{Luciferase assay}

Transfection of anti-19b and its inhibition of endogenous miR-19b were confirmed by luciferase reporter assay in primary oligodendrocytes. For measurement of endogenous miR-19b levels, the firefly luciferase based pMiR19b-Luc Reporter Vector (Signosis Inc.; see the chapter Plasmid maps) with a miR-19b binding site was used. Binding of endogenous miR-19b to the vector leads to the inhibition of firefly luciferase transcription. Thus inhibition of endogenous miR-19b by anti-19b is leading to firefly luciferase transcription and protein expression. The vector was co-transfected together with anti-19b nucleotides and with a renilla firefly vector without a miRNA bindig site for normalization (Promega; see Plasmid maps). Luciferase activity of both constructs was determined 48 hours post-transfection. Measurements were performed with a Mithras LB 940 Multilabel Reader. The average signal intensity of each sample ( $n=3$ individual samples for each condition) is the result of measurements from five replicates.

\subsubsection{TUNEL assay}

Apoptosis was assessed by TdT-mediated dUTP nick-end labelling (TUNEL) with fluorescein labelled dUTPs. The DeadEnd ${ }^{\mathrm{TM}}$ Fluorometric TUNEL System (Promega) was used according to manufacture's recommendations. The mean number of apoptotic cells was counted in 10 randomly selected microscopic fields with a Zeiss Axiophot 
fluorescence microscope at 40-fold magnification. Nuclei staining with DAPI was used the check the total cell number.

\subsubsection{BrdU assay}

Cell proliferation was measured by detecting the incorporation of the thymidine analog bromodeoxyuridine (BrdU) in newly synthesized DNA. The BrdU Assay kit (Millipore) includes anti-BrdU mouse primary antibody and corresponding Cy3-conjugated donkey anti-mouse IgG secondary antibody. The kit was used according to manufacture's recommendations. Cells were grown in $10 \mathrm{ng} / \mathrm{ml}$ PDGF (Sigma). PDGF is necessary for enhancing the overall oligodendroglial cell proliferation, because in cell culture the main number of primary oligodendrocytes is switching to the postmitotic phase in the first one to two days after shaking. Oligodendrocytes were transfected 4 hours after plating. BrdU (20 $\mu \mathrm{M}$ ) was added 24 hours after shaking. The study was terminated after 24 hours of BrdU incubation. The average number of proliferating cells was determined by counting 10 randomly selected microscopic fields with a Zeiss Axiophot fluorescence microscope at 40-fold magnification. Hoechst nuclei staining was used to control the total cell number.

\subsubsection{Confocal microscopy}

To get a high resolution and eliminate out-of-focus light, immunfluorescence imaging was performed with confocal laser scanning microscopy. A Leica DMIRE2 microscope combined with a Leica TCS SP2 AOBS confocal laser scanning setup was used for the imaging of tissue slices and cells on cover slips. 


\subsubsection{Statistical analysis}

For each statistical analysis at least four knock-out mice and four control animals were used. All cell culture experiments were performed at least three times. Results were expressed as mean + standard deviation (s.d.). Statistical significance was assessed by using Student's $t$-test, in which $\mathrm{p}<0.05$ was defined as statistically significant. Significance levels in the figures are depicted as * (95\% confidence; $\mathrm{p}<0.05),{ }^{*} \quad(99 \%$ confidence; $\mathrm{p}<0.01)$ and $* * *(99.9 \%$ confidence; $\mathrm{p}<0.001)$. 


\section{Results}

\subsection{Reduction of oligodendrocyte cell number by CNP-Cre mediated deletion of Dicer}

miRNAs are transcribed as long primary transcripts which are processed in the nucleus by the enzyme Drosha into stem-loop precursors (pre-miRNA). These pre-miRNAs are transported from the nucleus to the cytoplasm, where they are processed further by the type III ribonuclease Dicer to 22 nt miRNAs. Dicer knock-out mice do not produce any functional miRNAs and die at an early embryonic stage (Bernstein et al., 2003). In order to understand the roles of miRNAs in oligodendrocyte development, we deleted Dicer using the Cre-loxP recombination system. We used the 2'3'-cyclic nucleotide 3'phosphodiesterase (CNP) promoter to drive Cre expression in oligodendrocytes. CNP expression is detectable in oligodendrocyte precursors as early as E12 and maintained in mature oligodendrocytes.

When homozygous floxed Dicer mice (Dicer ${ }^{\text {flox/flox}}$ ) with two loxP sites flanking the second RNase III domain in the exon 23 of the Dicer gene (Figure 3.1) were crossed with heterozygous Dicer ${ }^{+/ \text {flox }} \mathrm{CNP}^{+/ \text {Cre }}$ mice, we surprisingly did not collect offspring at the expected Mendelian ratio. The expected percentage of the target knock-out genotype Dicer ${ }^{\text {flox/flox }} \mathrm{CNP}^{+/ \text {Cre }}$ would be $25 \%$ of the offspring (Figure 3.2). Out of more than 250 newborns only 3 Dicer ${ }^{\text {flox/flox }} \mathrm{CNP}^{+/ \text {Cre }}$ mice survived into adulthood. All other knock-out animals died within the first three weeks after birth.

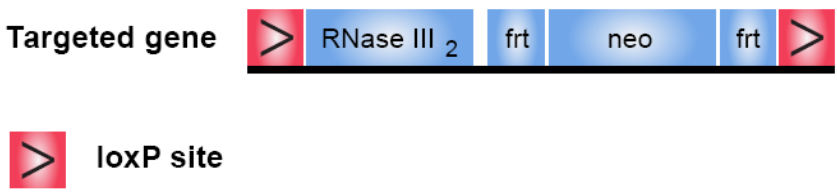

Figure 3.1: Targeting strategy for Dicer conditional deletion. The exon 23 of the Dicer gene, which encodes most of the second RNase III domain, is flanked by two loxP sites. Dicer without this domain is non-functional and not able to process pre-miRNAs into mature miRNAs. 


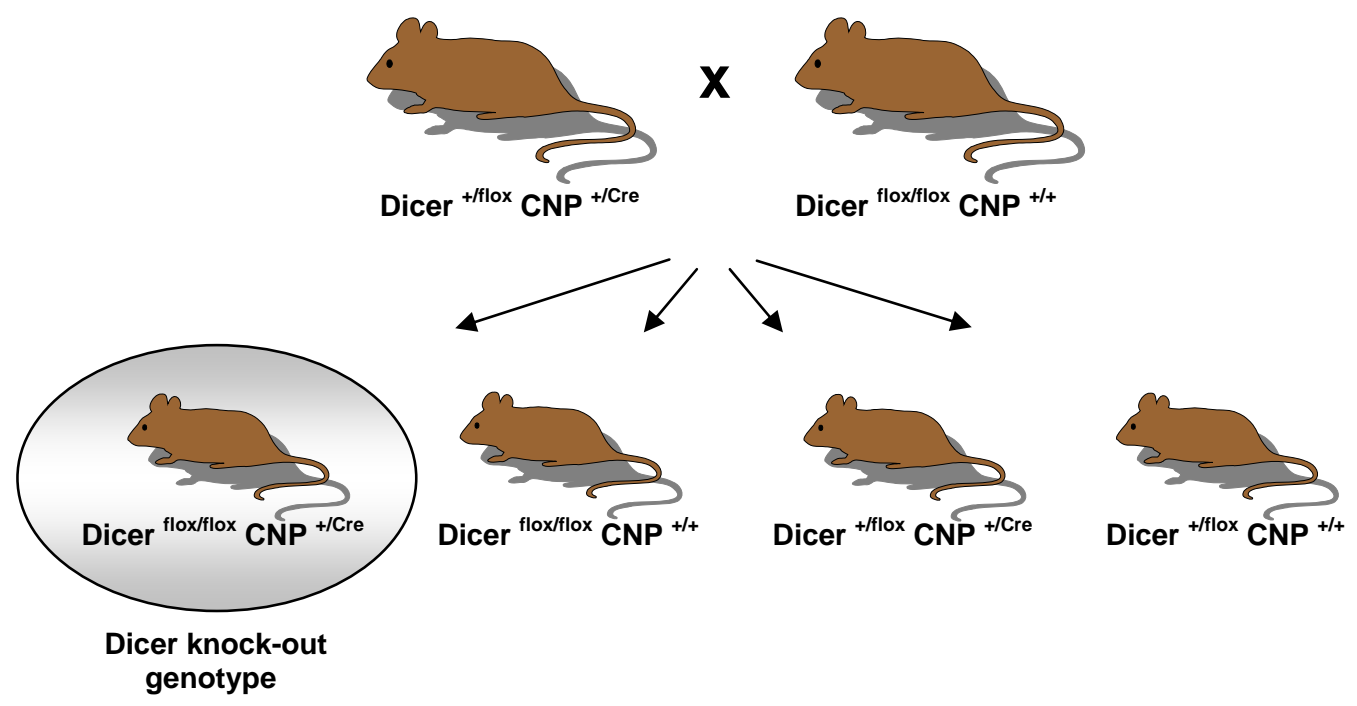

Figure 3.2: Breeding strategy for Dicer conditional deletion in oligodendrocytes. In the final breeding step heterozygous Dicer ${ }^{+/ f l o x} \mathrm{CNP}^{+/ C r e}$ mice are mated with homozygous Dicer ${ }^{\text {flox/llox }} \mathrm{CNP}^{+/+}$mice. The theoretical percentage of the Dicer knock-out genotype Dicer ${ }^{\text {flox/flox }} \mathrm{CNP}^{+/ C r e}$ is $25 \%$ within the offspring.

Since Dicer ${ }^{\text {flox/flox }} \mathrm{CNP}^{+/ \text {Cre }}$ mice were detected at a normal ratio at late embryonic and early postnatal stages, we used mice from E18.5 or directly after birth (P0) for our analysis.

Primary cultures of oligodendrocytes were prepared from E18.5 Dicer ${ }^{\text {flox/flox }} \mathrm{CNP}^{+/ C r e}$ mice and compared to control littermates by immunostaining for markers of oligodendrocyte differentiation. We used the antibody $\mathrm{O} 1$ to label both immature and mature oligodendrocytes and an antibody against myelin basic protein (MBP) to selectively detect terminally differentiated oligodendrocytes. The number of MBP positive cells in the knock-out condition was slightly but not significantly reduced (Figure 3.3). Due to the detection of fully differentiated MBP positive oligodendrocytes in knockout and control cultures, it is reasonable that the absence of Dicer does not lead to a major impairment of oligodendrocyte differentiation. 


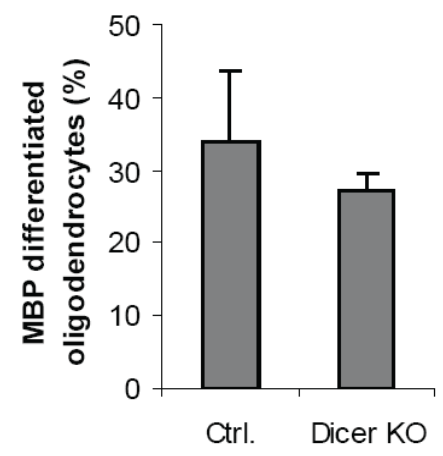

Figure 3.3: Conditional deletion of Dicer using CNP-Cre does not significantly impair oligodendrocyte differentiation. Primary cultures of oligodendrocytes prepared from E18.5 Dicer ${ }^{\text {floxflox }} \mathrm{CNP}^{+/ \mathrm{Cre}}$ knock-out mice compared to control littermate cultures. To determine the level of differentiation, cells were stained for $\mathrm{O} 1$ and MBP, a marker for mature oligodendrocytes. The percentage of MBP positive O1-labelled cells are shown as means + s.d. ( $n=3$ independent cultures).

Next, we had a closer look at the phenotype of the Dicer ${ }^{\text {flox/flox }} \mathrm{CNP}^{+/ \text {Cre }}$ knock-out mice in vivo. Therefore, we analyzed whether the number of oligodendrocytes was changed in Dicer knock-out brains by staining coronal P0 sections for Olig2. Olig2 is a marker for oligodendroglial lineage cells and expressed in both OPCs and mature oligodendrocytes. We observed a $\sim 40 \%$ reduction of Olig2-positive cells in the periventricular brain region of Dicer ${ }^{\text {flox/flox }} \mathrm{CNP}^{+/ \mathrm{Cre}}$ mice compared to control animals (Figure 3.4). Similar results were obtained when Dicer was depleted by RNA interference (RNAi) in primary cultures of oligodendrocytes. The successful knock-down of Dicer protein levels in these cultures was controlled by Western blot analyses (Figure 3.5 A). The cultures were stained for $\mathrm{O} 1$ and we found a $40 \%$ decreased cell number (Figure 3.5 B). Surprisingly, spinal cord slices of Dicer ${ }^{\text {flox/flox }} \mathrm{CNP}^{+/ C r e}$ knock-out animals did not show a reduction in the number of oligodendrocytes (Figure 3.6). 

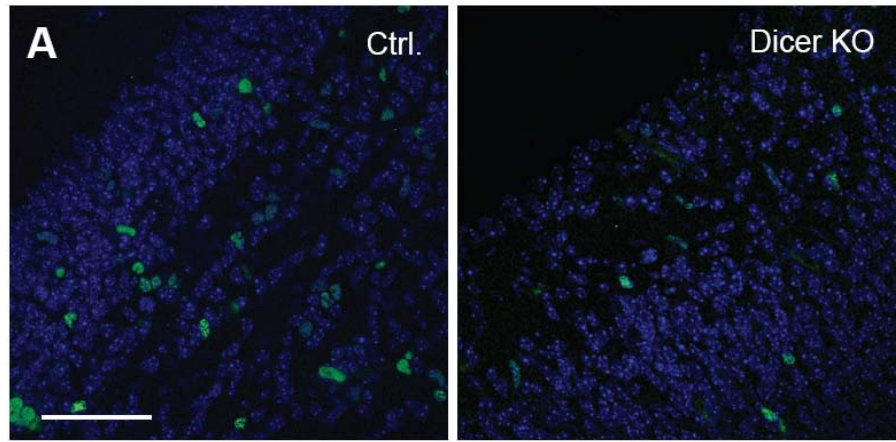

B

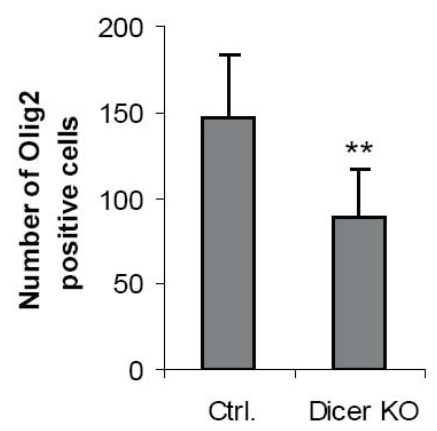

Figure 3.4: Conditional deletion of Dicer using CNP-Cre reduces the cell number of oligodendrocytes. (A) Coronal sections of PO brain of Dicer flox/flox $\mathrm{CNP}^{+/ C r e}$ knock-out mice and littermate controls were analyzed by immunohistochemistry with Olig2 antibodies. Scale bar: $60 \mu \mathrm{m}$. (B) Changes in Olig-2-positive cell number are shown as means $+\mathrm{s} . \mathrm{d}$. $\left({ }^{\star \star} \mathrm{p}<0,01 ; \mathrm{n}=5\right.$ different animals, average cell number in 40-fold magnification microscopic field).
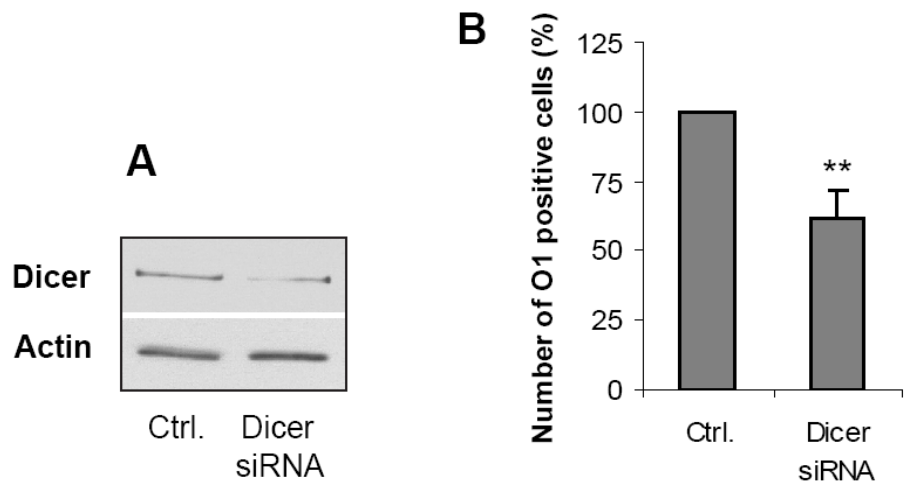

Figure 3.5: Dicer knock-down results in a reduction of 01-positive oligodendrocytes. Cells were transfected with siRNA directed against Dicer or control siRNA one day after shake and harvested two days after transfection. (A) Confirmation of knock-down of Dicer protein level by Western Blot. (B) Number of oligodendrocytes stained with 01 antibody $\left(n=3 ;{ }^{* \star} p<0.01\right)$. 

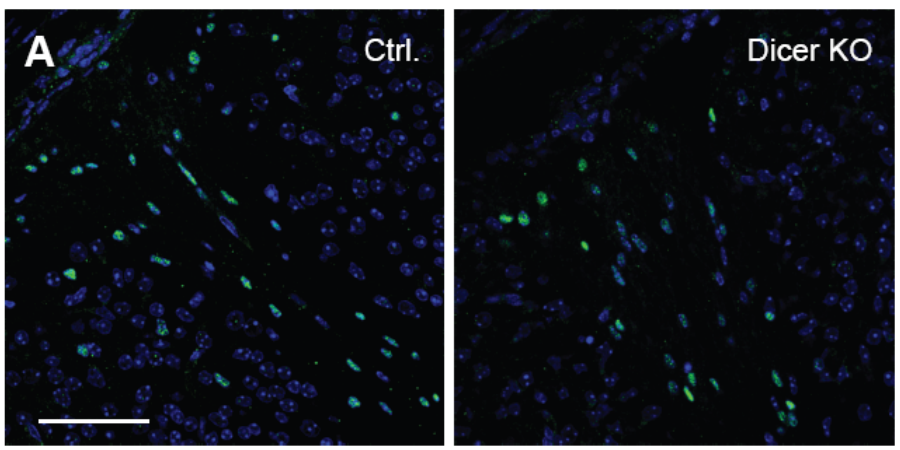

B

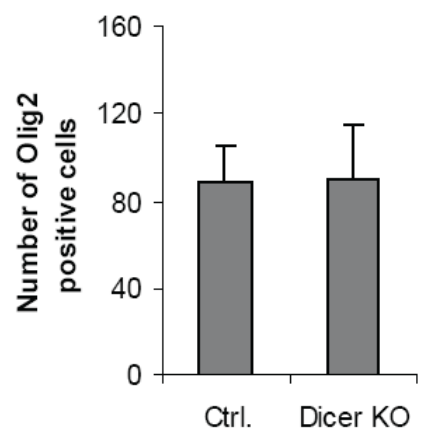

Figure 3.6: Conditional deletion of Dicer using CNP-Cre does not reduce the cell number of oligodendrocytes in the spinal cord. (A) Cross-sections of spinal cord of Dicer ${ }^{\text {flox/flox }} \mathrm{CNP}^{+/ C r e}$ knock-out mice and littermate controls were analyzed by immunostaining against Olig2. Scale bar: $60 \mu \mathrm{m}$. (B) Changes in Olig-2-positive cell number are shown as means + s.d. (average cell number in 40-fold magnification microscopic field).

To get insights in the mechanisms responsible for the decreased cell number in the knockout brains, we performed TUNEL stainings to detect apoptotic cells in the brain slices. We found a minor increase of apoptotic cells in Dicer knock-out brains, but the numbers did not reach statistical significance (Figure 3.7). To look at apoptotic events specifically in oligodendrocytes, TUNEL and Olig2 co-stainings were used. The number of apoptotic Olig2-positive cells was similar in knock-out and control brains (Figure 3.7 B).

Together, these data point at a role of the Dicer dependent miRNA pathway in the regulation of oligodendrocyte cell number in the brain. However, the regulation does not seem to be mediated by apoptosis or changes in differentiation. 

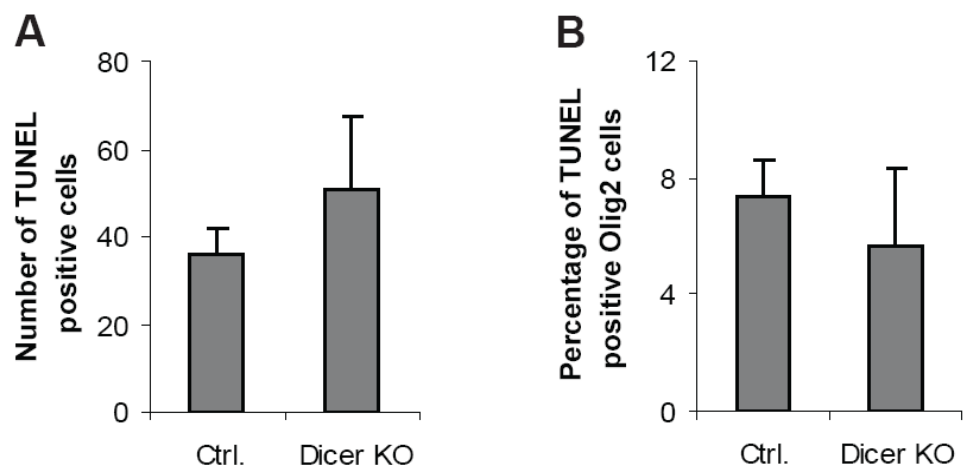

Figure 3.7: Dicer knock-out does not change the apoptosis rate in the brain. (A) Number of TUNEL positive cells in coronal sections of the periventricular brain region of Dicer ${ }^{\text {flox/flox }} \mathrm{CNP}^{+/ C r e}$ knock-out mice and control littermates ( $n=5$ different animals). (B) Percentage of TUNEL positive Olig2-labelled cells in brain slices ( $n=3$ different animals).

\subsection{Role of the miR-17 92 cluster in oligodendrocyte development}

\subsubsection{Identification of the miR-17 92 cluster as highly enriched miRNAs in oligodendrocytes by microarray profiling}

In order to identify the responsible miRNAs in the regulation of oligodendrocyte cell number, we performed miRNA expression profiling of oligodendrocytes. Therefore, we used microarrays with miRNA probes for binding the endogenous miRNAs to evaluate the different expression levels of miRNAs. The purity of primary oligodendrocyte cultures used for the microarrays, was confirmed by staining with antibodies for oligodendrocytes (O1), microglia (Iba-1), and astrocytes (GFAP). Only cultures with a purity of at least $\sim 80 \%$ oligodendrocytes were used for the microarray analyses.

First of all, we verified the microarray approach by comparison of the mRNA transcriptome of cultured oligodendrocytes and astrocytes. The approach was aiming at the identification of oligodendrocyte enriched transcripts. Indeed, among the top 20 mRNAs expressed by oligodendrocytes (Table 3.1) were many of the previously described oligodendroglial-enriched genes (Cahoy et al., 2008). Essential oligodendrocyte-specific genes such as PLP, MBP, MAG and MOBP were strongly up-regulated in the primary oligodendrocyte cultures. Due to the expression of these genes, the array was able to identify oligodendrocyte-specific transcripts. 


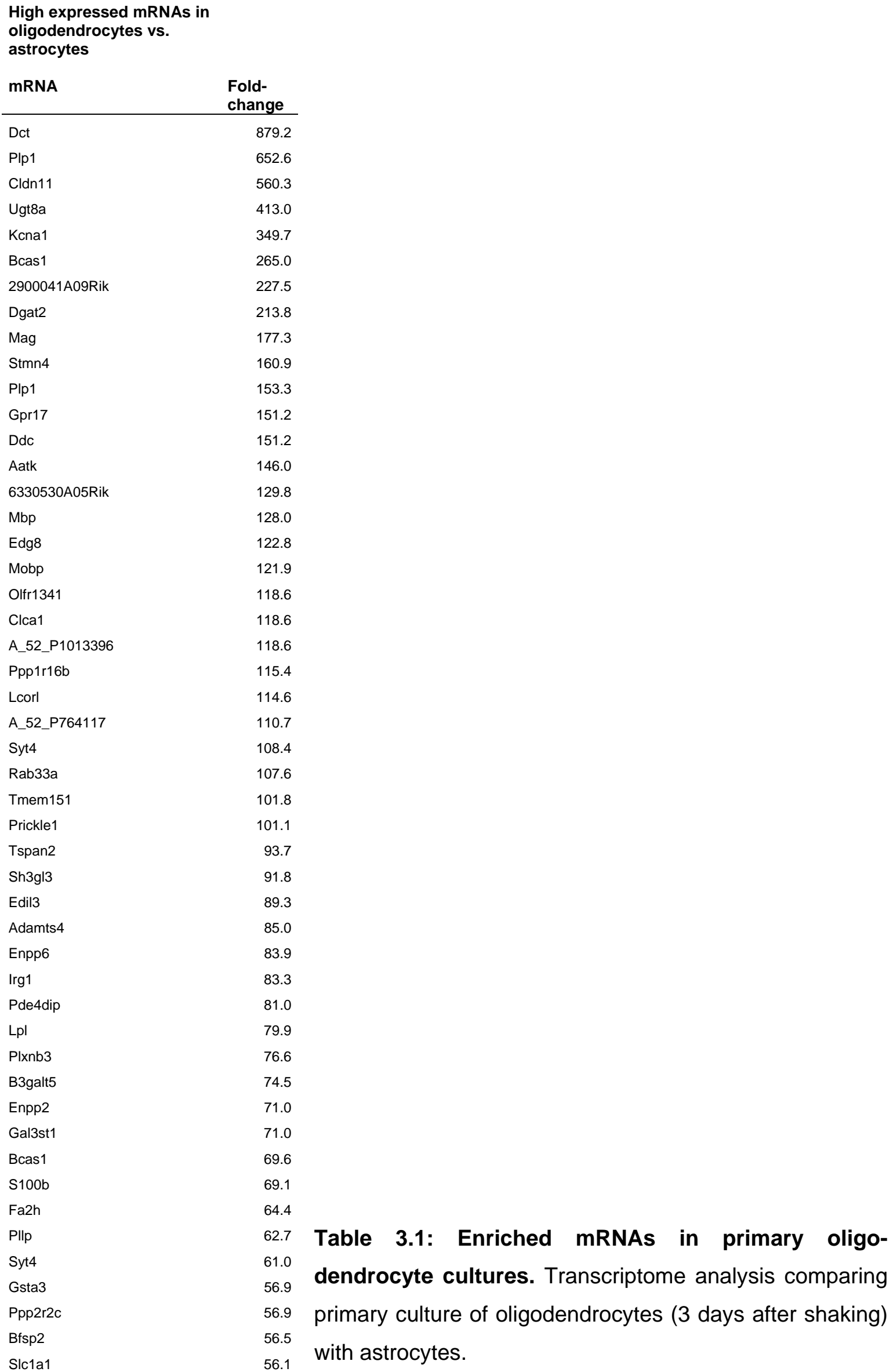


For miRNA identification in primary oligodendrocyte cultures, we performed two different microarrays. First, oligodendroglial enriched or depleted miRNAs were indentified by comparing expression levels of miRNAs in primary oligodendrocytes and astrocytes. The concept of the comparison was based on the differentiation potential of NG2-positive cells. These cells are known for their ability to differentiate in both oligodendrocytes and astrocytes (Nishiyama et al., 2009). Hence, a comparison of the developmental related oligodendrocytes and astrocytes should detect miRNAs specific for oligodendrocyte development. When the miRNA expression was analysed, we detected 31 miRNAs that were more than 2-fold enriched in oligodendrocytes compared to astrocytes. The miRNAs with the largest differences are shown in Table 3.2.

Interestingly, the miR-17 92 cluster appeared to be enriched in oligodendrocytes. This cluster consists of six miRNAs that are processed from a common precursor transcript (Figure 3.8) (Mendell, 2008). Furthermore, there are two known paralogs, the miR106a 363 and the miR-106b 25 cluster. Our microarray analysis revealed that four miRNAs of the miR-17 92 and two miRNAs of the miR-106a 363 cluster were enriched in oligodendrocytes compared to astrocytes (Table 3.2). The miRNAs, miR-20b, miR-19a, miR-106a, miR-17, miR-20a and miR-19b were up-regulated 3.5 to 12.7 fold in oligodendrocytes.

To confirm the miRNA microarray data, we performed quantitative real-time PCR analysis for selected differentially expressed miRNAs. We tested miR-17 and miR-19b which are enriched miRNAs in oligodendrocytes and miR-125b and miR-34b which are depleted in oligodendrocytes in comparison to astrocytes. The differential expression of all four miRNAs was confirmed by quantitative real-time PCR (Figure 3.9). Most importantly, real-time PCR analysis revealed that the two miRNAs of the miR-17 92 cluster - miR-19b and miR17 - were 11-16 fold enriched in oligodendrocytes as compared to astrocytes. 


\begin{tabular}{|c|c|c|c|}
\hline \multirow[t]{2}{*}{$\begin{array}{l}\text { High expression } \\
\text { in OPC vs. Astrocytes }\end{array}$} & \multirow[b]{2}{*}{ Foldchange } & \multicolumn{2}{|c|}{$\begin{array}{l}\text { Low expression } \\
\text { in OPC vs. Astrocytes }\end{array}$} \\
\hline & & & Foldchange \\
\hline$m i R-542-5 p$ & 34.06 & miR-30a & -3.14 \\
\hline $\mathrm{miR}-32^{\star}$ & 31.12 & miR-9 & -3.41 \\
\hline miR-142-3p & 24.76 & miR-100 & -4.06 \\
\hline miR-138 & 21.71 & miR-335-5p & -4.17 \\
\hline miR-146a & 15.45 & $\operatorname{miR}-9^{*}$ & -4.82 \\
\hline miR-19b & 12.73 & miR-125b-5p & -7.16 \\
\hline miR-124 & 10.63 & miR-449b & -10.13 \\
\hline$m i R-574-5 p$ & 10.13 & $\mathrm{miR}-34 \mathrm{c}$ & -14.62 \\
\hline miR-20a & 9.06 & miR-34b-5p & -16.22 \\
\hline miR-494 & 9.00 & miR-449a & -24.42 \\
\hline miR-185 & 8.75 & & \\
\hline miR-219 & 8.34 & & \\
\hline miR-338-3p & 7.57 & & \\
\hline miR-706 & 7.57 & & \\
\hline$m i R-146 b$ & 7.31 & & \\
\hline miR-298 & 6.92 & & \\
\hline miR-17 & 6.82 & & \\
\hline $\operatorname{miR}-658$ & 6.59 & & \\
\hline miR-106a & 5.46 & & \\
\hline miR-709 & 5.35 & & \\
\hline $\operatorname{miR}-467 b^{*}$ & 5.06 & & \\
\hline miR-24 & 4.76 & & \\
\hline miR-19a & 4.50 & & \\
\hline miR-690 & 3.92 & & \\
\hline $\operatorname{miR}-665$ & 3.71 & & \\
\hline$m i R-30 b^{*}$ & 3.51 & & \\
\hline miR-23a & 3.48 & & \\
\hline miR-20b & 3.48 & & \\
\hline miR-15a & 3.27 & & \\
\hline $\operatorname{miR}-185^{\star}$ & 3.25 & & \\
\hline miR-642 & 2.87 & & \\
\hline
\end{tabular}

Table 3.2: Identification of the miR-17 92 cluster as highly enriched miRNAs in oligodendrocytes by microarray profiling. miRNA profiling of primary cultures of oligodendrocytes and astrocytes to identify highly (left table) and poorly (right table) expressed miRNAs in oligodendrocytes. The fold-enrichments of miRNAs are shown. The miRNAs of the miR-17 92 cluster and its paralogs are marked in bold. 


\begin{tabular}{c|c|c|c|c|c|c}
$\begin{array}{c}\text { miR-17-92 } \\
\text { Chr 13 }\end{array}$ & 17 & $18 a$ & $19 a$ & $20 a$ & $19 b-1$ & $92 a-1$ \\
\cline { 2 - 4 } $\begin{array}{c}\text { miR-106a-363 } \\
\text { Chr 7 }\end{array}$ & $106 a$ & $18 b$ & $20 b$ & $19 b-2$ & $92 a-2$ & 363 \\
\hline $\begin{array}{c}\text { miR-106b-25 } \\
\text { Chr X }\end{array}$ & $106 b$ & 93 & 25 & & & \\
\cline { 2 - 3 } & & & & & & \\
\end{tabular}

Figure 3.8: Schematic representation of the miR-17 92 cluster and its two paralogs miR-106a 363 and miR-106b 25 cluster. Each cluster is transcribed as a single polycistronic transcription unit. The sequences of the miRNAs within the three clusters show a high similarity.

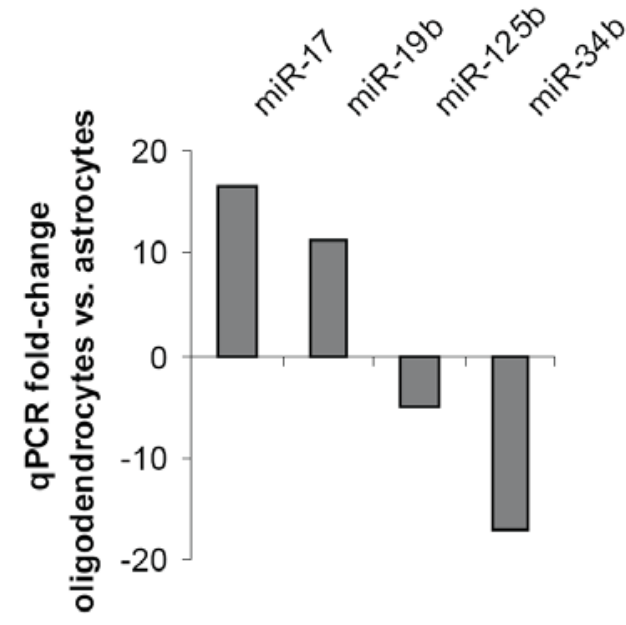

Figure 3.9: Validation of differentially expressed miRNAs by qRT-PCR. miR-17 and miR-19b of the miR-17 92 cluster were found to be highly enriched in primary oligodendrocytes compared to astrocytes. In contrast, miR-125b and miR-34b show a low expression level in oligodendrocytes. 
To analyse whether the expression of these miRNAs changes during oligodendrocyte differentiation, microarray profiling was performed on cultured oligodendrocytes. The primary oligodendrocytes cultures were isolated from mixed glial cultures by differential shaking. In this culture system, oligodendrocytes start to differentiate after isolation. We used primary cultures of immature oligodendrocytes directly after shaking (d0), one day after shaking (d1) and cultures of mature oligodendrocytes six days after shaking (d6). miRNAs were sorted according to their mean signal intensities to identify the most highly expressed miRNAs in oligodendrocytes. We observed that five miRNAs of the miR-17 92 cluster and its paralogs (miR-19b, miR-20a, miR-92a, miR-20b and miR-106b) were among the 35 most abundant miRNAs (Table 3.3). The expression of the miRNAs of the miR-17 92 cluster was already high at early stages of oligodendrocyte development (Table 3.3, left column). There was no change in the high expression of these miRNAs during oligodendrocyte differentiation. Only a relatively small number of 8 miRNAs with significant different expression levels were found during oligodendrocyte differentiation (Table 3.4).

We performed an additional microarray analysis to compare the miRNA profiles of oligodendocytes to different other cells in the brain, including neurons, astrocytes and microglia. In this array we used white-matter cell lysates on the one hand and grey-matter lysates on the other hand. White-matter was extracted from the corpus callosum and therefore representing mainly oligodendrocytes and some astrocytes and microglia. Greymatter cells were prepared from the frontal cortex and containing especially neurons but also astrocytes and some microglia. The microarray profiling revealed an enrichment of miR-17, miR-92a and miR-106a of the miR-17 92 cluster and its paralogs in the myelinating white-matter of adult mice (Table 3.5).

Together, these data show that the miR-17 92 cluster appears as one of the most abundant miRNA cluster in oligodendrocytes. 
Top expressed miRNAs in oligodendrocyte differentiation

\begin{tabular}{|c|c|c|c|c|c|}
\hline \multicolumn{2}{|c|}{ d0 oligodendrocytes } & \multicolumn{2}{|c|}{ d1 oligodendrocytes } & \multicolumn{2}{|c|}{ d6 oligodendrocytes } \\
\hline miRNA & $\begin{array}{r}\text { Mean signal } \\
(\log 2)\end{array}$ & miRNA & $\begin{array}{r}\text { Mean signal } \\
(\log 2)\end{array}$ & miRNA & $\begin{array}{r}\text { Mean signal } \\
(\log 2)\end{array}$ \\
\hline $\operatorname{miR}-21$ & 13.52 & miR-21 & 13.71 & $\operatorname{miR}-21$ & 13.64 \\
\hline miR-720 & 13.44 & miR-720 & 13.32 & $\operatorname{miR}-720$ & 13.38 \\
\hline miR-1224 & 11.46 & miR-125b-5p & 11.47 & miR-9 & 11.59 \\
\hline let-7f & 11.28 & $\operatorname{miR}-9$ & 11.35 & let-7f & 11.15 \\
\hline miR-9 & 11.20 & let-7f & 11.18 & let-7a & 10.94 \\
\hline miR-125b-5p & 11.11 & let-7a & 11.01 & $\operatorname{miR}-9^{\star}$ & 10.79 \\
\hline let-7a & 11.09 & $\operatorname{miR}-9^{\star}$ & 10.77 & $m i R-125 b-5 p$ & 10.72 \\
\hline let-7c & 10.61 & let-7c & 10.63 & $\operatorname{miR}-16$ & 10.67 \\
\hline$m i R-9^{\star}$ & 10.57 & miR-1224 & 10.57 & $\operatorname{miR}-24$ & 10.56 \\
\hline miR-16 & 10.53 & $\mathrm{miR}-16$ & 10.46 & $\operatorname{miR}-19 b$ & 10.53 \\
\hline miR-24 & 10.48 & $\operatorname{miR}-24$ & 10.35 & let-7c & 10.30 \\
\hline miR-709 & 10.40 & $\operatorname{miR}-19 b$ & 10.30 & miR-26a & 10.28 \\
\hline $\operatorname{miR}-22$ & 10.22 & $\mathrm{miR}-22$ & 10.16 & miR-709 & 10.12 \\
\hline miR-19b & 10.21 & miR-709 & 10.13 & miR-22 & 10.08 \\
\hline $\operatorname{miR}-26 a$ & 10.02 & miR-26a & 10.12 & miR-23b & 10.01 \\
\hline miR-23a & 9.93 & miR-23a & 10.11 & miR-23a & 9.94 \\
\hline let-7b & 9.89 & miR-130a & 10.09 & miR-1224 & 9.90 \\
\hline miR-338-3p & 9.84 & let-7b & 9.96 & miR-20a & 9.87 \\
\hline$m i R-23 b$ & 9.80 & miR-27a & 9.80 & miR-142-3p & 9.80 \\
\hline miR-494 & 9.63 & $m i R-29 a$ & 9.80 & miR-15a & 9.71 \\
\hline miR-15a & 9.60 & miR-15a & 9.71 & miR-338-3p & 9.68 \\
\hline $\operatorname{miR}-27 a$ & 9.58 & miR-20a & 9.63 & miR-130a & 9.67 \\
\hline let-7g & 9.58 & let-7i & 9.63 & let-7b & 9.61 \\
\hline let-7d & 9.51 & let-7d & 9.56 & let-7i & 9.60 \\
\hline miR-20a & 9.50 & let-7g & 9.44 & $m i R-27 b$ & 9.59 \\
\hline let-7i & 9.43 & $\operatorname{miR}-23 b$ & 9.41 & let-7g & 9.58 \\
\hline miR-29a & 9.43 & miR-142-3p & 9.40 & miR-27a & 9.55 \\
\hline miR-130a & 9.40 & miR-15b & 9.35 & miR-29a & 9.52 \\
\hline miR-27b & 9.35 & miR-223 & 9.26 & miR-690 & 9.48 \\
\hline $\operatorname{miR}-15 b$ & 9.27 & $m i R-27 b$ & 9.18 & let-7d & 9.42 \\
\hline miR-30c & 9.22 & miR-690 & 9.16 & miR-223 & 9.20 \\
\hline miR-146a & 9.20 & miR-30c & 9.08 & $\operatorname{miR}-15 b$ & 9.12 \\
\hline miR-690 & 9.16 & miR-29b & 9.01 & miR-92a & 9.12 \\
\hline miR-92a & 9.02 & miR-338-3p & 8.92 & miR-20b & 8.99 \\
\hline miR-142-3p & 8.99 & miR-20b & 8.86 & miR-221 & 8.96 \\
\hline miR-223 & 8.89 & miR-92a & 8.82 & miR-30c & 8.94 \\
\hline miR-107 & 8.87 & miR-146a & 8.74 & miR-494 & 8.76 \\
\hline $\operatorname{miR}-221$ & 8.87 & miR-99a & 8.74 & miR-107 & 8.68 \\
\hline miR-20b & 8.69 & miR-221 & 8.65 & miR-30b & 8.60 \\
\hline$m i R-30 b$ & 8.60 & miR-107 & 8.63 & miR-26b & 8.59 \\
\hline miR-103 & 8.59 & miR-494 & 8.62 & miR-106b & 8.57 \\
\hline miR-181a & 8.58 & miR-106b & 8.61 & miR-29b & 8.56 \\
\hline miR-99a & 8.57 & miR-103 & 8.55 & miR-103 & 8.51 \\
\hline$m i R-26 b$ & 8.55 & miR-30b & 8.51 & miR-34a & 8.49 \\
\hline miR-106b & 8.50 & miR-26b & 8.49 & miR-146a & 8.43 \\
\hline
\end{tabular}

Table 3.3: miRNA microarray profiling showing the expression levels of miRNAs in

oligodendrocyte differentiation. miRNA levels of immature and proliferating 
oligodendrocyte precursor cells (directly after shaking, d0), immature but almost postmitotic oligodendrocyte precursors (one day after shaking, d1) and mature post-mitotic oligodendrocytes (six days after shaking, d6) were compared by microarray profiling. The miRNAs of the miR-17 92 cluster did not show changes in their expression levels. miRNAs of this cluster are indicated in bold.

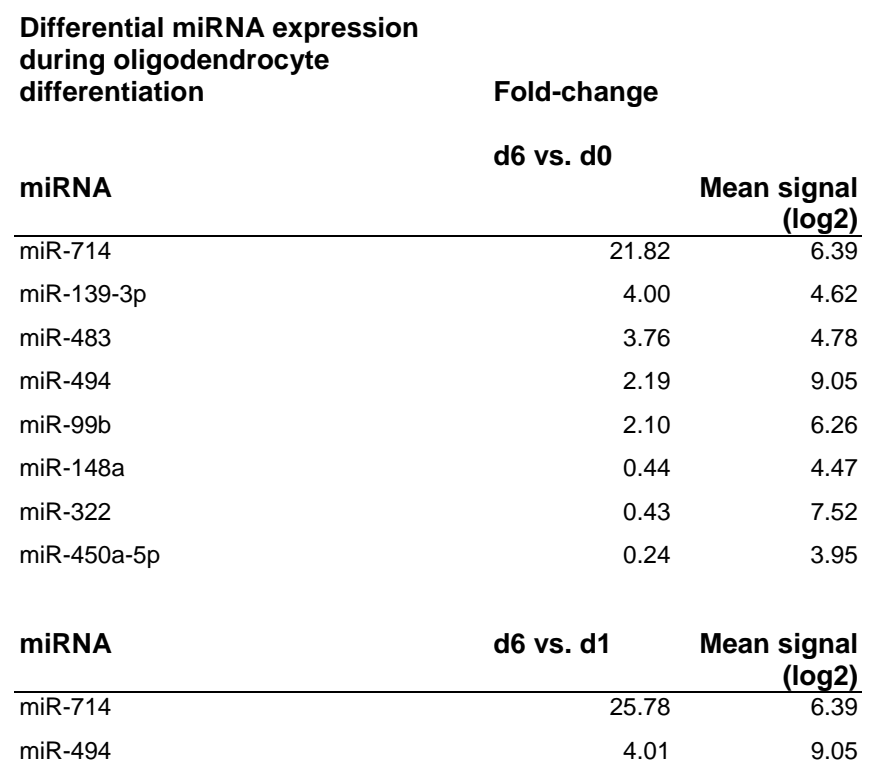

Table 3.4: Differential miRNA expression in developing oligodendrocytes. miRNA levels of immature and proliferating oligodendrocyte precursor cells (directly after shaking, d0), immature but almost post-mitotic oligodendrocyte precursors (one day after shaking, d1) and mature post-mitotic oligodendrocytes (six days after shaking, d6) were compared by microarray profiling. 


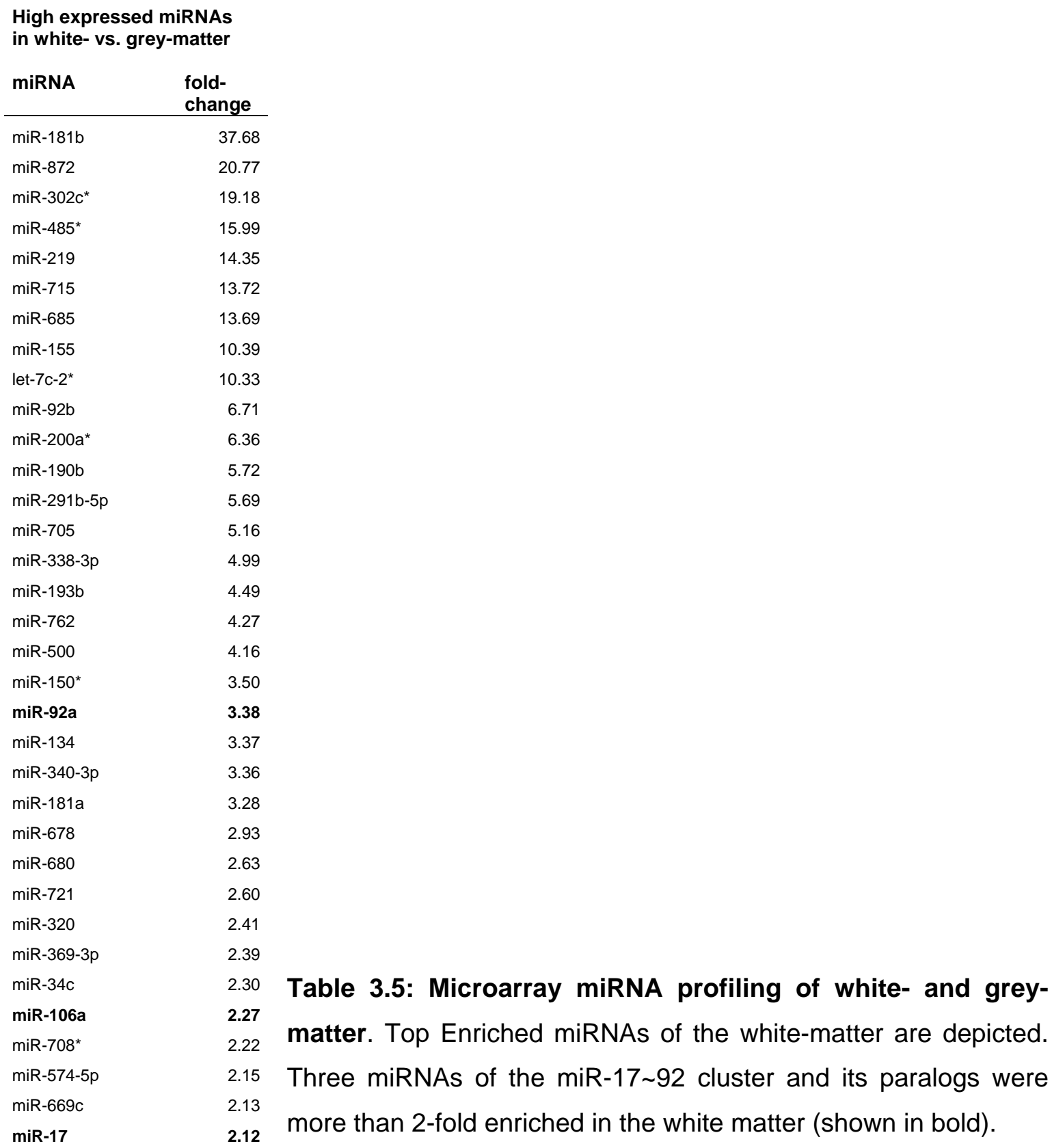

\subsubsection{The miR-17 92 cluster regulates oligodendrocyte cell number - in vivo evidence}

Previous studies have shown that the miR-17 92 cluster is essential for the development of the heart, the lung and the immune system (Mendell, 2008). Mice deficient for miR-17 92 die shortly after birth with lung hypoplasia and ventricular septal defects (Ventura et al., 2008). miR-17 92 is also essential for B cell development (Koralov et al., 2008; Xiao et al., 2008) and has been implicated in the pathogenesis of human cancers (He et al., 2005). 
To address the role of the miR-17 92 cluster in oligodendrocyte development, mice with loxP-sites flanking the cluster (miR-17 92 ${ }^{\text {flox/flox }}$ ) were bred with $\mathrm{CNP}^{+/ \mathrm{Cre}}$ mice to delete the miR-17 92 cluster specifically in oligodendrocytes. We genotyped the offspring directly after birth and stained coronal sections of the brains with antibodies against Olig2 to analyse whether the number of oligodendrocytes was changed in miR$17 \sim 92^{\text {flox/flox }} \mathrm{CNP}^{+/ \text {Cre }}$ knock-out brains. We observed a $\sim 25 \%$ reduction of Olig2-positive cells in the brains after miR-17 92 deletion as compared to control littermates (Figure 3.10).
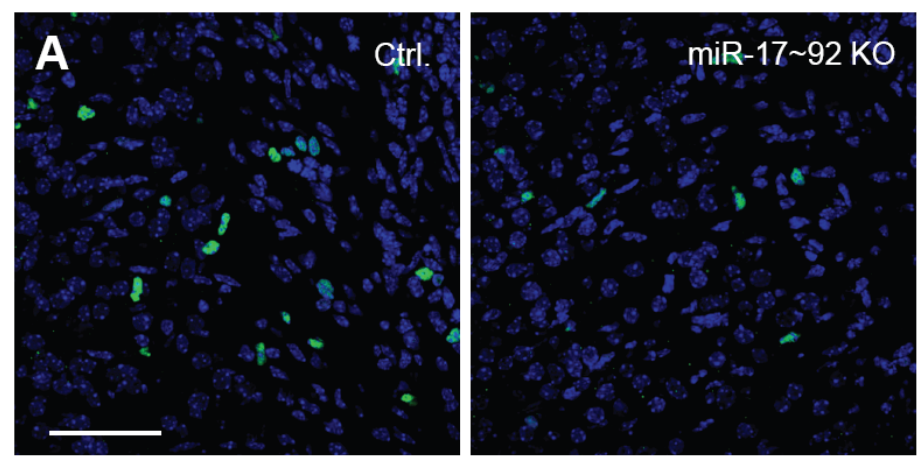

B

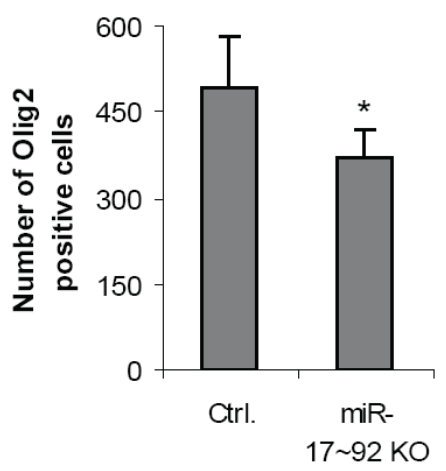

Figure 3.10: Deletion of the miR-17 92 cluster reduces the number of oligodendrocytes. (A) Coronal sections of PO brain of miR-17 $92^{\text {flox/lox }} \mathrm{CNP}^{+/ C r e}$ knock-out mice and littermate controls were analysed by immunostainings for Olig2. Scale bar: 60 $\mu \mathrm{m}$. (B) Changes in Olig-2-positive cell number are shown as means + s.d. $\left({ }^{*} p<0,05 ; n=4\right.$ different animals; average cell number in 20-fold magnification microscopic field). 


\subsubsection{The miR-17 92 cluster regulates oligodendrocyte cell number - in vitro evidence}

To efficiently interfere with the function of the miR-17 92 cluster, miRNA precursor molecules of miR-17 and miR-19b or oligonucleotides directed against these miRNAs were combined. With this strategy we targeted different functional groups of the miR17 92 cluster. miR-17 and miR-19b oligonucleotides were chosen to represent the majority of the miRNAs of the miR-17 92 cluster because of the sequence similarity among the miRNAs of the cluster. The nucleotides 2-7 (seed sequence) of a mammalian miRNA represent the most important site for the target recognition. Matsubara et al., 2007 demonstrated considerable cross-inhibitions between antisense oligonucleotides directed against miR-17 and miR-20a. By using one of the two antisense constructs they could show the down-regulation of both miRNAs in Northern Blot analysis, caused by the suppression mediated by the same seed sequence. miR-17 has the same seed sequence as miR-20a, miR-20b, miR-106a, miR-106b and miR-93 (Table 3.6). The seed sequence of miR-19b is identical with the one of miR-19a (Table 3.6). Therefore it was possible to cover all seed sequences of the oligodendrocyte enriched miRNAs miR-17, miR-19a, miR19b, miR-20a, miR-20b and miR-106a (Table 3.2) by using antisense or precursor oligonucleotides for miR-17 and miR-19b. These two miRNAs were also strongly enriched in oligodendrocytes compared to astrocytes shown by the miRNA microarray (Table 3.2) and by quantitative real-time PCR (Figure 3.9).

We controlled the transfection efficiency of the miRNA oligonucleotides by transfecting FITC-labelled miRNA control oligonucleotides into primary oligodendrocytes. The FITC signal could be deteted in almost all oligodendrocytes (Figure 3.11) pointing to a very high transfection efficiency. 


\begin{tabular}{ll} 
miRNA & Mature sequence \\
\hline miR-17 & CAAAGUGCUUACAGUGCAGGUAG \\
miR-20a & UAAAGUGCUUAUGUGCAGGUAG \\
miR-20b & CAAAGUGCUCAUAGUGCAGGUAG \\
miR-106a & AAAAGGCUUACAGUGCAGGUAG \\
miR-106b & UAAAGUGCUGACAGUGCAGAU \\
miR-93 & CAAAGUGCUCUUCGUGCAGGUAG \\
miR-18a & UAAGGUGCAUCUAGUGCAGAUAG \\
miR-18b & CAAGGUGCAUCUAGUGCAGUUAG \\
miR-19a & UGUGCAAAUCUAUGCAAAACUGA \\
miR-19b & UGUGCAAAUCCAUGCAAAACUGA \\
miR-25 & CAUUGCACUUGUCUCGGUCUGA \\
miR-92a & UAUUGCACUUGUCCCGGCCUGU \\
miR-363 & AAUUGCACGGUAUCCAUCUGUA
\end{tabular}

Table 3.6: Seed sequences of the miR-17 92 cluster. miRNAs of the related clusters miR-17 92, miR-106b 25 and miR-106a-363, grouped into four functional families based on their target recognition seed sequence. The seed sequences (nucleotides 2-7) are shown in red.
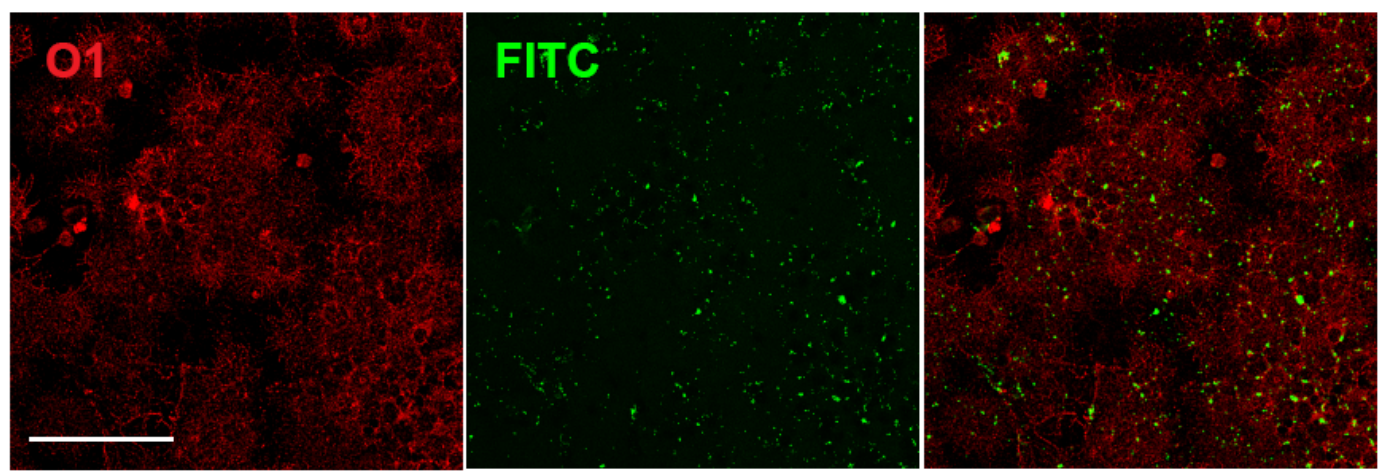

Figure 3.11: Transfection of FITC-labelled oligonucleotides in primary oligodendrocytes. Oligodendrocytes were stained for $\mathrm{O} 1$ (in red). The FITC-signal (in green) of the transfected miRNA control oligonucleotides could be detected in almost all oligodendrocytes. Scale bar: $200 \mu \mathrm{m}$. 
To get insights whether the precursor and antisense molecules are inhibiting or contributing to the endogenous miRNA activity, we performed two functional assays after transfecting the oligonucleotides into the primary oligodendrocytes.

In order to inhibit the function of miR-19b, we transfected antisense oligonucleotides directed against miR-19b into the cells. This leads to binding of the antisense oligonucleotide to endogenous miR-19b and thereby causing its functional inactivation. We controlled the inhibitory effects of the antisense oligonucleotides by performing a luciferase based assay for miR-19b. For measurement of endogenous miR-19b levels, the firefly luciferase based pMiR19b-Luc Reporter Vector with a miR-19b binding site was used (see the chapter Plasmid maps). Binding of endogenous miR-19b leads to the inhibition of firefly luciferase transcription in this assay. We found that transfection of antisense oligonucleotides directed against miR-19b lead to an activation of luciferase activity (Figure 3.12). These results show that antisense oligonucleotides against miR-19b does inactivate the function of endogenous miR-19b in primary cultures of oligodendrocytes.

In addition, to show that the transfection of precursor molecules of miR-17 and miR-19b leads to delivery of the microRNA into primary oligodendrocytes, we performed quantitative real-time PCR experiments. We observed a strong increase in the miR-17 and miR-19b levels after transfection of the corresponding precursors (Figure 3.13). These results clearly show that both miR-17 and miR-19b are targeted to oligodendrocytes. The specificity of the primers in the PCR reaction was shown by a control PCR as indicated in the figure legend. Primers for miR-19b did not lead to amplification of miR-17 miRNA or vice versa (Figure 3.13). 


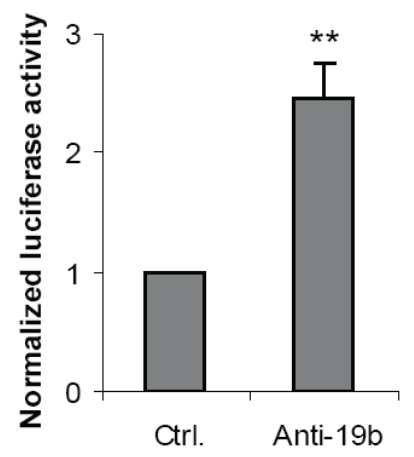

Figure 3.12: Analysis of miR-19b inhibition by a luciferase-based assay. To monitor the down-regulation of miR-19b, the firefly luciferase based pMiR19b-Luc Reporter Vector with a miR-19b binding site was used. The vector was co-transfected with a renilla luciferase vector without a miRNA bindig site for normalization. Luciferase activity of both constructs was determined 48 hours post-transfection. Transfection of antisense oligonucleotides directed against miR-19b leads to an activation of luciferase activity demonstrating that anti-19b inactivates the function of endogenous miR-19b in primary cultures of oligodendrocytes.

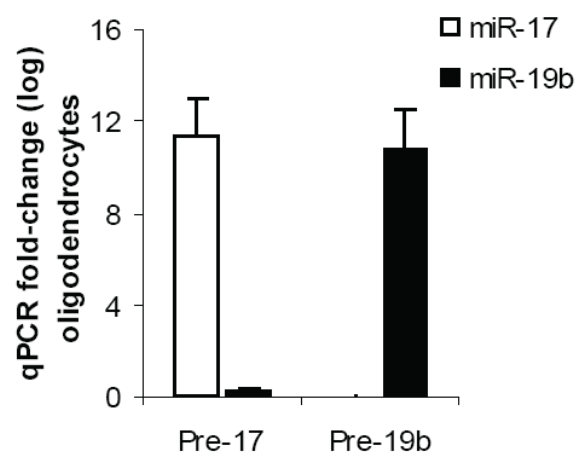

Figure 3.13: Real-time PCR analysis of miR-17 and miR-19b levels after transfection of pre-17 and pre-19b into oligodendrocytes. Oligodendrocytes were transfected one day after shaking with precursor molecules of miR-17 or miR-19b. Two days after transfection, cells were harvested and real time PCR analysis was performed for miR-17 and miR-19. Results are shown as fold-change as compared to control-miR. 


\subsubsection{The miR-17 92 cluster regulates Oli-neu cell number}

To address the mechanisms of how miR-17 92 acts in oligodendrocytes, we expressed the miR-17 and miR-19b in the oligodendroglial cell line Oli-neu. Transfection of precursors of miR-17and miR-19b resulted in a higher number of Oli-neu cells (Figure 3.14). Conversely, in a loss of function approach using antisense oligonucleotides against miR-17 and miR-19b, the Oli-neu cell number was decreased.

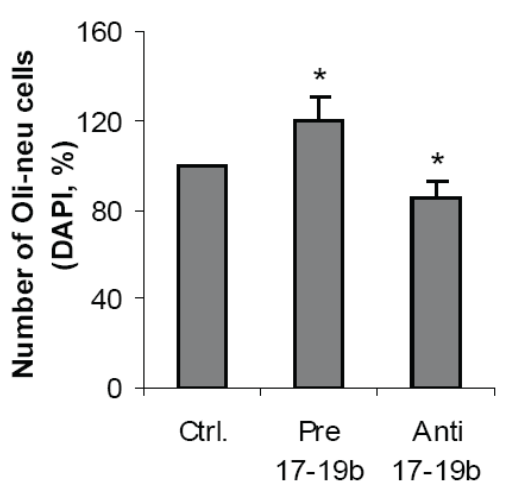

Figure 3.14: The miR-17 92 cluster regulates Oli-neu cell number. Pre-17 and pre$19 \mathrm{~b}$ or oligonucleotides directed against miR-17 and miR-19b were expressed the oligodendroglial cell line Oli-neu. Changes in cell number (DAPI stainings) are shown as mean + s.d. $\left(n=3 ;{ }^{*} p<0.05\right)$.

\subsubsection{The miR-17 92 cluster regulates the cell number of primary oligodendrocytes}

Similar results were obtained when the experiments were performed with primary cultures of oligodendrocytes. Transfection of miR-17 and miR-19b precursors increased the cell number (Figure 3.15). On the other hand, antisense treatment reduced the number of oligodendrocytes (Figure 3.15). Both, the number of immature oligodendrocytes stained with antibodies against A2B5 or GalC (O1 antibody) and the number of mature MBP differentiated oligodendrocytes changed to a similar degree (Figure 3.15). These results suggest that the differentiation of oligodendrocytes was not impaired by miR-17 and miR-19b. 

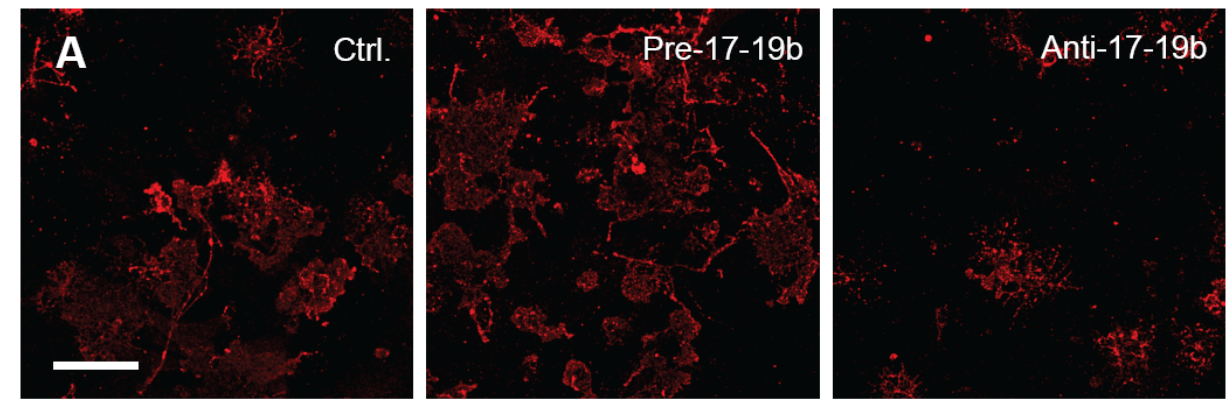

B
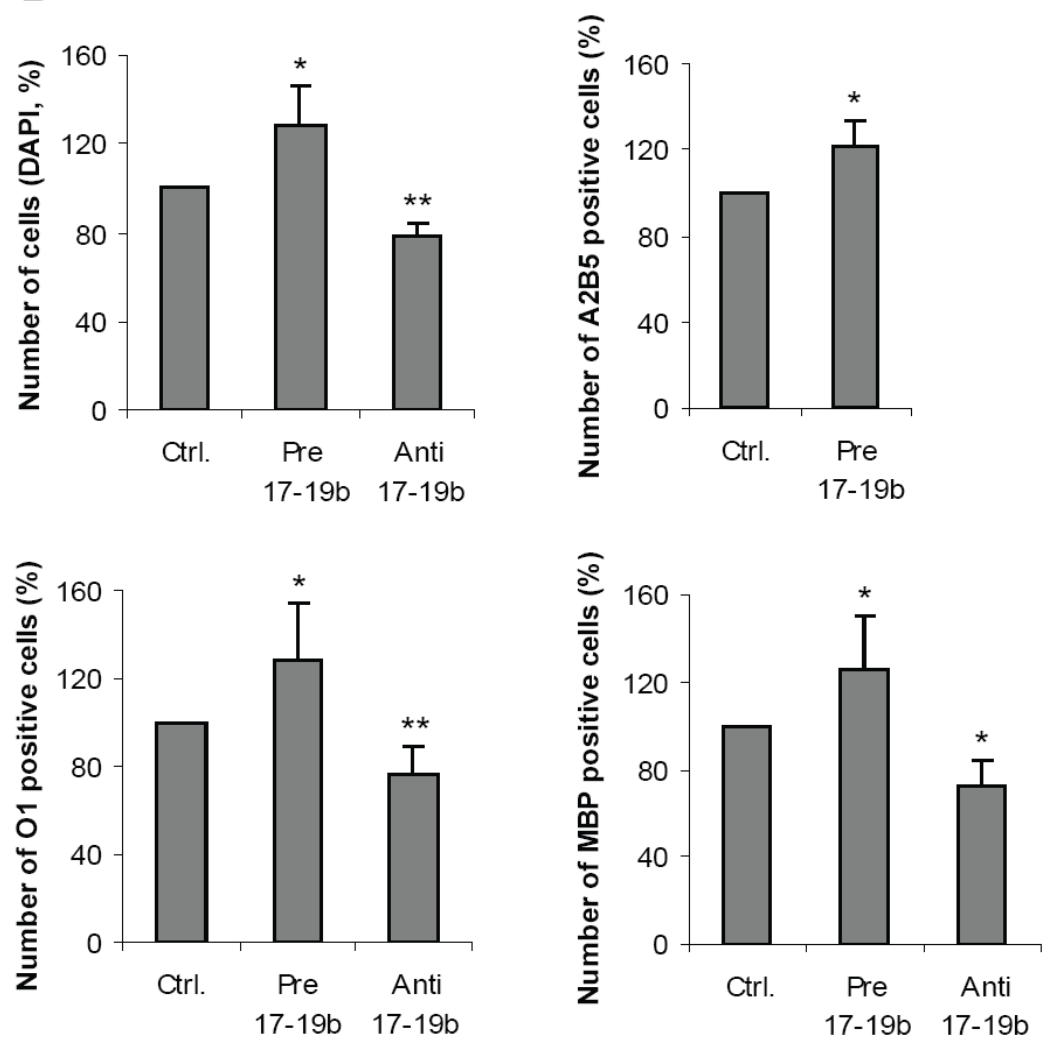

Figure 3.15: The miR-17 92 cluster regulates primary oligodendrocyte cell number. Pre-17-19b or anti-17-19b were expressed in primary oligodendrocytes. (A) Cells were stained for $\mathrm{O} 1$ (red). Scale bar: $100 \mu \mathrm{m}$. (B) Changes in cell number (DAPI-, A2B5-, O1-, MBP- positive cells) are shown as mean + s.d. $\left(n=3-4 ;{ }^{\star} p<0.05,{ }^{* *} p<0.01\right)$.

\subsubsection{Apoptosis of oligodendrocytes is not affected by the miR-17 92 cluster}

The changes in oligodendrocyte cell number by miR-17 and miR-19b could be due to the regulation of cell proliferation and/or cell survival. In order to distinguish between these two processes, we established an oligodendrocyte survival assay, which is based on the 
withdrawal of growth factors. When primary oligodendrocytes are switched to serum free medium without supplemental growth factors (medium without B27 serum supplement), about $80 \%$ of the cells die within 48 hours (Figure 3.16). As previously shown, addition of insulin or neuronal-conditioned medium strongly prevented cell death (Figure 3.16) (Barres et al., 1992). In order to determine whether miR-17 and miR-19b are able to rescue oligodendrocytes from apoptosis, miR-17 and miR-19b precursors were expressed in oligodendrocyes before growth factor deprivation. However, a rescue by miR-17 and miR-19b from cell death was not observed (Figure 3.17 A). Next, we tested whether insulin or neuronal conditioned medium, which efficiently protected oligodendrocytes from cell death, induced miR-17 and miR-19b expression. By real-time PCR we did not detect significance differences in the levels of miR-17 or miR-19b by adding insulin or conditioned neuronal medium to the cultures. Furthermore, the number of apoptotic cells did not change after transfection of miR-17 and miR-19b precursors as evaluated by TUNEL staining (Figure 3.17 B). We although could not observe any significant changes in the protein level of the pro-apoptotic protein Bim after primary oligodendrocytes were transfected with antisense nucleotides against miR-17 and miR-19b. Together, these data argue against a role of miR-17 and miR-19b in regulating oligodendrocyte survival.

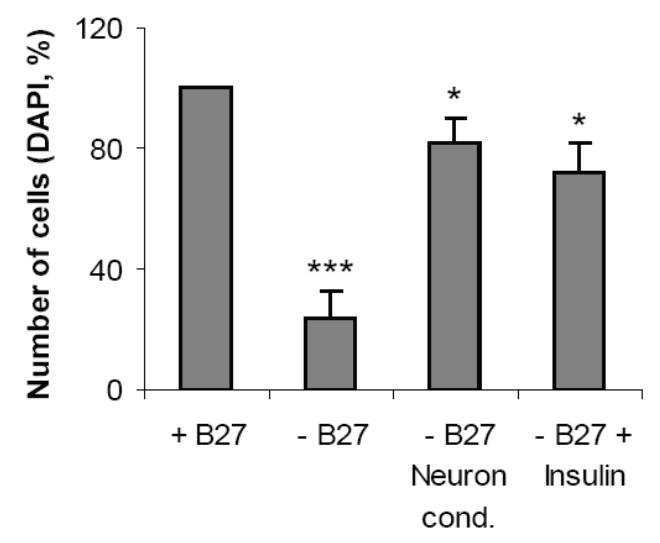

Figure 3.16: Down-regulation of oligodendrocyte cell number by growth factor deprivation and cell rescue by neuronal conditioned medium or insulin. Primary cultures of oligodendrocytes were grown in serum-free medium containing B27 supplement (+B27), without B27 supplement (-B27), in neuronal conditioned medium (Neuron cond.) or supplemented with $10 \mu \mathrm{g} / \mathrm{ml}$ insulin. Changes in cell number after B27 deprivation and the rescue by insulin or neuronal conditioning are shown as means + s.d. $\left(n=3-4 ;{ }^{*} p<0.05,{ }^{* * *} p<0.001\right)$ 
A

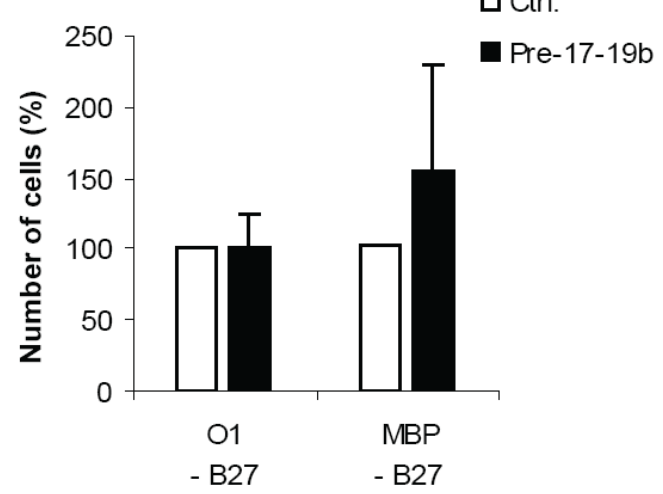

B

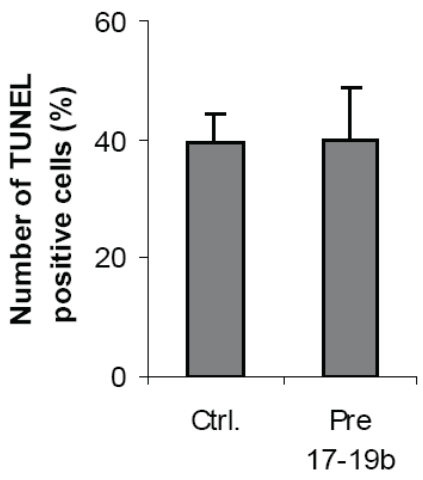

Figure 3.17: The miR-17 92 cluster has no influence on oligodendrocyte survival. (A) Pre-17-19b expression does not rescue oligodendrocyte cell death induced by B27 supplement deprivation $(n=4)$ and $(B)$ does not change the number of TUNEL positive cells $(n=3)$.

\subsubsection{The miR-17 92 cluster promotes oligodendrocyte cell proliferation}

In order to resolve whether miR-17 and miR-19b functions in the regulation of oligodendroglial cell proliferation, we performed BrdU assays. One day after shaking, cells were transfected with miR-17 and miR-19b or control miRNA. BrdU was added 24 hours after transfection and incorporated for one day into oligodendrocytes. Afterwards, oligodendrocytes were fixed and incorporation of BrdU into DNA was detected using a monoclonal antibody against BrdU. We found that the expression of mir-17 and miR-19b significantly increased the oligodendrocyte proliferation rate compared to the control miRNA (Figure 3.18).

Since miR-19b is a functional key component of the miR-17 92 cluster (Olive et al., 2010), we tested whether miR-19b alone is able to increase the proliferation rate of oligodendrocytes. Indeed, the results show that the transfection of miR-19b without miR-17 is sufficient to increase oligodenrocyte cell proliferation (Figure 3.21). 


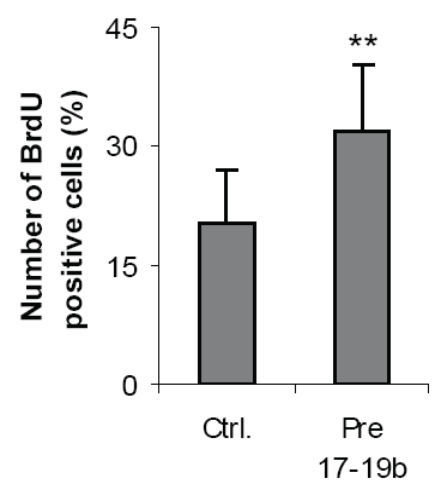

Figure 3.18: The miR-17 92 cluster regulates oligodendrocyte cell proliferation. Pre17 and pre-19b transfection in oligodendrocytes increase the number of BrdU positive cells. Changes in cell number are shown as mean $+s . d .\left(n=5 ;{ }^{* \star} p<0.01\right)$.

\subsubsection{Activation of the Pten-Akt signalling pathway in oligodendrocytes by miR-19b}

Based on our findings that miR-19b is sufficient to promote oligodendrocyte proliferation and that miR-19b is the most enriched miRNA of the cluster in oligodendrocytes, we started to look for potential mRNA targets of miR-19b. Since miRNAs are acting by downregulating the expression of their mRNA targets, the depletion of a negative regulator of cell proliferation is supposed to result in a subsequent up-regulation of cell proliferation. Hence, our strategy to identify potential targets in computational databases combined the search for predicted targets of miR-19b with the search for negative regulators of cell proliferation. The online database Gene Ontology (www.geneontology.org) revealed 242 potential candidates involved in the inhibition of cell proliferation. We compared these candidates to predicted mRNA targets of miR-19, which are present in both online miRNA target databases TargetScanS (http://targetscan.org) and PicTar (http://pictar.mdcberlin.de). This strategy revealed a small specific subset of three potential mRNA targets: Epiregulin, Pten and Smarca2. We reasoned, that among the different targets predicted for miR-19b, the tumor suppressor Pten might be of particular importance, due to its known function in regulating oligodendrocyte development (Barros et al., 2009) (Narayanan et al., 2009). Actually, transfection of miR-19b precursors resulted in a $\sim 40 \%$ reduction of Pten protein levels in primary oligodendrocytes (Figure 3.19) (Olive et al., 2009). Pten is wellknown for its role in inhibiting the Akt signalling pathway which is involved in several 
cellular processes such as cell proliferation, cell survival, glucose metabolism and many others. We observed that transfection of miR-19b into oligodendrocyte precursors leads to increased Akt phosphorylation and thereby activates Akt signalling (Figure 3.20). The overall levels of Akt were not influenced by miR-19b (Figure 3.20).

To provide functional evidence for these findings we had a closer look at the influence of Akt signalling on cell proliferation in our primary oligodendrocyte cultures. First, we controlled whether the oligodendrocyte proliferation in primary cultures depends on Akt signalling. By using BrdU assay we could show that treatment of oligodendrocyte precursors with an Akt1/2 kinase inhibitor (Akt Inhibitor VIII trifluoroacetate salt hydrate) clearly reduces cell proliferation (Figure 3.21). Next, we inhibited the Akt signalling pathway with the Akt kinase inhibitor and transfected miR-19 precursors at the same time to stimulate cell proliferation. The previously shown proliferation promoting effect of miR19b was completely blocked by the down-stream inhibition of the Akt signalling (Figure 3.21). Therefore the miR-19b effect on oligodendrocyte cell proliferation is mediated by the Akt signalling pathway. The effects of miR-19b can be, thus, at least partially explained by the inactivation of in Pten, which in turns stimulates Akt phosphorylation and subsequent oligodendrocyte cell proliferation.
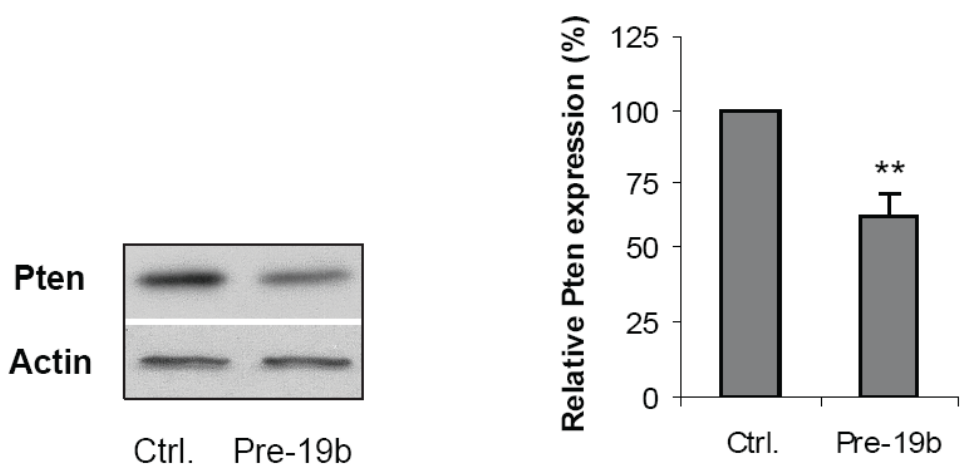

Figure 3.19: miR-19b down-regulates Pten in oligodendrocytes. Western blot analyses showing reduced Pten protein levels after miR-19b precursor transfection in primary oligodendrocyte cultures $\left(n=3 ;{ }^{*} p<0.01\right)$. 


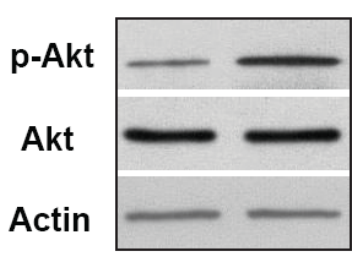

Ctrl. Pre-19b

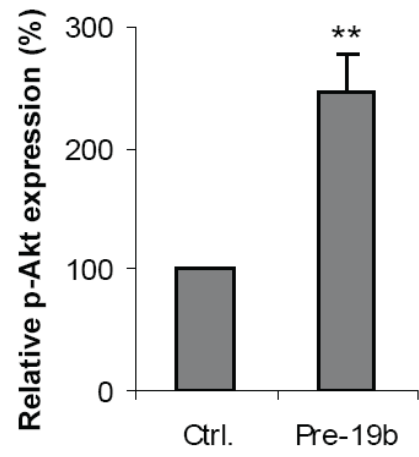

Figure 3.20: miR-19b leads to enhanced phosphorylation of Akt. Primary oligodendrocyte cultures were transfected with miR-19b precursor oligonucleotides or control miRNA. Investigating Akt protein levels by Western blot analyses revealed that the active phospho-Akt isoform is up-regulated by miR-19b without affecting overall levels of Akt protein. $\left(n=3 ;{ }^{* \star} p<0.01\right)$.

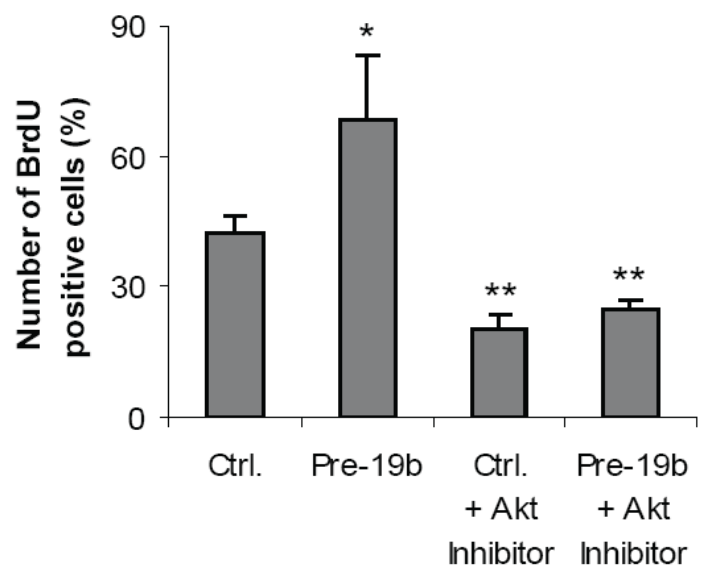

Figure 3.21: miR-19b is sufficient to increase oligodendrocyte cell proliferation and is involved in the Akt signalling pathway in oligodendrocytes. Primary oligodendrocytes were transfected with miR-19b precursors, resulting in increased proliferation detected by BrdU incorporation. Inhibition of Akt signalling pathway with an Akt1/2 kinase inhibitor strongly reduced oligodendrocyte proliferation. The increase in cell proliferation induced by miR-19b was totally prevented in the presence of the Akt kinase inhibitor $\left(n=3 ;{ }^{*} p<0.05,{ }^{*} p<0.01\right)$. 


\section{Discussion}

\subsection{Influence of the miR-17 92 cluster on oligodendrocytes}

\subsubsection{The miR-17 92 cluster}

A typical feature of many miRNAs is the transcription of different miRNAs in one polycistronic primary transcript (Stefani and Slack, 2008). These transcripts are processed into several single miRNAs. The majority of these clusters are highly conserved and therefore it is possible that the miRNAs of one cluster play a common role in distinct regulatory processes. The miR-17 92 cluster is an important miRNA cluster which is highly conserved in vertebrates and supposed to be generated in the early evolution of the vertebrate lineage (Tanzer and Stadler, 2004). The miR-17 92 cluster itself encodes for six miRNAs (miR-17, miR-18a, miR-19a, miR-20a, miR-19b-1 and miR-92-1) which are located on chromosome 13 in humans (Figure 3.8). The sequence is highly conserved and transcribed from an intron in the C13orf25 transcript (Ota et al., 2004). Two paralogs of this cluster have developed by gene duplications. These paralogs are located in humans on chromosome 7 (miR-106b 25 cluster) and on chromosome X (miR-106a 363 cluster). The miRNAs of the evolutionary related clusters can be subdivided into four functional families (Table 3.6). These families are based on their identical seed sequences, which are the crucial regions for the mRNA target recognition.

The miR-17 92 cluster is essential for the development of different cell types and tissues. Knock-out mice deficient for the miR-17 92 cluster die within minutes after birth and no viable knock-out mice were observed at later time points (Ventura et al., 2008). Investigation of miR-17 92 knock-out mice at late embryonic stages (E18.5-P0) revealed severe hypoplastic lungs and strong ventricular septal defects in the hearts. This defects cause the early prenatal death of the animals. The observations are underlined by a study showing that over-expression of the miR-17 92 cluster strongly increases proliferation and inhibits differentiation in the developing lung epithelium (Lu et al., 2007). Furthermore, functional interactions between the miR-17 92 and the miR-106b 25 cluster has been 
observed in double knock-out mice in which both cluster were deleted (Ventura et al., 2008). Double knock-out mice for miR-106a-363 and mir-106b-25 cluster exhibit no obvious phenotypic consequences whereas the double knock-out for the miR-17 92 and the miR-106b 25 cluster results in embryonic lethality before E15. These embryos show oedema, vascular congestion, severe cardiac abnormalities and apoptosis in the liver, the ventral horns of the spinal cord and the lateral ganglionic eminences.

Another observed function of the miR-17 92 cluster is the regulation of $B$ cell development. The miR-17 92 knock-out mice display a strong decreased number of pre-B cells but not of earlier B cell progenitors pointing at an enhanced apoptosis rate in these cells (Ventura et al., 2008; Xiao et al., 2008). Bim, a well known pro-apoptotic gene, was found to be a direct target which is down-regulated by the miR-17 92 cluster. In another study Dicer and therefore all miRNAs were depleted in B cells (Koralov et al., 2008). The phenotype in this study was similar to the miR-17 92 deletion and showed a reduction of pre-B cells.

Furthermore, a regulatory effect of the miRNA cluster was shown in monocytes of the hematopoietic system (Fontana et al., 2007). Over-expression of miRNAs of the miR17 92 cluster inhibits monocyte differentiation, whereas an inhibition of the miRNAs enhances the differentiation process.

Mice over-expressing the miR-17 92 cluster in B cells and T cells exhibit a shortened live span (Xiao et al., 2008). The animals show enhanced proliferation and survival of both B cell and $\mathrm{T}$ cell lymphocytes and develop autoimmunity. Four- to sixfold higher serum concentrations of immunoglobin $\mathrm{M}$ (IgM), IgG2a, IgG2b and $\operatorname{IgG} 3$ were found. A massive infiltration of lymphocytes in non-lymphoid tissues, especially in the lungs, can be observed in these mice. Bim and phosphatase and tensin homolog (Pten) were found to be specifically targeted by the miR-17 92 cluster in B cells and T cells. Pten has several cellular functions including the inhibition of cell proliferation and the activation of apoptosis. It is therefore a reasonable candidate to explain the observations in cell proliferation and apoptosis.

However, the most extensively studied function of the miR-17 92 cluster is its striking role in numerous cancer pathologies. Therefore the miRNAs of the miR-17 92 cluster are referred to as the 'oncomirs'. The genes of the miR-17 92 cluster were reported to undergo amplification in different types of tumours. Evidence for the involvement of the cluster in oncogenic processes was given by the observation that over-expression of these miRNAs 
in B cell lymphoma strongly accelerated the onset of the disease (He et al., 2005). The apoptosis rate in these artificial induced tumours was decreased. Further evidence came from a study showing activation of the miR-17 92 cluster transcription by c-Myc, a transcription factor often found up-regulated in tumours (O'Donnell et al., 2005). By expression profiling, up-regulation of the miRNA cluster was found in hematopoietic cancer and in numerous solid tumours for example lung, pancreas, breast, colon, prostate and stomach tumours (Petrocca et al., 2008; Volinia et al., 2006). Under normal conditions the expression of the paralog cluster miR-106a 363 is very low but when over-expressed, the functions resemble different functions of the miR-17 92 cluster (Landais et al., 2007). This is supported by the finding that the cyclin-dependent kinase inhibitor CDKN1A (p21) is a target of the miR-17 92 cluster and both paralogs (Ivanovska et al., 2008; Li et al., 2009; Petrocca et al., 2008). Inhibition of $p 21$, which itself inhibits the $\mathrm{G}_{1} / \mathrm{S}$-phase cell cycle transition, accelerates cell proliferation. In addition, the miR-17 92 and miR-106b25 clusters impair the TGF- $\beta$ signalling (Petrocca et al., 2008). TGF- $\beta$ can activate the $p 21$ mediated cell cycle arrest and blocking of TGF- $\beta$ subsequently abolishes cell cycle arrest. The E2F-family of transcription factors influences both proliferation and apoptosis. E2F1, E2F2 and E2F3 are validated targets of the miR-17 92 cluster (O'Donnell et al., 2005; Woods et al., 2007). The interaction of the miRNAs with the transcription factors involves also a negative feedback loop in which the factors E2F1 and E2F3 activate the transcription of their antagonistic miRNAs (Sylvestre et al., 2007).

The c-Myc oncogene supports angiogenesis and thereby tumour-propagation. In this process c-Myc mediates the down-regulation of the anti-angiogenic proteins thrombospondin-1 (Tsp1) and connective tissue growth factor (CTGF). The miR-17 92 cluster is involved in this process by its activation through c-Myc (Dews et al., 2006) and targeting of Tsp1 and CTGF mRNAs.

Recent studies have revealed miR-19 as a key oncogenic component of the miR-17 92 cluster (Mavrakis et al.; Olive et al., 2009). In a B-lymphoma model miR-19 was shown to be both necessary and sufficient to promote the c-Myc induced lymphomagenesis (Olive et al., 2009). Furthermore the study demonstrates that miR-19 is also sufficient to downregulate the expression level of Pten. The subsequently up-regulation of Akt after targeting of Pten was also confirmed in this study. In Notch1-induced T-cell leukaemia two additional negative regulators of the PI3K-Akt pathway were found: AMP-activated kinase (Prkaa1) and PP2A (Mavrakis et al., 2010). Therefore miR-19 is involved in the 
carcinogenic mediation of the PI3K-Akt pathway by suppressing several inhibitors of this signalling pathway including Bim, Pten, Prkaal and PP2A.

\subsubsection{Functions of the miR-17 92 cluster in oligodendrocyte proliferation}

\subsubsection{1 miRNA microarray profiling shows that the miR-17 92 cluster is enrichend in oligodendrocytes}

We used different approaches of miRNA microarray profilings to elucidate which particular miRNAs are important in oligodendrocytes. Comparison of miRNA expression levels of astrocytes and oligodendrocytes seemed to be a reasonable approach to identify miRNAs important for the development of the oligodendroglial lineage. Astrocytes and oligodendrocytes share a common early precursor (Nishiyama et al., 2009). Therefore miRNAs differentially expressed in these two cell types clearly give rise to the oligodendrocyte specific miRNA candidates. We confirmed the specificity of our approach by mRNA transcriptome profiling of astrocytes versus oligodendrocytes. Within the top 20 highly enriched mRNAs in oligodendrocytes compared to astrocytes we could show important oligodendrocyte-specific genes for example PLP, MBP, MAG and MOBP (Table 3.1). Our data are consistent with a previously published transcriptome database for oligodendrocytes (Cahoy et al., 2008). Furthermore, we did control stainings of each primary oligodendrocyte culture to exclude contaminations of the cultures with other CNS cell types. Only cultures with an oligodendrocyte purity of at least $80 \%$ were used for microarray profiling to ensure a low contamination level with other primary cell types. Our miRNA profiling revealed that several miRNAs of the miR-17 92 cluster and its paralogs are highly enriched in oligodendrocytes. The expression levels of the six miRNAs miR20b, miR-19a, miR-106a, miR-17, miR-20a and miR-19b were $\sim 3.5$ to 12.7 times higher in oligodendrocytes in comparison to astrocytes (Table 3.2). The overall miRNA profiling data are consistent with two recently pulished studies in which three single miRNAs miR-219, miR-138 and miR-338 were shown to be involved in oligodendrocyte differentiation (Dugas et al., 2010; Zhao et al., 2010). These miRNAs were also enriched 7.6 to 21.7 fold in oligodendrocytes in our miRNA profiling (Table 3.2). Moreover, another published miRNA microarray profiling showed miR-17 and miR-20a of the miR17 92 cluster up-regulated in both, immature A2B5 positive - GalC negative OPCs and 
more mature A2B5 negative - GalC positive cells of the oligodendroglial lineage (Lau et al., 2008). We got additional confirmation of our miRNA profiling by investigating the expression levels of miR-17, miR-19b, miR-125b and miR-34b with quantitative real-time PCR (Figure 3.9). Both miR-17 and miR-19b were more than 10-fold up-regulated and the down-regulation of miR-125b and miR-34b could be confirmed as well.

Taken together the results of these arrays clearly show the microarray profiling as a robust and reproducible method to elucidate cell-specific miRNAs. Most of our oligodendrocyte array data are confirmed by the results of other independent studies.

To investigate the different miRNA expression in oligodendrocytes compared to both neurons and other glial cells in the brain, we performed an additional miRNA microarray. In this profiling we quantified the miRNA levels of the oligodendrocyte-enriched whitematter and of neuron-containing grey-matter. Three miRNAs of the miR-17 92 cluster were up-regulated in the white-matter (Table 3.5). This result indicates that there is not only a specificity of the cluster in oligodendrocytes versus astrocytes, but also in oligodendrocytes versus other cell types in the CNS, including neurons. Moreover, the recently published oligodendrocyte-related miRNAs miR-219 and miR-338 were also found to be enriched in the white-matter samples of our microarray, supporting the reproducibility of our white- versus grey-matter approach (Dugas et al., 2010; Zhao et al., 2010).

Finally we performed a third miRNA profiling to investigate whether the miRNA expression of the miR-17 92 cluster changes during oligodendrocyte maturation. Therefore we compared different developmental stages in the oligodendroglial lineage. Three time points were chosen, OPCs directly after shaking ( $\mathrm{d} 0$, immature and proliferative), one day after shaking ( $\mathrm{d} 1$, immature but with reduced proliferation potential) and six days after shaking (d6, mature and post-mitotic). First of all, the microarray confirmed the relevance of the miR-17 92 cluster in the oligodendroglial lineage by showing that miR-106b, miR-20b, miR-92a, miR-20a and miR-19b are among the 45 highest expressed miRNAs (Table 3.3). Importantly, the data showed no noticeable changes in the expression of these five miRNAs during the oligodendrocyte differentiation. These results are pointing to an important role of the miR-17 92 cluster in oligodendrocytes but not in the differentiation process of these cells. In contrast to the miR-17 92 cluster, some other miRNAs were found to undergo changes in their expression levels during the oligodendroglial lineage maturation (Table 3.4). The highest 
changes were found in the miR-714 expression, which is up-regulated more than 20-fold in mature oligodendrocytes. Therefore miR-714 could maybe inhibit the translation of factors involved in the suppression of oligodendrocyte differentiation. However, the cellular function of miR-714 still remains unclear.

Interestingly miR-19b was found to be the most enriched miRNA of the cluster in both, the microarray investigating enriched miRNAs in oligodendrocytes versus astrocytes and the microarray of the different developmental oligodendroglial lineage stages (Table 3.2 and Table 3.3). This indicates a crucial role of miR-19b in oligodendroctyes. The observation is consistent with two recently published studies in cancer research, in which miR-19b was uncovered as a key oncogenic component of the miR-17 92 cluster (Mavrakis et al., 2010; Olive et al., 2009). The uncontrolled action of the cluster in cancer cells probably reflects functions of the cluster in normal cell development.

\subsubsection{Factors and pathways in OPC proliferation}

Growth factors and mitogens are important for the proliferation of immature cells of the oligodendroglial lineage. OPCs are produced in excess and later removed by apoptosis which is mediated by the limiting amount of local growth and survival factors. Actually, $\sim 50 \%$ of the initially produced OPCs undergo apoptosis during normal CNS development (Barres et al., 1992).

The best known mitogen in the oligodendroglial lineage is PDGF. PDGF is secreted by neurons and astrocytes and plays a major role in both OPC proliferation and survival (Richardson et al., 1988; Yeh et al., 1991). The receptor (PDGF $\alpha \mathrm{R})$ is expressed by highly proliferating OPCs and therefore an important marker for immature OPCs after the commitment to the oligodendroglial lineage (Pfeiffer et al., 1993). The expression of the $\mathrm{PDGF} \alpha \mathrm{R}$ in OPCs is regulated by the transcription factors Olig1 and Olig2, which are under the control of a gradient expression of Sonic Hedgehog (Butts et al., 2008). Expression of PDGF $\alpha \mathrm{R}$ is lost at initial stages of oligodendrocyte maturation. $\mathrm{O} 4$ positive oligodendrocytes do not show immunoreactivity for PDGF $\alpha$ R. Over-expression of PDGF $\alpha$ results in a strong increase in OPC number, while PDGF $\alpha$ R knock-out mice display a dramatically decreased OPC population (Calver et al., 1998; Fruttiger et al., 1999). Activation of both phosphatidylinositol-3 kinase (PI3K) and phosphoinositide 
phospholipase $\gamma$ (PLC $\gamma$ ) signalling pathways are required for the PDGFaR mediated increase in oligodendrocyte precursor proliferation (McKinnon et al., 2005).

FGF 2 is another proliferation factor for oligodendrocyte progenitors (Eccleston and Silberberg, 1984). The expression of the PDGFaR in immature oligodendrocytes is upregulated by FGF 2 (McKinnon et al., 1990). The combination of PDGF and FGF 2 results in a dramatically increased OPC proliferation (Bogler et al., 1990). Moreover, FGF 2 blocks the differentiation into mature oligodendrocytes and therefore contributes to the maintaining of the immature proliferative stage (Gard and Pfeiffer, 1993). Different responses of OPCs to FGF 2 are mediated by the expression of several FGF-receptors during oligodendrocyte development (Bansal et al., 1996). FGF-receptor 1 expression increases with the differentiation level, FGF-receptor 2 expression is observed in mature oligodendrocytes and FGF receptor 3 expression maximum is found in late progenitors and decreases during oligodendrocyte differentiation. A direct link to the FGF-2 mediated proliferation is given by the fact that FGF-2 stimulates the mitogen-activated protein kinase (MAPK) signalling pathway. This pathway results in an induction of the cyclin D1 mRNA expression and therefore regulates the $\mathrm{G}_{1} / \mathrm{S}$-phase cell-cycle progression (Frederick et al., 2007). Furthermore, FGF-2 was shown to down-regulate the cyclin dependent kinase (cdk) inhibitor p27 (Frederick and Wood, 2004).

Another factor promoting OPC proliferation is IGF-I. IGF-I receptors have been shown to be expressed in OPCs (McMorris and Dubois-Dalcq, 1988). IGF-I functions are mainly mediated by the type I IGF receptor (Liu et al., 1993). Like PDGF, IGF-I is also a survival factor preventing OPC apoptosis (Barres et al., 1992). IGF-I and FGF-2 synergistically enhance OPC proliferation by promoting S-phase entry (Frederick and Wood, 2004). The role of IGF-I in this process is the activation of the PI3K signalling pathway followed by the inhibition of cyclin D1 degradation (Frederick et al., 2007). Furthermore, the mitogenic effect of IGF-I on OPCs is mediated by the activation of the Src-like tyrosine kinases (Cui and Almazan, 2007). Downstream signalling in this proliferation process involves the PI3K/Akt signalling pathway as well as the MEK1/ERK signalling pathway, which are shown to be activated by IGF-I in OPCs.

Neurotophin-3 (NT-3) acts as a mitogen for OPC proliferation in the optic nerve (Barres and Raff, 1994). However, the combination of this factor with insulin or PDGF was necessary to exhibit the NT-3 effect in enhancing OPC proliferation. Another study demonstrates that the combination of NT-3 with brain-derived neurotrophic factor (BDNF) 
also induces oligodendrocyte progenitor proliferation (McTigue et al., 1998). BDNF itself is promoting OPC proliferation through the activation of the tyrosine kinase receptor TrkB, which is expressed on oligodendrocytes (Van't Veer et al., 2009). TrkB in turn mediates OPC proliferation by activating the MAPK signalling pathway but not the PI3K pathway. Glial growth factor (GGF) is a member of the neuregulin family and also functions as a mitogen for oligodendrocyte precursors (Canoll et al., 1996). GGF is not only stimulating OPC proliferation it acts as well as a survival factor and delays the oligodendrocyte differentiation (Canoll et al., 1999).

CNTF is another factor involved in promoting OPC genesis. In animals depleted of CNTF, OPC proliferation was shown to be decreased (Linker et al., 2002).

In contrast to the various mitogenic factors, transforming growth factor $\beta$ (TGF- $\beta$ ) is a inhibitor of the PDGF-mediated OPC proliferation and in turn is supporting the differentiation process (McMorris and McKinnon, 1996).

However, the involvement of miRNAs in the regulation of OPC proliferation was not investigated up to now. Hence, our work is the first reference for the role of miRNAs in oligodendrocyte proliferation.

\subsubsection{The miR-17 92 cluster regulates OPC proliferation}

Important in vivo evidence for the control of the oligodendrocyte cell number by the miR17 92 cluster was given by the phenotype of the miR-17 92 cluster knock-out mouse (miR-17 92 ${ }^{\text {flox/flox }} \mathrm{CNP}^{+/ \mathrm{Cre}}$ ) (Figure 3.10). These mice, in which the cluster is deleted in oligodendrocytes, exhibit a $\sim 25 \%$ reduction of Olig2-positive cells in the brains of the miR-17 92 ${ }^{\text {flox/flox }} \mathrm{CNP}^{+/ \mathrm{Cre}}$ mice compared to control animals. This result reflects the phenotype of our Dicer knock-out mice (Figure 3.4) and points at a crucial role of the miR17 92 cluster in oligodendrocytes. Similar observations were made by studies investigating B cell development. B cell miR-17 92 knock-out mice show a similar phenotype compared to B cell Dicer knock-out mice (Koralov et al., 2008; Ventura et al., 2008). Therefore, in some cell types like oligodendrocytes and B cells, the miR-17 92 cluster seems to constitute some of the most important miRNAs.

The role of the miR-17 92 cluster in regulating oligodendrocyte cell number was further assessed by in vitro cell culture experiments. First, in the oligodendroglial cell line, Oli- 
neu, the cell number could be up- and down-regulated by transfection of miR-17 and miR-19b precursor- or inhibitor-oligonucleotides (Figure 3.14).

As immortalised cell lines differ from primary cells in terms of proliferation and maturation, investigation of primary oligodendrocytes was necessary to proof these findings. In primary oligodendrocytes we obtained similar findings compared to Oli-neu cells. The cell number was regulated by miR-17 and miR-19b in immature OPCs stained for A2B5 and GalC (O1) and in mature oligodendrocytes stained for MBP (Figure 3.15). Together with the findings of the miR-17 92 flox/flox $\mathrm{CNP}^{+/ \mathrm{Cre}}$ mice, the miR-17 92 cluster is apparently promoting the oligodendrocyte cell number. However, the mechanisms of this regulatory process were still undefined. The first evidence that the oligodendrocyte differentiation was not affected by the miR-17 92 cluster was given by the constantly high expression of the cluster in both immature and mature oligodendrocytes (Table 3.3). This result is supported by the finding that the oligodendrocyte cell number is increased after transfection with miR-17 and miR-19b molecules in both immature A2B5/O1 positive cells and in differentiated MBP positive cells. Therefore, it is unlikely that the oligodendrocyte differentiation is regulated by the miR-17 92 cluster.

The miR-17 92 cluster is known for its anti-apoptotic effect in several cancer types. Because a lot of the initially generated OPCs die during normal CNS development by apoptosis, we tested whether the miR-17 92 cluster could control the oligodendrocyte cell number by preventing apoptosis. First, we induced apoptosis in primary oligodendrocytes by the withdrawal of survival factors included in the B27 serum supplement (Figure 3.16) (Barres et al., 1992). Transfection of miR-17 and miR-19b precursor molecules could not rescue O1-positive OPCs or MBP-differentiated oligodendrocytes from cell death, indicated by the unchanged cell numbers after transfection of the precursors (Figure 3.17 A). In TUNEL assays we did not observe differences in the apoptosis rate of ctrl-miR and miR-17, -19b precursor transfected oligodendrocytes (Figure 3.17 B). Furthermore, we tested whether miR-17 and miR-19b down-regulate the pro-apoptotic protein Bim, as observed in lymphoma cells (Ventura et al., 2008; Xiao et al., 2008). However, we could not detect a down-regulation of Bim protein levels after transfecting oligodendrocytes with miR-17, and miR-19b precursors. Therefore it seems to be unlikely that the miR-17 92 cluster regulates the oligodendrocyte cell number in normal development by preventing apoptosis. Moreover, our qRT-PCR experiments revealed that insulin or neuronal conditioned medium, both factors preventing apoptosis in oligodendrocytes after B27 
withdrawal (Figure 3.16), do not change the miR-17 or miR-19b expression levels in oligodendrocytes. Insulin therefore does not influence the expression of the miR-17 92 cluster in oligodendrocytes.

There is a lot of evidence in the literature, that the miR-17 92 cluster is able to regulate cell proliferation in several cell types. The possibility of regulating the cell number by enhancing proliferation was assessed by BrdU assay in our primary oligodendrocyte cultures. Transfection of oligodendrocytes with a combination of miR-17 and miR-19b resulted in an increased proliferation (Figure 3.18). This finding is consistent with several other studies, in which the miR-17 92 cluster was found to promote cell proliferation (Ivanovska et al., 2008; Li et al., 2009; Petrocca et al., 2008).

Furthermore, investigation of miR-19b in particular was performed because miR-19b is the major expressed miRNA of the miR-17 92 cluster in the microarray profilings (Table 3.2 and Table 3.3). Recent publications also revealed miR-19b as a functional key component of this cluster (Mavrakis et al., 2010; Olive et al., 2009). Therefore we presumed an essential role of miR-19b in regulating oligodendrocyte proliferation. Indeed we could demonstrate that miR-19b alone is sufficient to up-regulate oligodendrocyte proliferation (Figure 3.21). Therefore it is reasonable, that miR-19b is also sufficient to inhibit the translation of some regulators of oligodendrocyte cell proliferation.

\subsubsection{4 miR-19b promotes OPC proliferation by regulating the Pten-Akt signalling pathway}

Searching the database Gene Ontology (www.geneontology.org) for negative regulators of cell proliferation and comparing these genes with the computational predicted targets (using TargetScanS and PicTar online softwares) of miR-19b was used to identify potential targets of miR-19b in cell proliferation pathways. Of the three potential candidates, Epiregulin, Pten and Smarca2, only Pten seemed to be a reasonable candidate which could mediate oligodendrocyte proliferation. Whereas little is known about Epiregulin or Smarca2, Pten is known for its regulation of the PI3K-Akt signalling pathway. Actually, we could confirm the down-regulation of Pten by transfection of miR-19 precursors in oligodendrocytes (Figure 3.19). Our data are consistent with recently published studies which revealed Pten as a target of miR-19b in lymphoma cells (Mavrakis et al., 2010; Olive et al., 2009). Pten is acting as a negative regulator of Akt (also known as protein 
kinase $\mathrm{B}$ or $(\mathrm{PKB}))$ and therefore involved in the Akt signalling. Controlling of cell survival and cell proliferation are important pathways in which Akt is involved. The regulation of OPC proliferation also depends on the PI3K-Akt signalling pathway (Ebner et al., 2000). Therefore we tested the connection of miR-19b to the Akt signalling pathway. We could show that the transfection of miR-19b precursors increases the level of phosphorylated Akt and therefore activates the Akt signalling (Figure 3.20). Furthermore we demonstrated that the inhibition of oligodendrocyte cell proliferation, using an Akt inhibitor, could not be rescued by miR-19b precursors (Figure 3.21). This result indicates that the regulation of oligodendrocyte proliferation by miR-19b is mediated downstream by the Akt signalling pathway. Therefore, we have functional evidence that miR-19b is targeting Pten and thereby activating Akt signalling in oligodendrocytes which subsequently leads to enhanced oligodendrocyte cell proliferation. The effect of the miR17 92 cluster on oligodendrocyte cell proliferation can be explained, at least in part, by the down-regulation of Pten through miR-19b.

Further indication for the miR-17 92 cluster involvement in cell proliferation is given by the assumption that the cluster also targets TGF- $\beta$, a negative regulator of OPC proliferation (McMorris and McKinnon, 1996; Petrocca et al., 2008). Another study showed that in lymphoma cells miR-17 and miR-20a are targeting the cell cycle inhibitor CDKN1A/p21 and thereby preventing cell cycle arrest at the $\mathrm{G}_{1} / \mathrm{S}$ phase (Inomata et al., 2009). Akt inactivates some negative cell cycle regulators, for example p21 and p27 (Liang and Slingerland, 2003). Akt-activation by miR-19b in oligodendrocytes could therefore promote cell proliferation by inactivation of cyclin-dependent kinase inhibitors.

\subsection{Dicer is essential in the regulation of oligodendrocyte cell number in vivo}

The miR-17 92 cluster is crucial for the control of oligodendrocyte cell number. It was therefore possible that a knock-out of all miRNAs in oligodendrocytes would exhibit a similar or even stronger phenotype in the mouse. The maturation of miRNAs is dependent on the cytoplasmic enzyme Dicer. Without this enzyme the last step in the miRNA biogenesis can not be completed and the miRNAs are trapped within the immature and inactive pre-miRNA stage. The pre-miRNAs are not incorporated into the RISC and the 
target mRNAs are therefore not inhibited by this complex. Dicer knock-out mice are used in several studies as a powerful tool to investigate the function of mature miRNAs in whole organisms or in specific cell types. Total disruption of Dicer in mice causes lethality in early development (Bernstein et al., 2003). These mice die at $\sim$ E7.5 and can therefore not display any functions of miRNAs in later development or cell-specific roles of the miRNAs. Conditional deletion of Dicer using mice with loxP sites flanking the second RNase III domain of Dicer was used to investigate miRNAs functions in later stages of development (Harfe et al., 2005). Total deletion of the second RNase III domain of Dicer resulted also in embryonic arrest at E7.5 similar to the disruption of the first RNase III domain (Bernstein et al., 2003). Mice with floxed second RNase III domain of Dicer allow site-specific Dicer deletion by cell-type-specific Cre-recombinase expression.

We observed that no Dicer ${ }^{\text {flox/flox }} \mathrm{CNP}^{+/ C r e}$ mice survived into adulthood. All animals died within the first three postnatal weeks. Another group, which also recently published a Dicer ${ }^{\text {flox/flox }} \mathrm{CNP}^{+/ \mathrm{Cre}}$ mouse, made the same observations (Dugas et al., 2010). They found that peripheral myelination was severely disrupted in the knock-out mice. The defect in the peripheral myelination is caused by the loss of miRNAs in the Schwann cells, which also express CNP-Cre and lose the Dicer enzyme due to Cre expression. Therefore, the defect of myelinating cells in the PNS could block or weaken essential pathways in the development or maintenance of vitally important organs.

Our generation of oligodendrocyte-specific Dicer knock-out mice shows a $\sim 40 \%$ reduction in the number of oligodendroglial lineage cells in the brains of the knock-out mice compared to the control animals (Figure 3.4). The effect was stronger than in the miR17 92 ${ }^{\text {flox/flox }} \mathrm{CNP}^{+/ \text {Cre }}$ mice (Figure 3.10). Hence, the miR-17 92 cluster is an important factor in the regulation of oligodendrocyte cell number, but also some other miRNAs apparently contribute to this process. In the spinal cord of the Dicer ${ }^{\text {flox/flox }} \mathrm{CNP}^{+/ \mathrm{Cre}}$ mice we did not detect significant changes in Olig2 positive cells (Figure 3.6) which could be due to different mechanisms of miRNAs in oligodendrocyte development in the spinal cord and the brain. Consistent with our Dicer knock-out phenotype in the brain, a recently generated Nestin-Cre Dicer knock-out mouse, in which late-born cortical neurons and oligodendrocytes are affected by the Dicer deletion, showed a reduced number of dividing cells in the ventricular and sub-ventricular zone of the embryo brains (Kawase-Koga et al., 2009). In addition to the decreased cell numbers they observed no newborn knock-out mice, pointing at a late prenatal death. Surprisingly they found a decreased 
oligodendrocyte cell number in the spinal cords of E18.5 Nestin-Cre Dicer embryos. In contrast, in our oligodendrocyte specific Dicer knock-out mice, we only observed reduced oligodendrocyte cell numbers in the brain. However, in the Nestin-Cre Dicer knock-out not only oligodendrocytes but also neurons are severely affected by the loss of mature miRNAs. The loss of neurons results in the subsequently loss of neuronal-secreted survival and proliferation factors for the oligodendrocyte proliferation and survival. Therefore the abolished neuron-oligodendrocyte interaction could explain the decreased number of oligodendrocytes in the Nestin-Cre Dicer spinal cords.

To test whether the reduction of oligodendrocytes in the brains of our $\mathrm{Dicer}^{\text {flox/flox }} \mathrm{CNP}^{+/ \mathrm{Cre}}$ mice was induced by apoptosis, we did TUNEL-stainings. We could not detect changes in the apoptotic rates in the knock-out mice compared to control littermates (Figure 3.7). This result matches with the data of our apoptosis assay performed in primary oligodendrocytes (Figure 3.17). Moreover, our data are consistent with the observations in the Nestin-Cre Dicer knock-out mice, in which the apoptosis rate was not altered compared to the control animals (Kawase-Koga et al., 2009).

We also tested whether oligodendrocytes in the $\mathrm{Dicer}^{\text {flox/flox }} \mathrm{CNP}^{+/ \mathrm{Cre}}$ mice are able to differentiate and produce myelin sheaths. For this purpose we cultured OPCs from Dicer knock-out and control animals. We observed a slightly, but non-significantly decreased number in MBP-differentiated oligodendrocytes in the knock-out animals (Figure 3.3). However, the experiment clearly demonstrated that the Dicer-depleted oligodendrocytes are able to differentiate in MBP-expressing mature oligodendroctes. Interestingly, the ability of Dicer depleted oligodendrocytes to differentiate in MBP-positive cells varies among Dicer knock-out mice according to the promoter which is driving Cre-recombinase expression.

In PLP-Cre Dicer knock-out mice the myelin protein levels are indistinguishable compared to the wild-type mice in the first month (Shin et al., 2009). In these mice the Dicer deletion was induced postnatally two weeks after birth by injection of tamoxifen. The PLP-Cre Dicer knock-out mice show decreased myelin expression at later time points (after 6 months). Due to this finding, miRNAs are supposed to participate in the maintenance of the myelin sheaths. Using the late PLP promoter, which is induced not in OPCs but in differentiating and mature oligodendrocytes, revealed some late effects of miRNAs in oligodendrocytes. Hence, this study contributed not to the early effects of miRNAs in oligodendrocyte proliferation and differentaiton, but importantly to the function of 
miRNAs in the maintenance of mature myelin. An interesting finding in the mice bearing a late Dicer deletion was the occurrence of inflammatory responses and axonal degeneration which are also found in demyelinating diseases such as multiple sclerosis. Therefore miRNAs could play a role in oligodendrocyte malfunction.

In another recent published study, which used CNP-Cre Dicer knock-out mice and Olig2Cre Dicer knock-outs, myelination was observed in both mice at P24 (Dugas et al., 2010). Myelination levels were found to be reduced at P24 but seemed to recover in the Olig2-Cre Dicer mice at P60. The recovery of normal myelin in the Olig2-Cre Dicer knock-out mice was suggested to be caused by a recurrence of Dicer expression through P45. The Olig2Cre Dicer and CNP-Cre-Dicer animals show functional deficits and a notable tremor from P9-10. In the Olig2-Cre Dicer animals the appearance of normal levels of compact myelin at later time points was accompanied by behavioural recovery. Comparable to the phenotype of our knock-out mouse, the CNP-Cre-Dicer animals died within the first month after birth.

Recently another Dicer knock-out mouse was published in which the Dicer deletion was caused by Cre expression driven by the Olig1 promoter (Zhao et al., 2010). These mice died around postnatal week 3 and showed severe tremor and ataxia before death. Markers for mature myelin were found to be decreased in the spinal cord and the brain. Interestingly, the Olig1-Cre Dicer mice showed increased proliferation of Olig2-positive cells in brains of P7 and P14 mice. However, OPC proliferation was not observed in the previous mentioned studies, in which Dicer deletion was driven by Cre expression via the CNP, PLP or Olig2 promoter.

In the comparison of the different Dicer knock-out animals it is important to consider the different activation times of the promoters used in these studies. The different knock-out models could maybe exhibit different grades of Dicer deletion, depending on the expression peak of the individually used Cre-promoter. This could explain some discrepancies in the effects of the Dicer deletion in the different knock-out mice. Furthermore, it is reasonable, that different miRNAs have different functions in oligodendrocyte development. In the early development, miRNAs seem to promote the OPC proliferation, whereas at later time points of development miRNAs presumable contribute to the oligodendrocyte differentiation. Finally in mature oligodendrocytes, miRNAs could be more likely involved in the maintenance of the oligodendrocyte and myelin structure. This argumentation strongly supports and combines the different miRNA 
functions found in the Dicer knock-out mice mediated by CNP-Cre, Olig1-Cre, Olig2-Cre or PLP-Cre.

\subsection{Different miRNA profilings uncover a subset of miRNAs important for oligodendrocytes}

In the last two years first evidence for the implication of miRNAs in oligodendrocyte development were uncovered.

Indirect information arised from a study, in which miR-9 was shown to downregulate the expression of the peripheral myelin protein PMP22 (Lau et al., 2008). However, PMP22 protein is only expressed in the peripheral Schwann cells, the corresponding PNS cells to the oliogdendrocytes in the CNS. We also found high expression of miR-9 in oligodendrocytes (Table 3.3), but the expression level was even higher in astrocytes (Table $3.2)$.

In another study, regulation of lamin B1 by miR-23 was observed (Lin and Fu, 2009). In the human disease autosomal dominant leukodystrophy, elevated expression levels of lamin B1 mRNA and protein can be observed due to a dublication of the lamin B1 gene. In patients, the enhanced expression is accompanied by a severe loss of myelin in the brain (Coffeen et al., 2000). miR-23 down-regulates lamin B1 mRNA and therefore the authors suggest a role of miR-23 in the maintenance of the myelin structure (Lin and $\mathrm{Fu}, 2009$ ). Our microarray profilings contribute to this finding by confirming high expression of miR23 in both, total oligodendrocyte miRNA levels (Table 3.3) and miRNA levels in the comparison of oligodendrocytes and astrocytes (Table 3.2).

Recently, the functions of several miRNAs in the differentiation process of oligodendrocytes were published. miR-219, miR-338 and miR-138 were found to promote oligodendrocyte differentiation in vitro (Dugas et al., 2010; Zhao et al., 2010). miR-219 was shown to down-regulate PDGF $\alpha \mathrm{R}$ and the transcription factors SRY-box containing gene6 (Sox6), forkhead box J3 (FoxJ3), zinc finger protein 238 (ZFP238) (Dugas et al., 2010). The second study showed that Sox6 and the transcription factor Hes5 were downregulated by both miR-219 and miR-338 (Zhao et al., 2010). PDGF $\alpha$ R, Sox6, FoxJ3 and ZFP238 are supposed to enhance OPC proliferation and inhibit oligodendrocyte differentiation (Barres et al., 1994; Besnard et al., 1987; Dugas et al., 2010; Stolt et al., 
2006). Hes5 was shown to inhibit oligodendrocyte differentiation (Kondo and Raff, 2000). Consistent with the results of both publications, our miRNA microarray profiling revealed that miR-219, miR-338 and miR-138 are enriched at least 7-fold in oligodendrocytes as compared to astrocytes (Table 3.2). 


\section{Summary and Conclusion}

In the last decade numerous studies have documented pivotal functions of miRNAs in the development of various cells in almost all tissues. However, only little is known about the function of miRNAs in oligodendrocytes. We reasoned that miRNAs could play an important role in cells of the oligodendroglial lineage by regulating crucial developmental genes.

In a knock-out mouse model we deleted Dicer and therefore all mature miRNAs specifically in oligodendrocytes by using the Cre-loxP recombination system. The mice showed a reduction in oligodendrocyte cell number in the brain, pointing at an important function of miRNAs in oligodendrocytes.

Furthermore, we used miRNA microarray profiling to identify oligodendrocyte-specific miRNAs. The profiling of primary oligodendrocytes identified the miR-17 92 cluster of miRNAs as highly enriched in oligodendrocytes. Based on the microarray data, we generated a knock-out mouse model, in which the miR-17 92 cluster was deleted in oligodendrocytes. These knock-out mice revealed a decreased number of oligodendrocytes in vivo. Therefore, the reduction of the oligodendrocyte cell number in the Dicer knock-out mice is mediated, at least in part, by the action of the miR-17 92 cluster. Experiments with primary oligodendrocyte cultures confirmed the regulation of the oligodendroglial cell number by the miR-17 92 cluster. Our cell culture experiments revealed that this miRNA cluster regulates the oligodendrocyte cell number by promoting OPC proliferation. Apoptosis and differentiation of oligodendrocytes did not seem to be influenced by the miR-17 92 cluster. Moreover, we could demonstrate that miR-19b, the most enriched miRNA of the miR-17 92 cluster in oligodendrocytes, is sufficient to significantly enhance OPC proliferation. In addition, the cell culture experiments showed that miR-19b is mediating OPC proliferation by the down-regulation of Pten and thereby regulating the Akt signalling pathway in oligodendrocytes. 
Altogether, our studies provide new evidence for miRNAs in oligodendrocyte development. In addition, our work can serve as a reference for future studies on miRNA function in normal oligodendrocyte development and demyelinating diseases such as multiple sclerosis. 


\section{Abbreviations}

\begin{tabular}{ll} 
APS & Ammonium persulfate \\
BMP & Bone morphogenetic protein \\
bp & Base pairs \\
BrdU & Bromodeoxyuridine \\
BSA & Bovine serum albumin \\
cDNA & Complementary deoxyribonucleic acid \\
CNP & $2^{\prime}, 3^{\prime}$-cyclic nucleotide 3 'phosphodiesterase \\
CNS & Central nervous system \\
CNTF & Ciliary neurotrophic factor \\
DGCR8 & DiGeorge syndrome critical region gene 8 \\
DMEM & Dulbecco's modified eagle medium \\
DMSO & Dimethyl sulfoxide \\
DNA & Deoxyribonucleic acid \\
DNase & Deoxyribonuclease \\
dNTP & Deoxynucleotide tri-phosphate \\
dsRNA & Double-stranded ribonucleic acid \\
E & Embryonic day \\
EDTA & Ethylendiaminetetraacetic acid \\
ESC & Embryonic stem cells \\
FCS & Fetal calf serum \\
FGF-2 & Fibroblast growth factor 2 \\
FITC & Fluorescein isothiocyanate \\
GalC & Galactosylceramide \\
GFAP & Glial fibrillary acidic protein \\
GGF & Glial growth factor \\
GTP & Guanosine triphosphate \\
HRP & Horseradish peroxidise \\
HS & Horse serum \\
\hline
\end{tabular}


Ig Immunoglobin

IGF-1 Insulin-like growth factor 1

kDa Kilo dalton

LB Lysogeny broth

LE/L Late endosomes/lysosomes

M Molar

MAG Myelin-associated glycoprotein

MAPK Mitogen-activated protein kinase

MBP Myelin basic protein

$\min \quad$ Minute

miRNA Micro ribonucleic acid

MOBP Myelin-associated oligodendrocyte basic protein

MOG Myelin oligodendrocyte glycoprotein

mRNA Messenger ribonucleic acid

MS Multiple sclerosis

nt Nucleotides

NT-3 Neurotrophine 3

$\mathrm{o} / \mathrm{n} \quad$ Over night

OPC Oligodendrocyte precursor cell

P Postnatal day

PAGE Polyacrylamide gel electrophoresis

PAZ Piwi, Argonaute and Zwille

PBS Phosphate buffered solution

PCR Polymerase chain reaction

PDGF Platelet-derived growth factor

$\mathrm{PDGF} \alpha \mathrm{R}$ Platelet-derived growth factor alpha receptor

Pen/Strep Penicilin/Streptomycin

PI3K Phosphoinositide 3-kinase

piRNA Piwi-interacting RNA

PLC Phosphoinositide phospholipase

PLL Poly-L-lysine

PLP Proteolipid protein

PNS Peripheral nervous system 
Pol Polymerase

PSA-NCAM Poly-sialyated neural cell adhesion molecule

PTEN Phosphatase and tensin homolog

RISC Ribonucleic acid induced silencing complex

RNA Ribonucleic acid

RNase Ribonuclease

RT Room temperature

s.d. Standard deviation

SDS Sodium dodecyl sulphate

sec Second

siRNA Small interfering ribonucleic acid

S-phase Synthesis phase

ssRNA Single-stranded ribonucleic acid

TNF Tumor necrosis factor

TUNEL Terminal deoxynucleotidyl transferase dUTP nick end labelling

UTR Untranslated region 


\section{Plasmid maps}

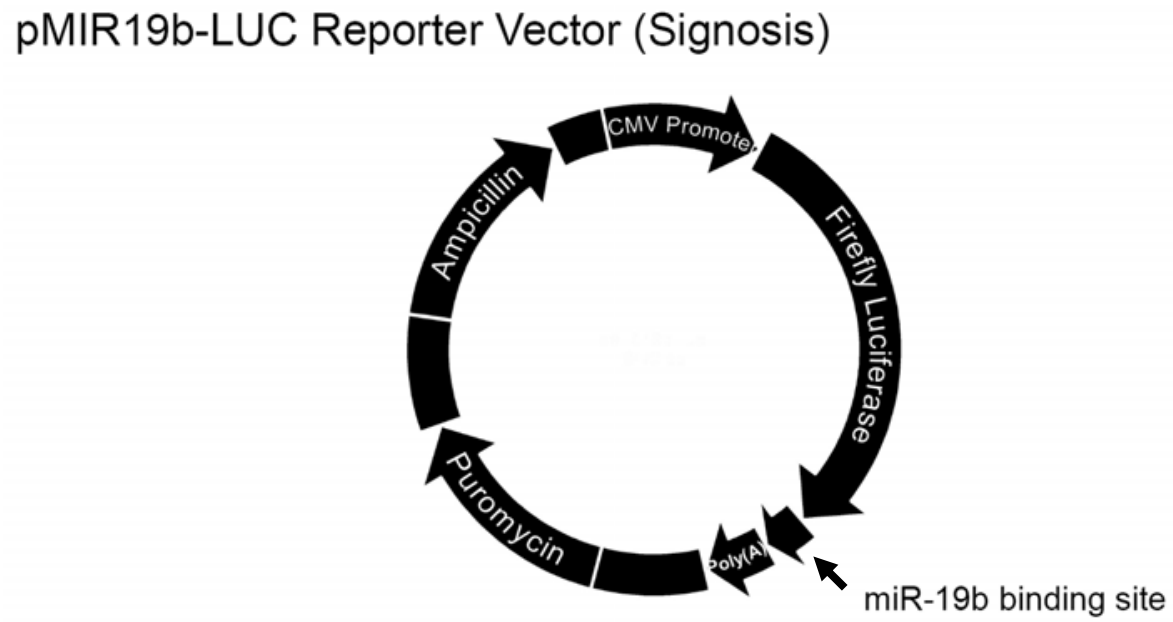

phRL-SV40 Vector (Promega)

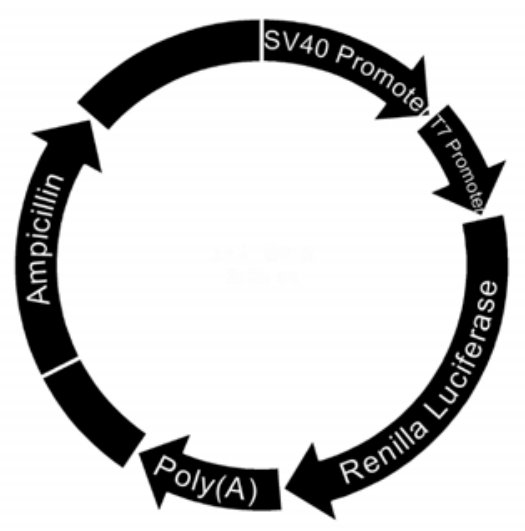




\section{References}

Aleman, L. M., Doench, J. and Sharp, P. A. (2007). Comparison of siRNA-induced offtarget RNA and protein effects. RNA 13, 385-95.

Ambros, V., Bartel, B., Bartel, D. P., Burge, C. B., Carrington, J. C., Chen, X., Dreyfuss, G., Eddy, S. R., Griffiths-Jones, S., Marshall, M. et al. (2003). A uniform system for microRNA annotation. RNA 9, 277-9.

Anitei, M., Ifrim, M., Ewart, M. A., Cowan, A. E., Carson, J. H., Bansal, R. and Pfeiffer, S. E. (2006). A role for Sec8 in oligodendrocyte morphological differentiation. $J$ Cell Sci 119, 807-18.

Aravin, A. A., Lagos-Quintana, M., Yalcin, A., Zavolan, M., Marks, D., Snyder, B., Gaasterland, T., Meyer, J. and Tuschl, T. (2003). The small RNA profile during Drosophila melanogaster development. Dev Cell 5, 337-50.

Arnett, H. A., Fancy, S. P., Alberta, J. A., Zhao, C., Plant, S. R., Kaing, S., Raine, C. S., Rowitch, D. H., Franklin, R. J. and Stiles, C. D. (2004). bHLH transcription factor Olig1 is required to repair demyelinated lesions in the CNS. Science 306, 2111-5.

Babiarz, J. E., Ruby, J. G., Wang, Y., Bartel, D. P. and Blelloch, R. (2008). Mouse ES cells express endogenous shRNAs, siRNAs, and other Microprocessor-independent, Dicerdependent small RNAs. Genes Dev 22, 2773-85.

Balabanov, R. and Popko, B. (2005). Myelin repair: developmental myelination redux? Nat Neurosci 8, 262-4.

Bansal, R., Kumar, M., Murray, K., Morrison, R. S. and Pfeiffer, S. E. (1996). Regulation of FGF receptors in the oligodendrocyte lineage. Mol Cell Neurosci 7, 263-75.

Barbarese, E., Brumwell, C., Kwon, S., Cui, H. and Carson, J. H. (1999). RNA on the road to myelin. J Neurocytol 28, 263-70.

Baron, W., Colognato, H. and ffrench-Constant, C. (2005). Integrin-growth factor interactions as regulators of oligodendroglial development and function. Glia 49, 467-79.

Barres, B. A., Hart, I. K., Coles, H. S., Burne, J. F., Voyvodic, J. T., Richardson, W. D. and Raff, M. C. (1992). Cell death and control of cell survival in the oligodendrocyte lineage. Cell 70, 31-46.

Barres, B. A., Lazar, M. A. and Raff, M. C. (1994). A novel role for thyroid hormone, glucocorticoids and retinoic acid in timing oligodendrocyte development. Development 120, 1097-108. 
Barres, B. A. and Raff, M. C. (1994). Control of oligodendrocyte number in the developing rat optic nerve. Neuron 12, 935-42.

Barros, C. S., Nguyen, T., Spencer, K. S., Nishiyama, A., Colognato, H. and Muller, U. (2009). Beta1 integrins are required for normal CNS myelination and promote AKTdependent myelin outgrowth. Development 136, 2717-24.

Bartel, D. P. (2004). MicroRNAs: genomics, biogenesis, mechanism, and function. Cell 116, 281-97.

Bartsch, U., Kirchhoff, F. and Schachner, M. (1989). Immunohistological localization of the adhesion molecules L1, N-CAM, and MAG in the developing and adult optic nerve of mice. J Comp Neurol 284, 451-62.

Baumann, N. and Pham-Dinh, D. (2001). Biology of oligodendrocyte and myelin in the mammalian central nervous system. Physiol Rev 81, 871-927.

Behm-Ansmant, I., Rehwinkel, J., Doerks, T., Stark, A., Bork, P. and Izaurralde, E. (2006). mRNA degradation by miRNAs and GW182 requires both CCR4:NOT deadenylase and DCP1:DCP2 decapping complexes. Genes Dev 20, 1885-98.

Bentwich, I., Avniel, A., Karov, Y., Aharonov, R., Gilad, S., Barad, O., Barzilai, A., Einat, P., Einav, U., Meiri, E. et al. (2005). Identification of hundreds of conserved and nonconserved human microRNAs. Nat Genet 37, 766-70.

Bernstein, E., Caudy, A. A., Hammond, S. M. and Hannon, G. J. (2001). Role for a bidentate ribonuclease in the initiation step of RNA interference. Nature 409, 363-6.

Bernstein, E., Kim, S. Y., Carmell, M. A., Murchison, E. P., Alcorn, H., Li, M. Z., Mills, A. A., Elledge, S. J., Anderson, K. V. and Hannon, G. J. (2003). Dicer is essential for mouse development. Nat Genet 35, 215-7.

Besnard, F., Perraud, F., Sensenbrenner, M. and Labourdette, G. (1987). Plateletderived growth factor is a mitogen for glial but not for neuronal rat brain cells in vitro. Neurosci Lett 73, 287-92.

Bjartmar, C., Karlsson, B. and Hildebrand, C. (1994). Cellular and extracellular components at nodes of Ranvier in rat white matter. Brain Res 667, 111-4.

Black, J. A. and Waxman, S. G. (1988). The perinodal astrocyte. Glia 1, 169-83.

Bogler, O., Wren, D., Barnett, S. C., Land, H. and Noble, M. (1990). Cooperation between two growth factors promotes extended self-renewal and inhibits differentiation of oligodendrocyte-type-2 astrocyte (O-2A) progenitor cells. Proc Natl Acad Sci U S A 87, 6368-72.

Bohnsack, M. T., Czaplinski, K. and Gorlich, D. (2004). Exportin 5 is a RanGTPdependent dsRNA-binding protein that mediates nuclear export of pre-miRNAs. RNA 10, 185-91. 
Boison, D., Bussow, H., D'Urso, D., Muller, H. W. and Stoffel, W. (1995). Adhesive properties of proteolipid protein are responsible for the compaction of CNS myelin sheaths. J Neurosci 15, 5502-13.

Braun, P. E., De Angelis, D., Shtybel, W. W. and Bernier, L. (1991). Isoprenoid modification permits 2',3'-cyclic nucleotide 3'-phosphodiesterase to bind to membranes. $J$ Neurosci Res 30, 540-4.

Brinkmann, B. G., Agarwal, A., Sereda, M. W., Garratt, A. N., Muller, T., Wende, H., Stassart, R. M., Nawaz, S., Humml, C., Velanac, V. et al. (2008). Neuregulin-1/ErbB signaling serves distinct functions in myelination of the peripheral and central nervous system. Neuron 59, 581-95.

Bunge, M. B., Bunge, R. P. and Pappas, G. D. (1962). Electron microscopic demonstration of connections between glia and myelin sheaths in the developing mammalian central nervous system. J Cell Biol 12, 448-53.

Butt, A. M. and Ransom, B. R. (1989). Visualization of oligodendrocytes and astrocytes in the intact rat optic nerve by intracellular injection of lucifer yellow and horseradish peroxidase. Glia 2, 470-5.

Butts, B. D., Houde, C. and Mehmet, H. (2008). Maturation-dependent sensitivity of oligodendrocyte lineage cells to apoptosis: implications for normal development and disease. Cell Death Differ 15, 1178-86.

Cahoy, J. D., Emery, B., Kaushal, A., Foo, L. C., Zamanian, J. L., Christopherson, K. S., Xing, Y., Lubischer, J. L., Krieg, P. A., Krupenko, S. A. et al. (2008). A transcriptome database for astrocytes, neurons, and oligodendrocytes: a new resource for understanding brain development and function. J Neurosci 28, 264-78.

Cai, X., Hagedorn, C. H. and Cullen, B. R. (2004). Human microRNAs are processed from capped, polyadenylated transcripts that can also function as mRNAs. RNA 10, 195766.

Calabrese, J. M., Seila, A. C., Yeo, G. W. and Sharp, P. A. (2007). RNA sequence analysis defines Dicer's role in mouse embryonic stem cells. Proc Natl Acad Sci U S A 104, 18097-102.

Calver, A. R., Hall, A. C., Yu, W. P., Walsh, F. S., Heath, J. K., Betsholtz, C. and Richardson, W. D. (1998). Oligodendrocyte population dynamics and the role of PDGF in vivo. Neuron 20, 869-82.

Campagnoni, A. T. and Macklin, W. B. (1988). Cellular and molecular aspects of myelin protein gene expression. Mol Neurobiol 2, 41-89.

Canoll, P. D., Kraemer, R., Teng, K. K., Marchionni, M. A. and Salzer, J. L. (1999). GGF/neuregulin induces a phenotypic reversion of oligodendrocytes. Mol Cell Neurosci 13, 79-94. 
Canoll, P. D., Musacchio, J. M., Hardy, R., Reynolds, R., Marchionni, M. A. and Salzer, J. L. (1996). GGF/neuregulin is a neuronal signal that promotes the proliferation and survival and inhibits the differentiation of oligodendrocyte progenitors. Neuron 17, 229-43.

Carmell, M. A., Xuan, Z., Zhang, M. Q. and Hannon, G. J. (2002). The Argonaute family: tentacles that reach into RNAi, developmental control, stem cell maintenance, and tumorigenesis. Genes Dev 16, 2733-42.

Carthew, R. W. and Sontheimer, E. J. (2009). Origins and Mechanisms of miRNAs and siRNAs. Cell 136, 642-55.

Chang, T. C., Yu, D., Lee, Y. S., Wentzel, E. A., Arking, D. E., West, K. M., Dang, C. V., Thomas-Tikhonenko, A. and Mendell, J. T. (2008). Widespread microRNA repression by Myc contributes to tumorigenesis. Nat Genet 40, 43-50.

Charles, P., Reynolds, R., Seilhean, D., Rougon, G., Aigrot, M. S., Niezgoda, A., Zalc, B. and Lubetzki, C. (2002). Re-expression of PSA-NCAM by demyelinated axons: an inhibitor of remyelination in multiple sclerosis? Brain 125, 1972-9.

Chatterjee, S. and Grosshans, H. (2009). Active turnover modulates mature microRNA activity in Caenorhabditis elegans. Nature 461, 546-9.

Chen, Y., Wu, H., Wang, S., Koito, H., Li, J., Ye, F., Hoang, J., Escobar, S. S., Gow, A., Arnett, H. A. et al. (2009). The oligodendrocyte-specific G protein-coupled receptor GPR17 is a cell-intrinsic timer of myelination. Nat Neurosci 12, 1398-406.

Chendrimada, T. P., Finn, K. J., Ji, X., Baillat, D., Gregory, R. I., Liebhaber, S. A., Pasquinelli, A. E. and Shiekhattar, R. (2007). MicroRNA silencing through RISC recruitment of eIF6. Nature 447, 823-8.

Chendrimada, T. P., Gregory, R. I., Kumaraswamy, E., Norman, J., Cooch, N., Nishikura, K. and Shiekhattar, R. (2005). TRBP recruits the Dicer complex to Ago2 for microRNA processing and gene silencing. Nature 436, 740-4.

Coffeen, C. M., McKenna, C. E., Koeppen, A. H., Plaster, N. M., Maragakis, N., Mihalopoulos, J., Schwankhaus, J. D., Flanigan, K. M., Gregg, R. G., Ptacek, L. J. et al. (2000). Genetic localization of an autosomal dominant leukodystrophy mimicking chronic progressive multiple sclerosis to chromosome 5q31. Hum Mol Genet 9, 787-93.

Colognato, H., Baron, W., Avellana-Adalid, V., Relvas, J. B., Baron-Van Evercooren, A., Georges-Labouesse, E. and ffrench-Constant, C. (2002). CNS integrins switch growth factor signalling to promote target-dependent survival. Nat Cell Biol 4, 833-41.

Coman, I., Barbin, G., Charles, P., Zalc, B. and Lubetzki, C. (2005). Axonal signals in central nervous system myelination, demyelination and remyelination. J Neurol Sci 233, 67-71. 
Croce, C. M. (2009). Causes and consequences of microRNA dysregulation in cancer. Nat Rev Genet 10, 704-14.

Cui, Q. L. and Almazan, G. (2007). IGF-I-induced oligodendrocyte progenitor proliferation requires PI3K/Akt, MEK/ERK, and Src-like tyrosine kinases. J Neurochem 100, 1480-93.

Czech, B., Malone, C. D., Zhou, R., Stark, A., Schlingeheyde, C., Dus, M., Perrimon, N., Kellis, M., Wohlschlegel, J. A., Sachidanandam, R. et al. (2008). An endogenous small interfering RNA pathway in Drosophila. Nature 453, 798-802.

Denli, A. M., Tops, B. B., Plasterk, R. H., Ketting, R. F. and Hannon, G. J. (2004). Processing of primary microRNAs by the Microprocessor complex. Nature 432, 231-5.

Dews, M., Homayouni, A., Yu, D., Murphy, D., Sevignani, C., Wentzel, E., Furth, E. E., Lee, W. M., Enders, G. H., Mendell, J. T. et al. (2006). Augmentation of tumor angiogenesis by a Myc-activated microRNA cluster. Nat Genet 38, 1060-5.

Diederichs, S. and Haber, D. A. (2007). Dual role for argonautes in microRNA processing and posttranscriptional regulation of microRNA expression. Cell 131, 1097108.

Diers-Fenger, M., Kirchhoff, F., Kettenmann, H., Levine, J. M. and Trotter, J. (2001). AN2/NG2 protein-expressing glial progenitor cells in the murine CNS: isolation, differentiation, and association with radial glia. Glia 34, 213-28.

Dugas, J. C., Cuellar, T. L., Scholze, A., Ason, B., Ibrahim, A., Emery, B., Zamanian, J. L., Foo, L. C., McManus, M. T. and Barres, B. A. (2010) Dicer1 and miR-219 Are required for normal oligodendrocyte differentiation and myelination. Neuron 65, 597-611.

Dupree, J. L., Girault, J. A. and Popko, B. (1999). Axo-glial interactions regulate the localization of axonal paranodal proteins. J Cell Biol 147, 1145-52.

Ebner, S., Dunbar, M. and McKinnon, R. D. (2000). Distinct roles for PI3K in proliferation and survival of oligodendrocyte progenitor cells. J Neurosci Res 62, 336-45.

Eccleston, P. A. and Silberberg, D. H. (1984). Fibroblast growth feactor is a mitogen for oligodendrocytes in vitro. Brain Res 210, 315-318.

Edwards, A. M., Ross, N. W., Ulmer, J. B. and Braun, P. E. (1989). Interaction of myelin basic protein and proteolipid protein. $J$ Neurosci Res 22, 97-102.

Esau, C. C. and Monia, B. P. (2007). Therapeutic potential for microRNAs. Adv Drug Deliv Rev 59, 101-14.

Fernandez, M., Giuliani, A., Pirondi, S., D'Intino, G., Giardino, L., Aloe, L., LeviMontalcini, R. and Calza, L. (2004). Thyroid hormone administration enhances remyelination in chronic demyelinating inflammatory disease. Proc Natl Acad Sci U S A 101, 16363-8. 
Fernandez, P. A., Tang, D. G., Cheng, L., Prochiantz, A., Mudge, A. W. and Raff, M. C. (2000). Evidence that axon-derived neuregulin promotes oligodendrocyte survival in the developing rat optic nerve. Neuron 28, 81-90.

Ferretti, E., De Smaele, E., Miele, E., Laneve, P., Po, A., Pelloni, M., Paganelli, A., Di Marcotullio, L., Caffarelli, E., Screpanti, I. et al. (2008). Concerted microRNA control of Hedgehog signalling in cerebellar neuronal progenitor and tumour cells. EMBO J 27, 2616-27.

Fitzner, D., Schneider, A., Kippert, A., Mobius, W., Willig, K. I., Hell, S. W., Bunt, G., Gaus, K. and Simons, M. (2006). Myelin basic protein-dependent plasma membrane reorganization in the formation of myelin. EMBO J 25, 5037-48.

Folch, J. and Lees, M. B. (1951). Proteolipids, a new type of tissue lipoproteins, their isolation from brain. $J$ Biol Chem 191, 807-817.

Fontana, L., Pelosi, E., Greco, P., Racanicchi, S., Testa, U., Liuzzi, F., Croce, C. M., Brunetti, E., Grignani, F. and Peschle, C. (2007). MicroRNAs 17-5p-20a-106a control monocytopoiesis through AML1 targeting and M-CSF receptor upregulation. Nat Cell Biol 9, 775-87.

Frail, D. E., Webster, H. D. and Braun, P. E. (1985). Developmental expression of the myelin-associated glycoprotein in the peripheral nervous system is different from that in the central nervous system. J Neurochem 45, 1308-10.

Frederick, T. J., Min, J., Altieri, S. C., Mitchell, N. E. and Wood, T. L. (2007). Synergistic induction of cyclin D1 in oligodendrocyte progenitor cells by IGF-I and FGF-2 requires differential stimulation of multiple signaling pathways. Glia 55, 1011-22.

Frederick, T. J. and Wood, T. L. (2004). IGF-I and FGF-2 coordinately enhance cyclin D1 and cyclin E-cdk2 association and activity to promote G1 progression in oligodendrocyte progenitor cells. Mol Cell Neurosci 25, 480-92.

Friedman, R. C., Farh, K. K., Burge, C. B. and Bartel, D. P. (2009). Most mammalian mRNAs are conserved targets of microRNAs. Genome Res 19, 92-105.

Fruttiger, M., Karlsson, L., Hall, A. C., Abramsson, A., Calver, A. R., Bostrom, H., Willetts, K., Bertold, C. H., Heath, J. K., Betsholtz, C. et al. (1999). Defective oligodendrocyte development and severe hypomyelination in PDGF-A knockout mice. Development 126, 457-67.

Fujita, N., Suzuki, K., Vanier, M. T., Popko, B., Maeda, N., Klein, A., Henseler, M., Sandhoff, K. and Nakayasu, H. (1996). Targeted disruption of the mouse sphingolipid activator protein gene: a complex phenotype, including severe leukodystrophy and widespread storage of multiple sphingolipids. Hum Mol Genet 5, 711-25.

Gard, A. L. and Pfeiffer, S. E. (1993). Glial cell mitogens bFGF and PDGF differentially regulate development of O4+GalC- oligodendrocyte progenitors. Dev Biol 159, 618-30. 
Ghildiyal, M., Seitz, H., Horwich, M. D., Li, C., Du, T., Lee, S., Xu, J., Kittler, E. L., Zapp, M. L., Weng, Z. et al. (2008). Endogenous siRNAs derived from transposons and mRNAs in Drosophila somatic cells. Science 320, 1077-81.

Giraldez, A. J., Mishima, Y., Rihel, J., Grocock, R. J., Van Dongen, S., Inoue, K., Enright, A. J. and Schier, A. F. (2006). Zebrafish MiR-430 promotes deadenylation and clearance of maternal mRNAs. Science 312, 75-9.

Gravel, M., Peterson, J., Yong, V. W., Kottis, V., Trapp, B. and Braun, P. E. (1996). Overexpression of 2',3'-cyclic nucleotide 3'-phosphodiesterase in transgenic mice alters oligodendrocyte development and produces aberrant myelination. Mol Cell Neurosci 7, 453-66.

Griffiths, I., Klugmann, M., Anderson, T., Yool, D., Thomson, C., Schwab, M. H., Schneider, A., Zimmermann, F., McCulloch, M., Nadon, N. et al. (1998). Axonal swellings and degeneration in mice lacking the major proteolipid of myelin. Science $\mathbf{2 8 0}$, 1610-3.

Gy, I., Gasciolli, V., Lauressergues, D., Morel, J. B., Gombert, J., Proux, F., Proux, C., Vaucheret, H. and Mallory, A. C. (2007). Arabidopsis FIERY1, XRN2, and XRN3 are endogenous RNA silencing suppressors. Plant Cell 19, 3451-61.

Han, J., Lee, Y., Yeom, K. H., Kim, Y. K., Jin, H. and Kim, V. N. (2004). The DroshaDGCR8 complex in primary microRNA processing. Genes Dev 18, 3016-27.

Han, J., Lee, Y., Yeom, K. H., Nam, J. W., Heo, I., Rhee, J. K., Sohn, S. Y., Cho, Y., Zhang, B. T. and Kim, V. N. (2006). Molecular basis for the recognition of primary microRNAs by the Drosha-DGCR8 complex. Cell 125, 887-901.

Han, J., Pedersen, J. S., Kwon, S. C., Belair, C. D., Kim, Y. K., Yeom, K. H., Yang, W. Y., Haussler, D., Blelloch, R. and Kim, V. N. (2009). Posttranscriptional crossregulation between Drosha and DGCR8. Cell 136, 75-84.

Harauz, G., Ladizhansky, V. and Boggs, J. M. (2009). Structural polymorphism and multifunctionality of myelin basic protein. Biochemistry 48, 8094-104.

Harfe, B. D., McManus, M. T., Mansfield, J. H., Hornstein, E. and Tabin, C. J. (2005). The RNaseIII enzyme Dicer is required for morphogenesis but not patterning of the vertebrate limb. Proc Natl Acad Sci U S A 102, 10898-903.

Harsan, L. A., Steibel, J., Zaremba, A., Agin, A., Sapin, R., Poulet, P., Guignard, B., Parizel, N., Grucker, D., Boehm, N. et al. (2008). Recovery from chronic demyelination by thyroid hormone therapy: myelinogenesis induction and assessment by diffusion tensor magnetic resonance imaging. J Neurosci 28, 14189-201.

He, L., He, X., Lowe, S. W. and Hannon, G. J. (2007). microRNAs join the p53 network--another piece in the tumour-suppression puzzle. Nat Rev Cancer 7, 819-22. 
He, L., Thomson, J. M., Hemann, M. T., Hernando-Monge, E., Mu, D., Goodson, S., Powers, S., Cordon-Cardo, C., Lowe, S. W., Hannon, G. J. et al. (2005). A microRNA polycistron as a potential human oncogene. Nature 435, 828-33.

Higuchi, R., Fockler, C., Dollinger, G. and Watson, R. (1993). Kinetic PCR analysis: real-time monitoring of DNA amplification reactions. Biotechnology (N Y) 11, 1026-30.

Holz, A. and Schwab, M. E. (1997). Developmental expression of the myelin gene MOBP in the rat nervous system. $J$ Neurocytol 26, 467-77.

Hornstein, E. and Shomron, N. (2006). Canalization of development by microRNAs. Nat Genet 38 Suppl, S20-4.

Hutvagner, G., McLachlan, J., Pasquinelli, A. E., Balint, E., Tuschl, T. and Zamore, P. D. (2001). A cellular function for the RNA-interference enzyme Dicer in the maturation of the let-7 small temporal RNA. Science 293, 834-8.

Hwang, H. W., Wentzel, E. A. and Mendell, J. T. (2007). A hexanucleotide element directs microRNA nuclear import. Science 315, 97-100.

Ibanez-Ventoso, C., Vora, M. and Driscoll, M. (2008). Sequence relationships among C. elegans, D. melanogaster and human microRNAs highlight the extensive conservation of microRNAs in biology. PLoS One 3, e2818.

Inomata, M., Tagawa, H., Guo, Y. M., Kameoka, Y., Takahashi, N. and Sawada, K. (2009). MicroRNA-17-92 down-regulates expression of distinct targets in different B-cell lymphoma subtypes. Blood 113, 396-402.

Inoue, K. (2005). PLP1-related inherited dysmyelinating disorders: Pelizaeus-Merzbacher disease and spastic paraplegia type 2. Neurogenetics 6, 1-16.

Inui, M., Martello, G. and Piccolo, S. (2010) MicroRNA control of signal transduction. Nat Rev Mol Cell Biol 11, 252-63.

Ivanovska, I., Ball, A. S., Diaz, R. L., Magnus, J. F., Kibukawa, M., Schelter, J. M., Kobayashi, S. V., Lim, L., Burchard, J., Jackson, A. L. et al. (2008). MicroRNAs in the miR-106b family regulate p21/CDKN1A and promote cell cycle progression. Mol Cell Biol 28, 2167-74.

Jakovcevski, I., Mo, Z. and Zecevic, N. (2007). Down-regulation of the axonal polysialic acid-neural cell adhesion molecule expression coincides with the onset of myelination in the human fetal forebrain. Neuroscience 149, 328-37.

Jiang, J. and Hui, C. C. (2008). Hedgehog signaling in development and cancer. Dev Cell 15, 801-12.

Jiang, Q., Wang, Y., Hao, Y., Juan, L., Teng, M., Zhang, X., Li, M., Wang, G. and Liu, Y. (2009). miR2Disease: a manually curated database for microRNA deregulation in human disease. Nucleic Acids Res 37, D98-104. 
Johnson, S. M., Lin, S. Y. and Slack, F. J. (2003). The time of appearance of the C. elegans let-7 microRNA is transcriptionally controlled utilizing a temporal regulatory element in its promoter. Dev Biol 259, 364-79.

Jones, S. A., Jolson, D. M., Cuta, K. K., Mariash, C. N. and Anderson, G. W. (2003). Triiodothyronine is a survival factor for developing oligodendrocytes. Mol Cell Endocrinol 199, 49-60.

Jung, M., Kramer, E., Grzenkowski, M., Tang, K., Blakemore, W., Aguzzi, A., Khazaie, K., Chlichlia, K., von Blankenfeld, G., Kettenmann, H. et al. (1995). Lines of murine oligodendroglial precursor cells immortalized by an activated neu tyrosine kinase show distinct degrees of interaction with axons in vitro and in vivo. Eur J Neurosci 7, 1245-65.

Jung, M., Sommer, I., Schachner, M. and Nave, K. A. (1996). Monoclonal antibody O10 defines a conformationally sensitive cell-surface epitope of proteolipid protein (PLP): evidence that PLP misfolding underlies dysmyelination in mutant mice. $J$ Neurosci 16, 7920-9.

Kanellopoulou, C., Muljo, S. A., Kung, A. L., Ganesan, S., Drapkin, R., Jenuwein, T., Livingston, D. M. and Rajewsky, K. (2005). Dicer-deficient mouse embryonic stem cells are defective in differentiation and centromeric silencing. Genes Dev 19, 489-501.

Kawahara, Y., Megraw, M., Kreider, E., Iizasa, H., Valente, L., Hatzigeorgiou, A. G. and Nishikura, K. (2008). Frequency and fate of microRNA editing in human brain. Nucleic Acids Res 36, 5270-80.

Kawamura, Y., Saito, K., Kin, T., Ono, Y., Asai, K., Sunohara, T., Okada, T. N., Siomi, M. C. and Siomi, H. (2008). Drosophila endogenous small RNAs bind to Argonaute 2 in somatic cells. Nature 453, 793-7.

Kawase-Koga, Y., Otaegi, G. and Sun, T. (2009). Different timings of Dicer deletion affect neurogenesis and gliogenesis in the developing mouse central nervous system. Dev Dyn 238, 2800-12.

Kessaris, N., Fogarty, M., Iannarelli, P., Grist, M., Wegner, M. and Richardson, W. D. (2006). Competing waves of oligodendrocytes in the forebrain and postnatal elimination of an embryonic lineage. Nat Neurosci 9, 173-9.

Ketting, R. F., Fischer, S. E., Bernstein, E., Sijen, T., Hannon, G. J. and Plasterk, R. H. (2001). Dicer functions in RNA interference and in synthesis of small RNA involved in developmental timing in C. elegans. Genes Dev 15, 2654-9.

Khvorova, A., Reynolds, A. and Jayasena, S. D. (2003). Functional siRNAs and miRNAs exhibit strand bias. Cell 115, 209-16.

Kies, M.W., Murphy, J.B. and Alvord, E.C. (1965). Fractionation of guinea-pig proteins with encephalitogenic activity. Federation Proc 19, 207 
Kim, V. N. (2004). MicroRNA precursors in motion: exportin-5 mediates their nuclear export. Trends Cell Biol 14, 156-9.

Kim, V. N. (2005). MicroRNA biogenesis: coordinated cropping and dicing. Nat Rev Mol Cell Biol 6, 376-85.

Kim, V. N., Han, J. and Siomi, M. C. (2009). Biogenesis of small RNAs in animals. Nat Rev Mol Cell Biol 10, 126-39.

Kippert, A., Trajkovic, K., Rajendran, L., Ries, J. and Simons, M. (2007). Rho regulates membrane transport in the endocytic pathway to control plasma membrane specialization in oligodendroglial cells. J Neurosci 27, 3560-70.

Kirby, B. B., Takada, N., Latimer, A. J., Shin, J., Carney, T. J., Kelsh, R. N. and Appel, B. (2006). In vivo time-lapse imaging shows dynamic oligodendrocyte progenitor behavior during zebrafish development. Nat Neurosci 9, 1506-11.

Kiriakidou, M., Tan, G. S., Lamprinaki, S., De Planell-Saguer, M., Nelson, P. T. and Mourelatos, Z. (2007). An mRNA m7G cap binding-like motif within human Ago2 represses translation. Cell 129, 1141-51.

Klugmann, M., Schwab, M. H., Puhlhofer, A., Schneider, A., Zimmermann, F., Griffiths, I. R. and Nave, K. A. (1997). Assembly of CNS myelin in the absence of proteolipid protein. Neuron 18, 59-70.

Knight, S. W. and Bass, B. L. (2001). A role for the RNase III enzyme DCR-1 in RNA interference and germ line development in Caenorhabditis elegans. Science 293, 2269-71.

Kondo, T. and Raff, M. (2000). Basic helix-loop-helix proteins and the timing of oligodendrocyte differentiation. Development 127, 2989-98.

Koralov, S. B., Muljo, S. A., Galler, G. R., Krek, A., Chakraborty, T., Kanellopoulou, C., Jensen, K., Cobb, B. S., Merkenschlager, M., Rajewsky, N. et al. (2008). Dicer ablation affects antibody diversity and cell survival in the B lymphocyte lineage. Cell 132, 860-74.

Lagos-Quintana, M., Rauhut, R., Lendeckel, W. and Tuschl, T. (2001). Identification of novel genes coding for small expressed RNAs. Science 294, 853-8.

Lai, E. C., Tam, B. and Rubin, G. M. (2005). Pervasive regulation of Drosophila Notch target genes by GY-box-, Brd-box-, and K-box-class microRNAs. Genes Dev 19, 1067-80.

Landais, S., Landry, S., Legault, P. and Rassart, E. (2007). Oncogenic potential of the miR-106-363 cluster and its implication in human T-cell leukemia. Cancer Res 67, 5699707.

Lappe-Siefke, C., Goebbels, S., Gravel, M., Nicksch, E., Lee, J., Braun, P. E., Griffiths, I. R. and Nave, K. A. (2003). Disruption of Cnp1 uncouples oligodendroglial functions in axonal support and myelination. Nat Genet 33, 366-74. 
Latronico, M. V. and Condorelli, G. (2009). MicroRNAs and cardiac pathology. Nat Rev Cardiol 6, 419-29.

Lau, N. C., Lim, L. P., Weinstein, E. G. and Bartel, D. P. (2001). An abundant class of tiny RNAs with probable regulatory roles in Caenorhabditis elegans. Science 294, 858-62.

Lau, P., Verrier, J. D., Nielsen, J. A., Johnson, K. R., Notterpek, L. and Hudson, L. D. (2008). Identification of dynamically regulated microRNA and mRNA networks in developing oligodendrocytes. J Neurosci 28, 11720-30.

Lebar, R., Lubetzki, C., Vincent, C., Lombrail, P. and Boutry, J. M. (1986). The M2 autoantigen of central nervous system myelin, a glycoprotein present in oligodendrocyte membrane. Clin Exp Immunol 66, 423-34.

Lee, R. C., Feinbaum, R. L. and Ambros, V. (1993). The C. elegans heterochronic gene lin-4 encodes small RNAs with antisense complementarity to lin-14. Cell 75, 843-54.

Lee, Y., Ahn, C., Han, J., Choi, H., Kim, J., Yim, J., Lee, J., Provost, P., Radmark, O., Kim, S. et al. (2003). The nuclear RNase III Drosha initiates microRNA processing. Nature 425, 415-9.

Lee, Y., Hur, I., Park, S. Y., Kim, Y. K., Suh, M. R. and Kim, V. N. (2006). The role of PACT in the RNA silencing pathway. EMBO J 25, 522-32.

Lee, Y., Jeon, K., Lee, J. T., Kim, S. and Kim, V. N. (2002). MicroRNA maturation: stepwise processing and subcellular localization. EMBO J 21, 4663-70.

Lee, Y., Kim, M., Han, J., Yeom, K. H., Lee, S., Baek, S. H. and Kim, V. N. (2004a). MicroRNA genes are transcribed by RNA polymerase II. EMBO J 23, 4051-60.

Lee, Y. S., Nakahara, K., Pham, J. W., Kim, K., He, Z., Sontheimer, E. J. and Carthew, R. W. (2004b). Distinct roles for Drosophila Dicer-1 and Dicer-2 in the siRNA/miRNA silencing pathways. Cell 117, 69-81.

Li, C., Tropak, M. B., Gerlai, R., Clapoff, S., Abramow-Newerly, W., Trapp, B., Peterson, A. and Roder, J. (1994). Myelination in the absence of myelin-associated glycoprotein. Nature 369, 747-50.

Li, G., Luna, C., Qiu, J., Epstein, D. L. and Gonzalez, P. (2009). Alterations in microRNA expression in stress-induced cellular senescence. Mech Ageing Dev 130, 73141.

Li, H., Lu, Y., Smith, H. K. and Richardson, W. D. (2007). Olig1 and Sox10 interact synergistically to drive myelin basic protein transcription in oligodendrocytes. $J$ Neurosci 27, 14375-82.

Liang, J. and Slingerland, J. M. (2003). Multiple roles of the PI3K/PKB (Akt) pathway in cell cycle progression. Cell Cycle 2, 339-45. 
Liang, X., Draghi, N. A. and Resh, M. D. (2004). Signaling from integrins to Fyn to Rho family GTPases regulates morphologic differentiation of oligodendrocytes. J Neurosci 24, 7140-9.

Lin, S. T. and Fu, Y. H. (2009). miR-23 regulation of lamin B1 is crucial for oligodendrocyte development and myelination. Dis Model Mech 2, 178-88.

Linker, R. A., Maurer, M., Gaupp, S., Martini, R., Holtmann, B., Giess, R., Rieckmann, P., Lassmann, H., Toyka, K. V., Sendtner, M. et al. (2002). CNTF is a major protective factor in demyelinating CNS disease: a neurotrophic cytokine as modulator in neuroinflammation. Nat Med 8, 620-4.

Liu, J., Carmell, M. A., Rivas, F. V., Marsden, C. G., Thomson, J. M., Song, J. J., Hammond, S. M., Joshua-Tor, L. and Hannon, G. J. (2004). Argonaute2 is the catalytic engine of mammalian RNAi. Science 305, 1437-41.

Liu, J. P., Baker, J., Perkins, A. S., Robertson, E. J. and Efstratiadis, A. (1993). Mice carrying null mutations of the genes encoding insulin-like growth factor I (Igf-1) and type 1 IGF receptor (Igf1r). Cell 75, 59-72.

Lu, Q. R., Sun, T., Zhu, Z., Ma, N., Garcia, M., Stiles, C. D. and Rowitch, D. H. (2002). Common developmental requirement for Olig function indicates a motor neuron/oligodendrocyte connection. Cell 109, 75-86.

Lu, Q. R., Yuk, D., Alberta, J. A., Zhu, Z., Pawlitzky, I., Chan, J., McMahon, A. P., Stiles, C. D. and Rowitch, D. H. (2000). Sonic hedgehog--regulated oligodendrocyte lineage genes encoding bHLH proteins in the mammalian central nervous system. Neuron 25, 317-29.

Lu, Y., Thomson, J. M., Wong, H. Y., Hammond, S. M. and Hogan, B. L. (2007). Transgenic over-expression of the microRNA miR-17-92 cluster promotes proliferation and inhibits differentiation of lung epithelial progenitor cells. Dev Biol 310, 442-53.

Lund, E., Guttinger, S., Calado, A., Dahlberg, J. E. and Kutay, U. (2004). Nuclear export of microRNA precursors. Science 303, 95-8.

Ma, J. B., Ye, K. and Patel, D. J. (2004). Structural basis for overhang-specific small interfering RNA recognition by the PAZ domain. Nature 429, 318-22.

Mack, G. S. (2007). MicroRNA gets down to business. Nat Biotechnol 25, 631-8.

Matsubara, H., Takeuchi, T., Nishikawa, E., Yanagisawa, K., Hayashita, Y., Ebi, H., Yamada, H., Suzuki, M., Nagino, M., Nimura, Y. et al. (2007). Apoptosis induction by antisense oligonucleotides against miR-17-5p and miR-20a in lung cancers overexpressing miR-17-92. Oncogene 26, 6099-105.

Mavrakis, K. J., Wolfe, A. L., Oricchio, E., Palomero, T., de Keersmaecker, K., McJunkin, K., Zuber, J., James, T., Khan, A. A., Leslie, C. S. et al. (2010) Genomewide RNA-mediated interference screen identifies miR-19 targets in Notch-induced T-cell acute lymphoblastic leukaemia. Nat Cell Biol 12, 372-9. 
Maziere, P. and Enright, A. J. (2007). Prediction of microRNA targets. Drug Discov Today 12, 452-8.

McKinnon, R. D., Matsui, T., Dubois-Dalcq, M. and Aaronson, S. A. (1990). FGF modulates the PDGF-driven pathway of oligodendrocyte development. Neuron 5, 603-14.

McKinnon, R. D., Waldron, S. and Kiel, M. E. (2005). PDGF alpha-receptor signal strength controls an RTK rheostat that integrates phosphoinositol 3'-kinase and phospholipase Cgamma pathways during oligodendrocyte maturation. J Neurosci 25, 3499-508.

McMorris, F. A. and Dubois-Dalcq, M. (1988). Insulin-like growth factor I promotes cell proliferation and oligodendroglial commitment in rat glial progenitor cells developing in vitro. J Neurosci Res 21, 199-209.

McMorris, F. A. and McKinnon, R. D. (1996). Regulation of oligodendrocyte development and CNS myelination by growth factors: prospects for therapy of demyelinating disease. Brain Pathol 6, 313-29.

McTigue, D. M., Horner, P. J., Stokes, B. T. and Gage, F. H. (1998). Neurotrophin-3 and brain-derived neurotrophic factor induce oligodendrocyte proliferation and myelination of regenerating axons in the contused adult rat spinal cord. $J$ Neurosci 18, 5354-65.

Mendell, J. T. (2008). miRiad roles for the miR-17-92 cluster in development and disease. Cell 133, 217-22.

Merzbacher, L. (1909). Gesetzmaessigkeiten in der Vererbung und Verbreitung verschiedener hereditaer-familiaerer Erkrankungen. Arch Rass Ges Biol 6, 172-98.

Miller, R. H. (2002). Regulation of oligodendrocyte development in the vertebrate CNS. Prog Neurobiol 67, 451-67.

Miyoshi, K., Tsukumo, H., Nagami, T., Siomi, H. and Siomi, M. C. (2005). Slicer function of Drosophila Argonautes and its involvement in RISC formation. Genes Dev 19, 2837-48.

Montag, D., Giese, K. P., Bartsch, U., Martini, R., Lang, Y., Bluthmann, H., Karthigasan, J., Kirschner, D. A., Wintergerst, E. S., Nave, K. A. et al. (1994). Mice deficient for the myelin-associated glycoprotein show subtle abnormalities in myelin. Neuron 13, 229-46.

Morlando, M., Ballarino, M., Gromak, N., Pagano, F., Bozzoni, I. and Proudfoot, N. J. (2008). Primary microRNA transcripts are processed co-transcriptionally. Nat Struct Mol Biol 15, 902-9.

Mullis, K., Faloona, F., Scharf, S., Saiki, R., Horn, G. and Erlich, H. (1986). Specific enzymatic amplification of DNA in vitro: the polymerase chain reaction. Cold Spring Harb Symp Quant Biol 51 Pt 1, 263-73. 
Narayanan, S. P., Flores, A. I., Wang, F. and Macklin, W. B. (2009). Akt signals through the mammalian target of rapamycin pathway to regulate CNS myelination. $J$ Neurosci 29, 6860-70.

Nishiyama, A., Komitova, M., Suzuki, R. and Zhu, X. (2009). Polydendrocytes (NG2 cells): multifunctional cells with lineage plasticity. Nat Rev Neurosci 10, 9-22.

Nishiyama, A., Lin, X. H., Giese, N., Heldin, C. H. and Stallcup, W. B. (1996). Colocalization of NG2 proteoglycan and PDGF alpha-receptor on O2A progenitor cells in the developing rat brain. J Neurosci Res 43, 299-314.

Noble, M., Murray, K., Stroobant, P., Waterfield, M. D. and Riddle, P. (1988). Platelet-derived growth factor promotes division and motility and inhibits premature differentiation of the oligodendrocyte/type-2 astrocyte progenitor cell. Nature 333, 560-2.

O'Donnell, K. A., Wentzel, E. A., Zeller, K. I., Dang, C. V. and Mendell, J. T. (2005). c-Myc-regulated microRNAs modulate E2F1 expression. Nature 435, 839-43.

Okamura, K., Chung, W. J., Ruby, J. G., Guo, H., Bartel, D. P. and Lai, E. C. (2008a). The Drosophila hairpin RNA pathway generates endogenous short interfering RNAs. Nature 453, 803-6.

Okamura, K., Phillips, M. D., Tyler, D. M., Duan, H., Chou, Y. T. and Lai, E. C. (2008b). The regulatory activity of microRNA* species has substantial influence on microRNA and 3' UTR evolution. Nat Struct Mol Biol 15, 354-63.

Olive, V., Bennett, M. J., Walker, J. C., Ma, C., Jiang, I., Cordon-Cardo, C., Li, Q. J., Lowe, S. W., Hannon, G. J. and He, L. (2009). miR-19 is a key oncogenic component of mir-17-92. Genes Dev 23, 2839-49.

Ota, A., Tagawa, H., Karnan, S., Tsuzuki, S., Karpas, A., Kira, S., Yoshida, Y. and Seto, M. (2004). Identification and characterization of a novel gene, C13orf25, as a target for 13q31-q32 amplification in malignant lymphoma. Cancer Res 64, 3087-95.

Palizaeus, F. (1885). Ueber eine eigentumliche Form spastischer Lahmung mit Cerebralerscheinungen auf hereditarer Grundlage (Multiple Sklerose). Arch Psychiat Nervenkr 16, 698-710.

Park, S. K., Miller, R., Krane, I. and Vartanian, T. (2001). The erbB2 gene is required for the development of terminally differentiated spinal cord oligodendrocytes. $J$ Cell Biol 154, 1245-58.

Pasquinelli, A. E., Reinhart, B. J., Slack, F., Martindale, M. Q., Kuroda, M. I., Maller, B., Hayward, D. C., Ball, E. E., Degnan, B., Muller, P. et al. (2000). Conservation of the sequence and temporal expression of let-7 heterochronic regulatory RNA. Nature 408, 86-9.

Peter, A., Palay, S. and Webster, H. de F. (1991). The fine structure of the nervous system: the neuron and the supporting Cells. Oxford Univ. Press 
Petrocca, F., Vecchione, A. and Croce, C. M. (2008). Emerging role of miR-106b25/miR-17-92 clusters in the control of transforming growth factor beta signaling. Cancer Res 68, 8191-4.

Peyron, F., Timsit, S., Thomas, J. L., Kagawa, T., Ikenaka, K. and Zalc, B. (1997). In situ expression of PLP/DM-20, MBP, and CNP during embryonic and postnatal development of the jimpy mutant and of transgenic mice overexpressing PLP. $J$ Neurosci Res 50, 190-201.

Pfeiffer, S. E., Warrington, A. E. and Bansal, R. (1993). The oligodendrocyte and its many cellular processes. Trends Cell Biol 3, 191-7.

Poliak, S. And Peles, E. (2003). The local differentiation of myelinated axons at nodes of ranvier. Nat Rev Neurosci 12, 668-80.

Poltorak, M., Sadoul, R., Keilhauer, G., Landa, C., Fahrig, T. and Schachner, M. (1987). Myelin-associated glycoprotein, a member of the L2/HNK-1 family of neural cell adhesion molecules, is involved in neuron-oligodendrocyte and oligodendrocyteoligodendrocyte interaction. J Cell Biol 105, 1893-9.

Preall, J. B. and Sontheimer, E. J. (2005). RNAi: RISC gets loaded. Cell 123, 543-5.

Pringle, N. P. and Richardson, W. D. (1993). A singularity of PDGF alpha-receptor expression in the dorsoventral axis of the neural tube may define the origin of the oligodendrocyte lineage. Development 117, 525-33.

Privat, A., Jacque, C., Bourre, J. M., Dupouey, P. and Baumann, N. (1979). Absence of the major dense line in myelin of the mutant mouse "shiverer". Neurosci Lett 12, 10712.

Raff, M. (2006). The mystery of intracellular developmental programmes and timers. Biochem Soc Trans 34, 663-70.

Rao, P. K., Kumar, R. M., Farkhondeh, M., Baskerville, S. and Lodish, H. F. (2006). Myogenic factors that regulate expression of muscle-specific microRNAs. Proc Natl Acad Sci U S A 103, 8721-6.

Rasband, M. N., Tayler, J., Kaga, Y., Yang, Y., Lappe-Siefke, C., Nave, K. A. and Bansal, R. (2005). CNP is required for maintenance of axon-glia interactions at nodes of Ranvier in the CNS. Glia 50, 86-90.

Raymond, S. and Weintraub, L. (1959). Acrylamide gel as a supporting medium for zone electrophoresis. Science 130, 711.

Reinhart, B. J., Slack, F. J., Basson, M., Pasquinelli, A. E., Bettinger, J. C., Rougvie, A. E., Horvitz, H. R. and Ruvkun, G. (2000). The 21-nucleotide let-7 RNA regulates developmental timing in Caenorhabditis elegans. Nature 403, 901-6. 
Reynolds, R. and Hardy, R. (1997). Oligodendroglial progenitors labeled with the O4 antibody persist in the adult rat cerebral cortex in vivo. $J$ Neurosci Res 47, 455-70.

Richardson, W. D., Pringle, N., Mosley, M. J., Westermark, B. and Dubois-Dalcq, M. (1988). A role for platelet-derived growth factor in normal gliogenesis in the central nervous system. Cell 53, 309-19.

Roach, A., Takahashi, N., Pravtcheva, D., Ruddle, F. and Hood, L. (1985). Chromosomal mapping of mouse myelin basic protein gene and structure and transcription of the partially deleted gene in shiverer mutant mice. Cell 42, 149-55.

Rosenberg, S. S., Kelland, E. E., Tokar, E., De la Torre, A. R. and Chan, J. R. (2008). The geometric and spatial constraints of the microenvironment induce oligodendrocyte differentiation. Proc Natl Acad Sci U S A 105, 14662-7.

Ruby, J. G., Jan, C. H. and Bartel, D. P. (2007). Intronic microRNA precursors that bypass Drosha processing. Nature 448, 83-6.

Rybak, A., Fuchs, H., Smirnova, L., Brandt, C., Pohl, E. E., Nitsch, R. and Wulczyn, F. G. (2008). A feedback loop comprising lin-28 and let-7 controls pre-let-7 maturation during neural stem-cell commitment. Nat Cell Biol 10, 987-93.

Saher, G., Brugger, B., Lappe-Siefke, C., Mobius, W., Tozawa, R., Wehr, M. C., Wieland, F., Ishibashi, S. and Nave, K. A. (2005). High cholesterol level is essential for myelin membrane growth. Nat Neurosci 8, 468-75.

Salzer, J. L., Holmes, W. P. and Colman, D. R. (1987). The amino acid sequences of the myelin-associated glycoproteins: homology to the immunoglobulin gene superfamily. $J$ Cell Biol 104, 957-65.

Shin, D., Shin, J. Y., McManus, M. T., Ptacek, L. J. and Fu, Y. H. (2009). Dicer ablation in oligodendrocytes provokes neuronal impairment in mice. Ann Neurol 66, 84357.

Simons, M., Kramer, E. M., Thiele, C., Stoffel, W. and Trotter, J. (2000). Assembly of myelin by association of proteolipid protein with cholesterol- and galactosylceramide-rich membrane domains. J Cell Biol 151, 143-54.

Simons, M. and Trajkovic, K. (2006). Neuron-glia communication in the control of oligodendrocyte function and myelin biogenesis. J Cell Sci 119, 4381-4389

Solly, S. K., Thomas, J. L., Monge, M., Demerens, C., Lubetzki, C., Gardinier, M. V., Matthieu, J. M. and Zalc, B. (1996). Myelin/oligodendrocyte glycoprotein (MOG) expression is associated with myelin deposition. Glia 18, 39-48.

Staugaitis, S. M., Smith, P. R. and Colman, D. R. (1990). Expression of myelin basic protein isoforms in nonglial cells. $J$ Cell Biol 110, 1719-27. 
Stefani, G. and Slack, F. J. (2008). Small non-coding RNAs in animal development. Nat Rev Mol Cell Biol 9, 219-30.

Stolt, C. C., Schlierf, A., Lommes, P., Hillgartner, S., Werner, T., Kosian, T., Sock, E., Kessaris, N., Richardson, W. D., Lefebvre, V. et al. (2006). SoxD proteins influence multiple stages of oligodendrocyte development and modulate SoxE protein function. Dev Cell 11, 697-709.

Sylvestre, Y., De Guire, V., Querido, E., Mukhopadhyay, U. K., Bourdeau, V., Major, F., Ferbeyre, G. and Chartrand, P. (2007). An E2F/miR-20a autoregulatory feedback loop. J Biol Chem 282, 2135-43.

Talbott, J. F., Cao, Q., Bertram, J., Nkansah, M., Benton, R. L., Lavik, E. and Whittemore, S. R. (2007). CNTF promotes the survival and differentiation of adult spinal cord-derived oligodendrocyte precursor cells in vitro but fails to promote remyelination in vivo. Exp Neurol 204, 485-9.

Tanzer, A. and Stadler, P. F. (2004). Molecular evolution of a microRNA cluster. $J$ Mol Biol 339, 327-35.

Tetzloff, S. U. and Bizzozero, O. A. (1998). Palmitoylation of proteolipid protein from rat brain myelin using endogenously generated 18O-fatty acids. J Biol Chem 273, 279-85.

Tomari, Y., Matranga, C., Haley, B., Martinez, N. and Zamore, P. D. (2004). A protein sensor for siRNA asymmetry. Science 306, 1377-80.

Trajkovic, K., Dhaunchak, A. S., Goncalves, J. T., Wenzel, D., Schneider, A., Bunt, G., Nave, K. A. and Simons, M. (2006). Neuron to glia signaling triggers myelin membrane exocytosis from endosomal storage sites. J Cell Biol 172, 937-48.

Trapp, B. D., Bernier, L., Andrews, S. B. and Colman, D. R. (1988). Cellular and subcellular distribution of 2',3'-cyclic nucleotide 3'-phosphodiesterase and its mRNA in the rat central nervous system. $J$ Neurochem 51, 859-68.

Trapp, B. D. and Quarles, R. H. (1982). Presence of the myelin-associated glycoprotein correlates with alterations in the periodicity of peripheral myelin. J Cell Biol 92, 877-82.

Van't Veer, A., Du, Y., Fischer, T. Z., Boetig, D. R., Wood, M. R. and Dreyfus, C. F. (2009). Brain-derived neurotrophic factor effects on oligodendrocyte progenitors of the basal forebrain are mediated through trkB and the MAP kinase pathway. $J$ Neurosci Res 87, 69-78.

Ventura, A., Young, A. G., Winslow, M. M., Lintault, L., Meissner, A., Erkeland, S. J., Newman, J., Bronson, R. T., Crowley, D., Stone, J. R. et al. (2008). Targeted deletion reveals essential and overlapping functions of the miR-17 through 92 family of miRNA clusters. Cell 132, 875-86.

Viswanathan, S. R., Daley, G. Q. and Gregory, R. I. (2008). Selective blockade of microRNA processing by Lin28. Science 320, 97-100. 
Vogel, U. S. and Thompson, R. J. (1988). Molecular structure, localization, and possible functions of the myelin-associated enzyme 2',3'-cyclic nucleotide 3'-phosphodiesterase. $J$ Neurochem 50, 1667-77.

Volinia, S., Calin, G. A., Liu, C. G., Ambs, S., Cimmino, A., Petrocca, F., Visone, R., Iorio, M., Roldo, C., Ferracin, M. et al. (2006). A microRNA expression signature of human solid tumors defines cancer gene targets. Proc Natl Acad Sci U S A 103, 2257-61.

Voorhoeve, P. M., le Sage, C., Schrier, M., Gillis, A. J., Stoop, H., Nagel, R., Liu, Y. P., van Duijse, J., Drost, J., Griekspoor, A. et al. (2006). A genetic screen implicates miRNA-372 and miRNA-373 as oncogenes in testicular germ cell tumors. Cell 124, 116981.

Wagner, M. (1964). [a Method for the Direct Determination of Desoxyribonuclease Following Agar Gel Electrophoresis.]. J Chromatogr 15, 107-8.

Wang, S., Sdrulla, A. D., diSibio, G., Bush, G., Nofziger, D., Hicks, C., Weinmaster, G. and Barres, B. A. (1998). Notch receptor activation inhibits oligodendrocyte differentiation. Neuron 21, 63-75.

Wang, Y., Medvid, R., Melton, C., Jaenisch, R. and Blelloch, R. (2007). DGCR8 is essential for microRNA biogenesis and silencing of embryonic stem cell self-renewal. Nat Genet 39, 380-5.

Watanabe, T., Totoki, Y., Toyoda, A., Kaneda, M., Kuramochi-Miyagawa, S., Obata, Y., Chiba, H., Kohara, Y., Kono, T., Nakano, T. et al. (2008). Endogenous siRNAs from naturally formed dsRNAs regulate transcripts in mouse oocytes. Nature 453, 539-43.

Werner, H. B., Kuhlmann, K., Shen, S., Uecker, M., Schardt, A., Dimova, K., Orfaniotou, F., Dhaunchak, A., Brinkmann, B. G., Mobius, W. et al. (2007). Proteolipid protein is required for transport of sirtuin 2 into CNS myelin. J Neurosci 27, 7717-30.

Winkler, S., Stahl, R. C., Carey, D. J. and Bansal, R. (2002). Syndecan-3 and perlecan are differentially expressed by progenitors and mature oligodendrocytes and accumulate in the extracellular matrix. J Neurosci Res 69, 477-87.

Woods, K., Thomson, J. M. and Hammond, S. M. (2007). Direct regulation of an oncogenic micro-RNA cluster by E2F transcription factors. J Biol Chem 282, 2130-4.

Wu, L., Fan, J. and Belasco, J. G. (2006). MicroRNAs direct rapid deadenylation of mRNA. Proc Natl Acad Sci U S A 103, 4034-9.

Wulczyn, F. G., Smirnova, L., Rybak, A., Brandt, C., Kwidzinski, E., Ninnemann, O., Strehle, M., Seiler, A., Schumacher, S. and Nitsch, R. (2007). Post-transcriptional regulation of the let-7 microRNA during neural cell specification. FASEB J 21, 415-26.

Xiao, C. and Rajewsky, K. (2009). MicroRNA control in the immune system: basic principles. Cell 136, 26-36. 
Xiao, C., Srinivasan, L., Calado, D. P., Patterson, H. C., Zhang, B., Wang, J., Henderson, J. M., Kutok, J. L. and Rajewsky, K. (2008). Lymphoproliferative disease and autoimmunity in mice with increased miR-17-92 expression in lymphocytes. Nat Immunol 9, 405-14.

Xin, M., Yue, T., Ma, Z., Wu, F. F., Gow, A. and Lu, Q. R. (2005). Myelinogenesis and axonal recognition by oligodendrocytes in brain are uncoupled in Olig1-null mice. $J$ Neurosci 25, 1354-65.

Yan, K. S., Yan, S., Farooq, A., Han, A., Zeng, L. and Zhou, M. M. (2003). Structure and conserved RNA binding of the PAZ domain. Nature 426, 468-74.

Yang, W., Chendrimada, T. P., Wang, Q., Higuchi, M., Seeburg, P. H., Shiekhattar, R. and Nishikura, K. (2006). Modulation of microRNA processing and expression through RNA editing by ADAR deaminases. Nat Struct Mol Biol 13, 13-21.

Yeh, H. J., Ruit, K. G., Wang, Y. X., Parks, W. C., Snider, W. D. and Deuel, T. F. (1991). PDGF A-chain gene is expressed by mammalian neurons during development and in maturity. Cell 64, 209-16.

Yool, D., Montague, P., McLaughlin, M., McCulloch, M. C., Edgar, J. M., Nave, K. A., Davies, R. W., Griffiths, I. R. and McCallion, A. S. (2002). Phenotypic analysis of mice deficient in the major myelin protein MOBP, and evidence for a novel Mobp isoform. Glia 39, 256-67.

Yu, B., Yang, Z., Li, J., Minakhina, S., Yang, M., Padgett, R. W., Steward, R. and Chen, X. (2005). Methylation as a crucial step in plant microRNA biogenesis. Science 307, 932-5.

Yu, W. P., Collarini, E. J., Pringle, N. P. and Richardson, W. D. (1994). Embryonic expression of myelin genes: evidence for a focal source of oligodendrocyte precursors in the ventricular zone of the neural tube. Neuron 12, 1353-62.

Zeger, M., Popken, G., Zhang, J., Xuan, S., Lu, Q. R., Schwab, M. H., Nave, K. A., Rowitch, D., D'Ercole, A. J. and Ye, P. (2007). Insulin-like growth factor type 1 receptor signaling in the cells of oligodendrocyte lineage is required for normal in vivo oligodendrocyte development and myelination. Glia 55, 400-11.

Zhao, X., He, X., Han, X., Yu, Y., Ye, F., Chen, Y., Hoang, T., Xu, X., Mi, Q. S., Xin, M. et al. (2010) MicroRNA-mediated control of oligodendrocyte differentiation. Neuron 65, 612-26.

Zhou, Q. and Anderson, D. J. (2002). The bHLH transcription factors OLIG2 and OLIG1 couple neuronal and glial subtype specification. Cell 109, 61-73.

Zhou, Q., Wang, S. and Anderson, D. J. (2000). Identification of a novel family of oligodendrocyte lineage-specific basic helix-loop-helix transcription factors. Neuron 25, 331-43. 


\section{Acknowledgements}

First of all, I would like to thank my advisor Prof. Mikael Simons who initiated and strongly supported the project. He made the project possible and always ensured outstanding working conditions.

I am grateful to Prof. Ivo Feußner for being first supervisor of my $\mathrm{PhD}$ thesis committee and for the helpful scientific discussions during the meetings.

Many thanks to the collaborators: The “Transkriptomanalyselabor” in Göttingen - Dr. Gabriela Salinas-Riester, Lennart Opitz and Susanne Luthin for their help in performing microarrays and Real-time PCR experiments; Sebastian Schmitt for his support in cell culture experiments and discussions; Dirk Fitzner for his contribution to the Dicer knockout mice and the first microarray; Prof. Klaus-Armin Nave for the CNP-mice; Dr. Moritz Rossner for white- and grey-matter tissue samples.

I am further grateful to Giselheid Schulz for excellent technical assistance and to all other members of the AG Simons for their help and the nice atmosphere in the group: Shweta Aggarwal, Mostafa Bakhti, Kirsten Fladung, Aniket Ghosh, Chieh Hsu, Angelika Kippert, Natalia Manrique-Hoyos, Mareike Schnaars, Anja Schneider, Olena Steshenko, Katrin Strauß, Hannes Treiber, Larisa Yurlova and Johannes Zimmermann.

Special thanks go to Daniela Opitz and to my parents for their love, trust and encouragement. 


\section{Curriculum vitae}

Holger Budde

born on $1^{\text {st }}$ January, 1982

in Bad Pyrmont, Germany

Hermann-Rein-Str. 3, 37075 Göttingen, Germany

Phone: + 495513899534

e-mail: budde@em.mpg.de

Education

$2007-2010$

Ph.D. thesis

"Role of miRNAs in Oligodendrocyte Development"

Max Planck Institute for Experimental Medicine, Göttingen, Germany

$2004-2007$

Diploma in Neuroscience

Otto von Guericke University Magdeburg, Germany

Diploma Thesis: Charité Berlin, Germany

$2001-2004$

Bachelor of Science in Molecular Biotechnology

University of Lübeck, Germany

Bachelor Thesis: University of Lübeck, Germany

$-2001$

Abitur

Gymnasium Barntrup, Germany

Publications

Holger Budde, Sebastian Schmitt, Dirk Fitzner, Lennart Opitz, Gabriela Salinas-Riester and Mikael Simons. (2010) Control of oligodendroglial cell number by the miR-17-92 cluster. Development 137, 2127-2133.

Kathrin Scheuch, Markus Höltje, Holger Budde, Marion Lautenschlager, Andreas Heinz, Gudrun Ahnert-Hilger and Josef Priller. (2009) Lithium modulates tryptophan hydroxylase 2 gene expression and serotonin release in primary cultures of serotonergic raphe neurons. Brain Research $1307,14-21$. 